\title{
Desarrollo y VALORES CULTURALES
}

\section{Caso de Estudio: ciudad de Berisso}

Autor: Uriel Charne

Director: Eduardo Quiroga

Junio 2015
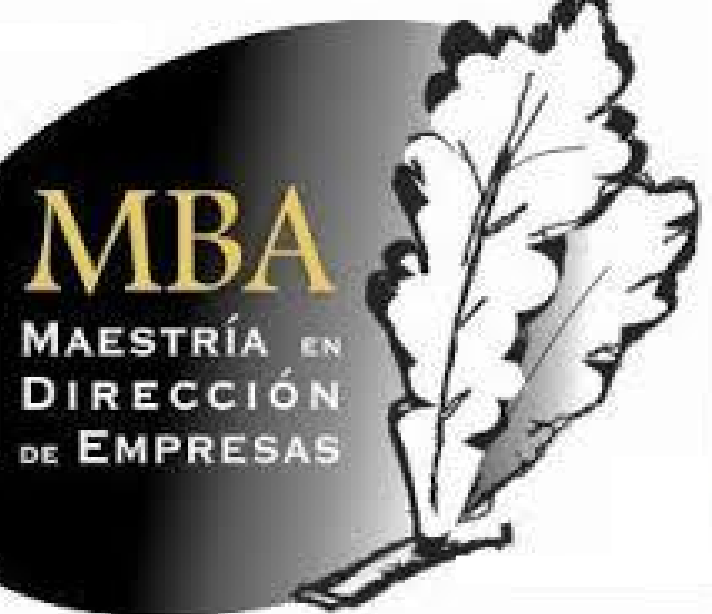


\section{ÍNDICE GENERAL}

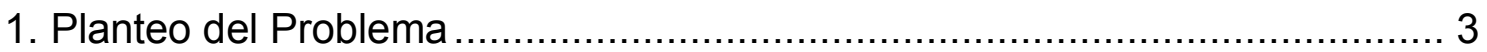

2. Objetivos de la Investigación .............................................................. 7

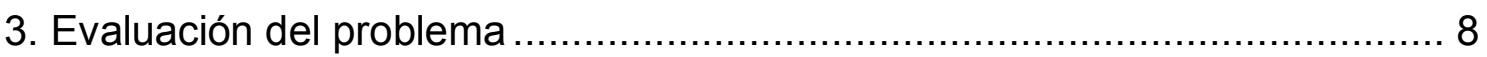

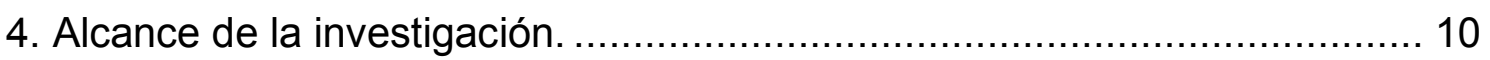

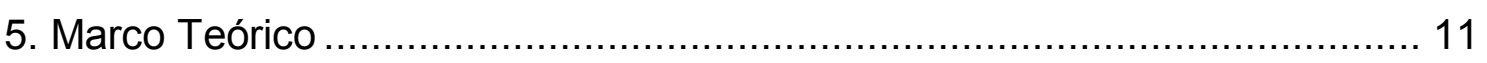

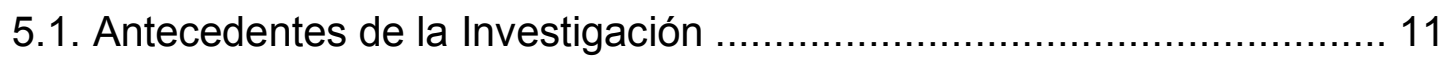

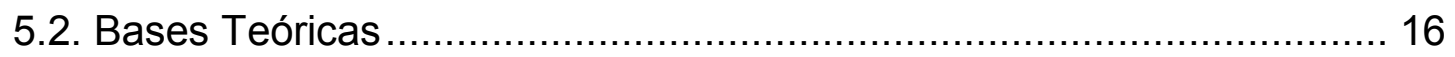

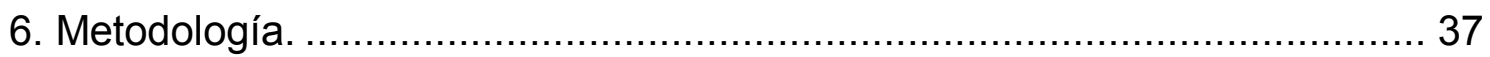

6.1. Población y muestra...................................................................... 37

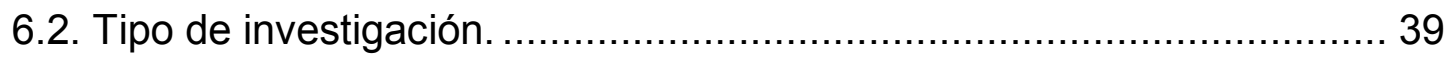

6.3. Técnicas de Recolección de Datos.................................................... 39

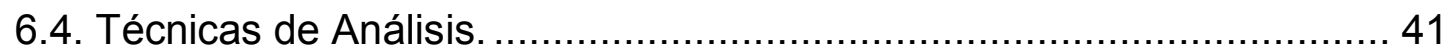

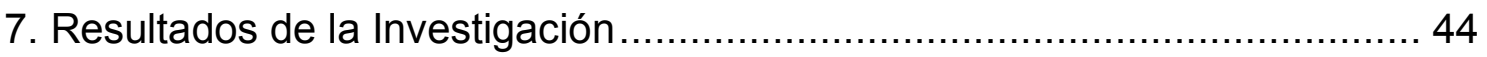

7.1. Perfil de los encuestados en Berisso ................................................ 44

7.2. Situación comparativa: Berisso con la Región .................................... 46

7.3. Situación comparativa: Berisso con Australia ……………................ 55

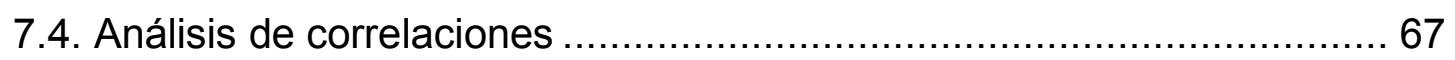

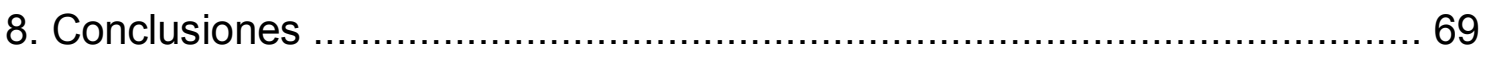

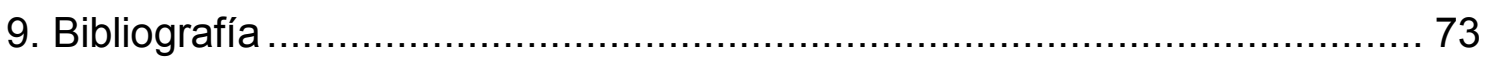

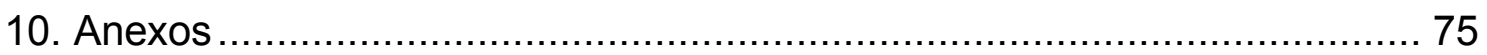

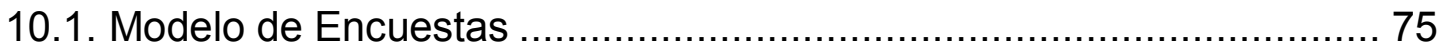

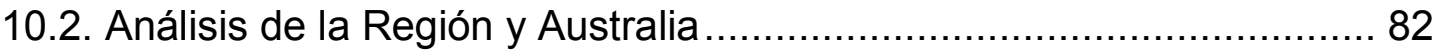

10.2.1 Situación: La Plata, Berisso y Ensenada ........................................ 82

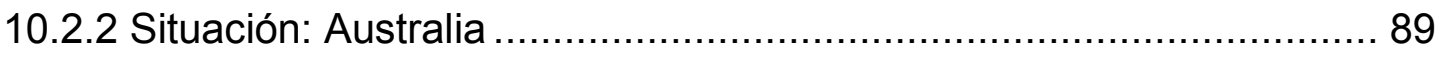

10.2.3 Situación comparativa: Australia con la Región ................................ 97

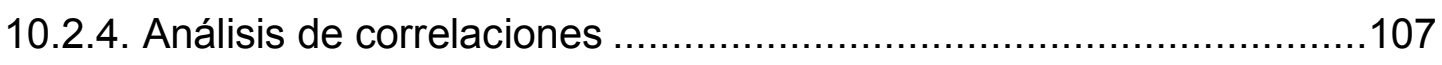




\section{ÍNDICE DE TABLAS}

Tabla 1: Evolución índices Argentina/Australia...................................... 5

Tabla 2: Tipos de Capital Social ...................................................... 23

Tabla 3: Índice de Desarrollo Humano y sus componentes........................... 29

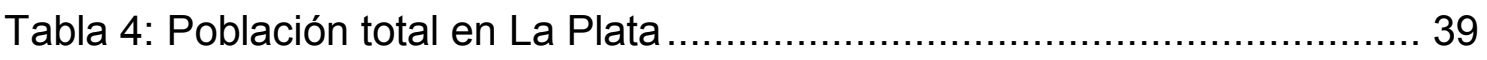

Tabla 5: Tabla modelo Importancia ................................................... 41

Tabla 6: Tabla modelo de Desempeño .................................................. 41

Tabla 7: Tabla modelo Discrepancia .................................................... 42

Tabla 8: Tabla modelo Gravedad Percibida ............................................... 42

Tabla 9: Berisso vs. Región La Plata, Berisso y Ensenada. Importancia......... 47

Tabla 10: Berisso vs. Región. Desempeño Real ..................................... 49

Tabla 11: Desempeño Región y ciudad de Berisso .................................. 50

Tabla 12: Discrepancia entre Importancia y Desempeño en la ciudad de Berisso y en la Región de La Plata, Berisso y Ensenada....................................... 52

Tabla 13: Discrepancia entre importancia asignada y desempeño. Ciudad de Berisso y Región de La Plata, Berisso y Ensenada................................... 53

Tabla 14: Gravedad percibida. Región y ciudad de Berisso. .......................... 54

Tabla 15: Importancia. Berisso y Australia ......................................... 56

Tabla 16: Desempeño. Berisso y Australia.......................................... 58

Tabla 17: Mejores desempeños. Berisso y Australia ..................................... 59

Tabla 18: Diferencias en Desempeño entre Australia y Berisso ..................... 59

Tabla 19: Peores desempeños. Berisso y Australia ...................................6 60

Tabla 20: Discrepancia entre importancia asignada y desempeño real, en

Berisso y Australia. .................................................................. 62

Tabla 21: Menores discrepancias. Berisso ...................................... 63

Tabla 22: Menores discrepancias. Australia ........................................ 63

Tabla 23: Mayores discrepancias. Berisso .............................................. 63

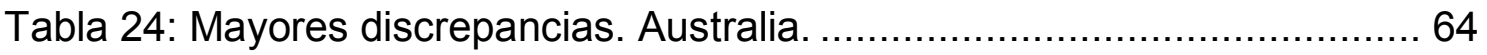

Tabla 25: Gravedad percibida. Berisso y Australia ..................................... 65

Tabla 26: Atributos de mayor Gravedad Percibida. Berisso .........................6 66

Tabla 27: Atributos de menor Gravedad Percibida. Berisso ..........................6 66 


\section{Planteo del Problema}

En la actualidad existe un debate permanente respecto a los atributos que favorecen el desarrollo de una sociedad y cuáles deben ser los parámetros a tener en cuenta a la hora de establecer, por ejemplo, indicadores de desarrollo social.

El pensamiento economicista predominante en Latinoamérica en los años 80 y 90 apunta a que lo único sustancial son los factores macroeconómicos. Allí se han acostumbrado a razonar en términos de que para ser prósperos la tasa de inflación debería ser baja, y que si el producto bruto per cápita fuera alto se hallarían en pleno bienestar. Han aprendido forzosamente que eso difiere de la realidad.

El desarrollo no está asociado exclusivamente con esos indicadores. Está dándose paso a una visión mucho más amplia en la discusión acerca de cómo se alcanza el desarrollo y allí apareció la idea de capital social. Se observan procesos silenciosos que surgen en el interior de la sociedad que permiten observar cómo influyen en la realidad de éstas a través de los nuevos instrumentos de medición de las ciencias sociales.

A estos procesos se los llama "capital social" y se relacionan con la cultura. Según Kliksberg (2004) el capital social tiene por lo menos cuatro dimensiones. La primera es el clima de confianza en las relaciones interpersonales; en qué medida la gente confía unos en otros en una sociedad. La segunda dimensión es la capacidad de asociatividad, es decir, la capacidad de una sociedad para construir formas de cooperación desde las más elementales, como cooperar en el vecindario para hacer cosas juntos, cuidar a los chicos, ayudarse, hasta las más elaboradas como ser capaces de hacer una gran concertación nacional sobre el modelo de desarrollo. El tercer componente del capital social es la conciencia cívica, refiere a cómo la gente actúa frente a todo lo que es de interés colectivo, desde cuidar los espacios verdes y los transportes públicos hasta pagar los impuestos. El cuarto y último componente, y definitivamente decisivo, son los valores éticos predominantes en una sociedad.

Entonces, una sociedad puede fortalecer o dañar su capital social. La desigualdad es un factor estratégico al respecto. Está demostrado que si existe en un alto nivel genera un deterioro serio de dicho capital. Si en una sociedad hay tanta desigualdad, las personas sienten que eso viola las reglas elementales de comportamiento, y se resiente profundamente en sus valores. Que países tan ricos en potencialidades como los latinoamericanos tengan tanta pobreza y estén polarizados, influye negativamente sobre todos los aspectos centrales del capital social.

Es posible realizar un análisis comparativo entre Argentina y Australia. Dos países que tienen similitudes como sus vastos territorios, con grandes 
distancias internas y externas, la necesidad de aumentar la población ante la escasa densidad demográfica inicial y las consecuentes migraciones masivas posteriores. Por otro lado, la disponibilidad en sus orígenes de recursos naturales, que daban origen a saldos exportables, y la consiguiente inserción en un mercado mundial crecientemente integrado durante la segunda mitad del siglo XIX.

Argentina es el octavo país del mundo en cuanto a dimensión, con aproximadamente 2,78 millones de $\mathrm{km}^{2}$ de extensión ${ }^{1}$. Posee una población de 40 millones de habitantes, lo que determina una densidad poblacional de 15 habitantes $/ \mathrm{km}^{2}{ }^{2}$

Se encuentra entre los países del mundo más ricamente dotados. Además de contar con suelos extraordinariamente fértiles, posee importantes reservas de petróleo y gas natural, capaces de satisfacer la mayor parte de sus necesidades energéticas.

Australia es el sexto país del mundo en extensión, con una superficie de 7,7 millones de $\mathrm{km}^{2}{ }^{3}$. Su población es de 22 millones de habitantes (estimado 2012). Al igual que Argentina, se encuentra escasamente poblado, con una densidad poblacional de 2,8 habitantes $/ \mathrm{km}^{2} .4$

Una enorme parte del país es desértica o semiárida; siendo Australia el país habitado más seco y llano del mundo, y el que menos suelos fértiles posee. Por otro parte, cuenta con importantes recursos minerales. Los más destacados, en cuanto a valor comercial son: la bauxita, el carbón bituminoso, el mineral de hierro, el níquel, el oro, el plomo, el zinc, la plata, el lignito; y el petróleo y el gas natural, ambos extraídos en las costas.

Ambos países fueron colonizados y poblados por europeos. Argentina, fue colonia española hasta declararse independiente en 1816; mientras que Australia fue colonia británica hasta 1901.

En materia de religión, tanto Argentina como Australia aseguran la libertad de culto en sus cartas magnas; siendo el cristianismo la fe predominante en ambos países. Según en el censo de 2001 , el $68 \%$ de los australianos se identificaban como cristianos (41\% Protestante y $27 \%$ Católico Romano); mientras que para el caso argentino esa cifra asciende al $88 \%$ (100\% Católico Romano) $)^{5}$.

Los gobiernos de ambos países se organizan en tres poderes: legislativo, ejecutivo y judicial. Argentina lo hace bajo la modalidad de

\footnotetext{
${ }^{1}$ Censo Indec 2010.

2 Censo Indec 2010.

3 Australia Bureau for Statistics 2014.

4 http://www.indexmundi.com/g/g.aspx?v=21\&c=as\&l=en [Población Australia; IndexMundi).

5 Guía Eclesiástica Nacional, editada por la Agencia Informativa Católica Argentina (AICA)
} 
República Federal Democrática; y Australia como una Monarquía Constitucional con sistema de gobierno parlamentario.

Más allá de las similitudes antes expuestas, la evolución de ambas naciones en los últimos 100 años ha sido completamente distinta. A principios del siglo XX, Argentina era considerada un país adelantado, con un alto nivel de alfabetización y avances en la salud pública; mientras que Australia recién estaba dando sus primeros pasos como nación independiente.

El panorama a inicios del siglo XXI cambia radicalmente. Australia cuenta con un producto bruto interno per cápita (PBI per cápita) casi 6 veces mayor al de la Argentina ${ }^{6}$; y se ubica $2^{\circ}$ en el ranking de Desarrollo Humano en contraste con Argentina que se encuentra en el puesto $49^{\circ}$ sobre 186 países bajo análisis. $^{7}$

La siguiente tabla expone cifras que evidencia estas diferencias:

Tabla 1: Evolución índices Argentina/Australia

\begin{tabular}{|c|c|c|}
\hline & Argentina & Australia \\
\hline $\begin{array}{l}\text { Índice de Desarrollo Humano } \\
\text { (2012) }\end{array}$ & 0,81 & 0,94 \\
\hline Tasa de Natalidad (2011) & 17,06 & 13,29 \\
\hline Índice de Fecundidad (2011) & 2,2 & 1,87 \\
\hline Tasa de Mortalidad (2011) & 7,72 & 6,58 \\
\hline Esperanza de Vida (2011) & 75,84 & 81,85 \\
\hline Deuda (2012) & $\begin{array}{c}226.805 \\
M \$\end{array}$ & $429.555 \mathrm{M \$}$ \\
\hline PBI (2012) & $\begin{array}{l}475.211 \\
M \$\end{array}$ & 1.541.700 M\$ \\
\hline Déficit (2012) & $\begin{array}{l}-20.415 \\
\mathrm{M} \$\end{array}$ & $-57.209 \mathrm{M} \$$ \\
\hline Deuda per Cápita (2012) & $5.520 \$$ & $18.937 \$$ \\
\hline PBI per Cápita (2012) & $11.566 \$$ & $67.304 \$$ \\
\hline Deuda (\% PBI) & $47,70 \%$ & $27,90 \%$ \\
\hline Déficit (\% PBI) & $-4,30 \%$ & $-3,70 \%$ \\
\hline Índice de Corrupción (2013) & 34 & 81 \\
\hline $\begin{array}{l}\text { Ranking de Competitividad } \\
\text { (2014) }\end{array}$ & 1049 & 210 \\
\hline $\begin{array}{l}\text { Euro/Moneda Nacional (julio } \\
\text { 2014) }\end{array}$ & 11,06 & 1,45 \\
\hline Inflación (2013) & $11 \%$ & $1 \%$ \\
\hline Índice "Doing Business" (2014) & 370 & 110 \\
\hline Exportaciones (2012) & $\begin{array}{c}80.927 \\
M \$\end{array}$ & $256.679,6 \mathrm{M \$}$ \\
\hline Importaciones (2012) & 68.508 & $260.942 \mathrm{M \$}$ \\
\hline
\end{tabular}

\footnotetext{
6 http://www.datosmacro.com

7 United Nations. Development Reports. 2013.
} 


\begin{tabular}{|ccc|}
\hline \multicolumn{3}{|c|}{ M\$ } \\
\hline Balanza Comercial (2012) & $\begin{array}{c}12.419 \\
\text { M\$ }\end{array}$ & $-4.262,4 \mathrm{M} \$$ \\
\hline & $17,10 \%$ & $16,70 \%$ \\
\hline Exportaciones \% PBI & $14,40 \%$ & $16,90 \%$ \\
\hline Importaciones \% PBI & $2,60 \%$ & $-0,30 \%$ \\
\hline Balanza Comercial \% PBI &
\end{tabular}

Fuente: Adaptación de datosmacro.com

Esto permite pensar que existen ciertas características en la cultura de estas sociedades que hicieron que ambas tomaran rumbos tan disímiles.

En consecuencia, se detecta la necesidad de indagar cuáles son los valores y componentes culturales que influyen en el desarrollo económico de una región; como así también identificar las relaciones que existen entre la economía, cultura, valores, ideologías y comportamiento social que conducen hacia el éxito de la sociedad en su conjunto. Sabiendo cuáles son, se facilitará el alcance de un impacto directo en las potencialidades de la sociedad para mejorar la gestión del desarrollo local y las condiciones de vida de sus habitantes. 


\section{Objetivos de la Investigación}

Objetivo general:

- Identificar los componentes culturales que favorecen u obstaculizan el desarrollo de la sociedad, según apreciaciones de la población de la ciudad de Berisso.

Objetivo específico:

- Realizar un estudio comparativo entre Berisso y la región de La Plata, Berisso y Ensenada para identificar posibles similitudes y diferencias en la importancia asignada a los distintos componentes culturales.

- Realizar un estudio comparativo entre una sociedad de un país en vías de desarrollo (Berisso) y una sociedad de un país desarrollado (Australia). 


\section{Evaluación del problema}

Se considera pertinente analizar en profundidad los atributos que hacen al desarrollo de una sociedad, entendiendo que esos factores presentan comportamientos diferentes en cada una de ellas, dependiendo no sólo de la estructura social particular de cada caso, sino también de las decisiones que se tomen desde los niveles políticos y las influencias que eso puede generar.

"La demanda por reevaluar el predominio del PBI y de su familia de indicadores surge desde varios frentes: los políticos y funcionarios públicos encuentran que los logros que obtienen de acuerdo a las metas fijadas no son correspondidos en la apreciación que de su gestión hacen los ciudadanos. Por su parte, éstos no sienten en toda su extensión los beneficios que de acuerdo al discurso político y a los planteamientos teóricos deberían estar recibiendo. Por otro lado, el escepticismo en la comunidad académica con respecto al predominio del PBI como indicador de progreso ha ido creciendo durante los últimos años, sobre todo conforme más economistas se unen a algunas de las críticas hechas al uso del PBI como indicador de progreso social y como aproximación del bienestar de sus habitantes". (Rojas, p.13)

En los últimos tiempos la cultura ha comenzado a redefinir gradualmente su papel frente a la economía y al desarrollo. Los sectores políticos comienzan a observar y aceptar que la cultura juega un papel mucho más importante de lo que suponían y constatado que las decisiones políticas, las iniciativas económicas y financieras y las reformas sociales, tienen muchas más posibilidades de avanzar con éxito si se tiene en cuenta la perspectiva cultural para atender las aspiraciones e inquietudes de la sociedad.

Debido a la priorización del desarrollo humano sostenible sobre otros modelos de desarrollo más economicistas, la cultura ha sido objeto de estudio como elemento necesario para el pleno desarrollo de las personas y las comunidades.

De acuerdo con el informe sobre el desarrollo humano elaborado por el Programa de las Naciones Unidas para el Desarrollo (2013), la inversión en desarrollo humano no tiene sólo una justificación moral, sino que además las mejoras en educación, salud y bienestar social son esenciales para triunfar en una economía mundial más competitiva y dinámica.

Una adecuada formulación de políticas debe contemplar las capacidades sociales, no solo las individuales. Las personas se desenvuelven en instituciones sociales que pueden limitar o fomentar su potencial de desarrollo. Las políticas que cambian las normas sociales que limitaban el potencial humano, como restricciones legales, pueden dar lugar a más oportunidades para que los individuos alcancen todo su potencial.

Las sociedades tienen características en común en cuanto a los individuos que las conforman, ya sean éstas de carácter social, demográfico, 
gustos, preferencias, educación, costumbres, idioma, cultura, etc. Esas particularidades permiten entender el comportamiento de cada una frente a ciertos factores y condiciones vinculadas con el micro y macro entorno.

Los valores, los sentimientos, los significados que pueden tener el trabajo, la esfera pública, la democracia, la participación cívica y las comunidades son cuestiones constitutivas de una sociedad y ésta sólo puede emprender de manera sólida el camino del desarrollo sobre la base de lo que ella es o puede imaginar ser en una coyuntura específica.

Acordando con lo que expresa Kliksberg (2000) aquellas sociedades como los países nórdicos, Canadá, Japón, Israel, entre otros, reconocidos por su elevado desarrollo económico y social, han logrado cultivar y poner en práctica a través de políticas e instituciones, valores positivos, favorables a la equidad y que, a su vez, facilitan el progreso financiero, tecnológico, y su competitividad.

El abordaje de esta problemática desde los aspectos internos de una sociedad, se halla en un todo de acuerdo con las aseveraciones de Vázquez Barquero (1988): "Las medidas a adoptar según la nueva concepción del desarrollo que valoriza lo local tienen su punto principal de referencia en el territorio, en el potencial endógeno, en la cercanía a los problemas y a quienes los sufren, y en la movilización, la cooperación y la solidaridad. El desarrollo endógeno se convierte de este modo en uno de los factores que definen el desarrollo local (...) las instituciones y los valores socio-culturales locales se convierten en la base de los procesos de desarrollo".

La cultura se gesta a partir de experiencias arraigadas, de modos de vida, en los cuales operan muchos factores internos de mayor peso que los elementos externos, que generalmente circulan a través de los medios de comunicación y del mercado (Figueroa, 2006). Los componentes de una cultura están estandarizados, pero la forma en que cada cultura los implementa son únicas.

Las sociedades exitosas desde una perspectiva social e integral, presentan rasgos distintivos con las que se las puede identificar y explicar el porqué de su bienestar social, económico y político. Lo mismo sucede con las sociedades menos exitosas (presentes en países en vías de desarrollo), las cuales poseen una serie de factores en común que las caracteriza y a través de los cuales se podrían identificar los motivos que obstaculizan su desarrollo. 


\section{Alcance de la investigación.}

El presente trabajo es una investigación comparativa entre los resultados obtenidos por el Proyecto Nacional de la Ciudadanía (Australia), a partir de la encuesta nacional ("Puntos de referencia de la ciudadanía Australiana") que se realizó en junio y julio de 1999 en tres regiones de la zona de Victoria, con una muestra aleatoria estratificada a través de siete grupos socio-económicos diferentes, identificados a partir de los índices presentados por la Oficina de Estadísticas de Australia y los resultados que se obtuvieron del estudio realizado a través de la encuesta distribuida en la ciudad de Berisso entre mayo y junio del año 2013.

En el presente estudio existe una limitación en lo que respecta a la información relevada, ya que no se ha podido encontrar estudios australianos de acceso público posteriores al año 1999, motivo por el cual podría no estar contemplándose cambios en los factores analizados. No obstante que estos aspectos son reconocidamente de lenta evolución. 


\section{Marco Teórico}

\subsection{Antecedentes de la Investigación}

\section{Antecedentes en Argentina}

Una encuesta realizada por Graciela Römer \& Asociados $^{8}$, relevada en octubre de 2003, examina los modos de valoración actual de los argentinos y muestra no sólo las inclinaciones de la sociedad, sino también sus paradojas y contradicciones.

Según el estudio, casi dos años después de la crisis de diciembre de 2001 , los valores que los argentinos rescataron como necesarios para mejorar el país son en primer lugar la honestidad (56\% de la suma de menciones), mayor educación (34\%), el patriotismo o sentido nacional $(21 \%)$, el esfuerzo, trabajo y sacrificio (21\%), la capacidad de conducción y liderazgo (19\%) y la solidaridad (15\%). Sin embargo, si se compara con los valores que suelen ocupar las primeras posiciones en los países desarrollados, estos están ubicados en los últimos lugares: el respeto por las normas jurídicas, sociales y morales alcanza apenas el $14 \%$, el sentido de la responsabilidad solo un $7 \%$ y aún menos el espíritu emprendedor $(2 \%)$ y la tolerancia $(4 \%)$.

El español Carmelo Angulo Barturen, representante del Programa para el Desarrollo de las Naciones Unidas (PNUD) y uno de los impulsores del Diálogo Argentino, considera que los valores esenciales universales son "la defensa de la paz y los derechos humanos, la promoción de las libertades y la democracia y la lucha contra la pobreza".

La Mesa del Diálogo Argentino representó una experiencia inédita de protagonismo por parte de la sociedad civil argentina, en el marco de la crisis política, económica y social experimentada por Argentina durante los años 2001 y 2002; que tensó hasta los límites los lazos que unen a la sociedad argentina en su conjunto y la puso al borde de la desintegración, el conflicto social generalizado y aún la guerra civil. La Mesa del Diálogo Argentino, fue integrada por tres representantes del gobierno nacional, tres representantes por la Conferencia Episcopal Argentina y tres representantes por el Programa de Naciones Unidas para el Desarrollo (PNUD).

A la luz de su experiencia en esta organización asegura que, contra lo que podría creerse, "pese a la tremenda crisis, algunos valores no sólo se mantuvieron sino que se potenciaron. Básicamente el apego a la democracia como único sistema posible de gobierno y la solidaridad, que emergió de un capital social de construir, pese a la pérdida de confianza en las instituciones, fuertes lazos de colaboración entre actores sociales de base."

\footnotetext{
${ }^{8}$ http://www.lanacion.com.ar/547621-los-valores-argentinos-en-su-laberinto
} 
Para el filósofo y ensayista Santiago Kovadloff, la crisis fue ante todo resultado de la profunda involución que afecta a la sociedad argentina desde mediados del siglo XX. ¿Qué valores se perdieron en ese más de medio siglo? En su opinión, los valores del bien común, aquellos que dan forma y sentido a una comunidad. Y lo que más le preocupa, lo que considera el gran dilema, es el cúmulo de efectos que la ausencia de ley produce sobre ellos.

Democracia, bien común, solidaridad, son algunos de los términos que ocupan prontamente el primer plano cuando se realizan consultas en un intento de cernir a que se hace referencia cuando se trata de valores.

En su Diccionario de Filosofía, José Ferrater Mora señala que por lo general se está de acuerdo en que los valores son tales si valen (es decir, aunque parezca redundante, si se consideran valiosos), si tienen objetividad ( $y$, consecuentemente, universalidad), si son interdependientes, si tienen polaridad (o en otras palabras: contravalores que se le oponen), cualidad (la calidad debe primar sobre la cantidad) y jerarquía.

Pero en el Informe para el desarrollo humano de 1998, dedicado a los valores, un trabajo realizado por una comisión del Senado con la colaboración del Programa para el Desarrollo de las Naciones Unidas (PNUD), los valores de bien público contrastaban con la acendrada tendencia a priorizar valores más personales y subjetivos, en particular el valor que se le da a la familia, a la amistad o a las relaciones interpersonales.

Graciela Römer cree que esta fuente de gratificación de los argentinos, este eje colocado sobre el particularismo, de orden cultural, aunque valioso, es una de las cosas que diferencia a Argentina de países más desarrollados. "Este predominio de los lazos familiares -asegura- tiene también consecuencias nefastas si lo que se privilegia son los lazos de sangre por sobre la objetividad y la universalidad. Lleva al privilegio de la lealtad personal por sobre las lealtades normativas. Es algo disfuncional si pensamos una sociedad democrática construida sobre los valores de tolerancia y respeto por la ley."

"Probablemente, en el escenario de crisis socio-económica y política de la gravedad que pasó la Argentina -reflexiona Angulo Barturen-, valores como la democracia y la solidaridad conforman la base de lo deseable en cuanto al comportamiento social: la convicción democrática garantiza un límite esencial a la crisis, pues todo puede estar muy mal, pero es sólo mediante las instituciones democráticas que gobierno y sociedad civil construyen las soluciones. $Y$, en ese sentido, la solidaridad tiene que ver con la emergencia: mientras las soluciones de fondo tardan en llegar, debe darse una respuesta ya, aquí y ahora, a quien más lo necesita. Y allí aparece la gesta solidaria."

El padre Rafael Braun, por su parte, considera que "en la Argentina hay una falsa comprensión de la solidaridad, porque la primera forma de solidaridad es pagar los impuestos y las contribuciones". 
Römer, en cambio, cree que el término es especial. Siete de cada diez entrevistados se definen como solidarios, pero, según la especialista, están lejos de "actuar" ese valor. "Los argentinos -dice- demandan solidaridad y repentinamente se observa la irrupción de comportamientos colectivos solidarios. Sin embargo, no son sistemáticos. El nivel de organizaciones comunitarias o de bien público en realidad es bastante bajo. Si se comparan con las de Chile o Brasil, las donaciones hechas por el sector empresario en la Argentina son muy pocas".

Si los valores ocupan lugar en los discursos o conversaciones, es en la historia donde puede entreverse qué se entiende por valores fundantes. Felipe Pigna, autor -junto con José Ignacio García Hamilton y Pacho O’Donnellde Historia confidencial, asegura que, en su contacto con la gente, a través de charlas públicas, conferencias o su propio programa radial, puede notarse que el tema ha vuelto a cobrar protagonismo.

"La Argentina es muy cambiante. En 2001 había una búsqueda de culpables, un intento de explicar lo que había sucedido a través del pasado. Después, con el apaciguamiento, la gente cambió de dirección y empezó a buscar ejemplos. $Y$ hay un interés importante por aquella gente insobornable que podía llegar a ir al exilio por sus convicciones o soportar la miseria, un interés por los valores que representa. En cierto modo es algo que tiene que ver con nuestra incapacidad para terminar de hacer los duelos."

Si los valores son, como se afirma, los constructores de una identidad colectiva, esta indagación o curiosidad por el pasado podría señalar la memoria común como un valor a no desdeñar.

Angulo Barturen, de hecho, destaca que la crisis le ha dado un nuevo impulso positivo a la identidad nacional, algo que en su opinión tal vez sea "una respuesta a las exacerbadas críticas que llegaban a la sociedad argentina desde el exterior".

Tras la década de los noventa, en que un término como "patriotismo" parecía relegado a un segundo plano, hoy parece cobrar, para algunos, renovado vigor. El reconocido politólogo polaco Zygmun Bauman sostiene que el patriotismo es un valor, pero que se da la paradoja de que "la tolerancia de la diferencia o la hospitalidad hacia las minorías son más comunes en los países en que no es un problema, es decir, en sociedades suficientemente seguras de su ciudadanía republicana que no tienen que preocuparse por el patriotismo, que no lo consideran un problema y menos aún un deber a cumplir".

Pigna hace la distinción entre el patriotismo y el nacionalismo. Mientras el primero sería un valor, el segundo sería su enfermedad y deformación, la apropiación de la nacionalidad para fines inconfesables. "El patriotismo es sentirse identificado con una historia, con una trayectoria, con las raíces, es como el apellido que debería llevarse con orgullo. La Argentina puede reclamarlo como un valor sin problemas porque, más allá de todas las 
desgracias políticas, siempre tuvo gente que fue honesta, que luchó, que se sacrificó. En ese sentido nos cuentan muy mal la historia cuando se la retrata como la de un país conformista".

También la educación, a pesar de o por culpa de su maltrecho estado, suele ser algo que, según se desprende de la encuesta de Römer y asociados, los argentinos valoran particularmente. Pero, ¿es la educación un valor por sí mismo? ¿Se trata de formación, de simples buenos modales? La educación escolar, en todo caso, carga con una pesada mochila. Sandra Carli, doctora en educación e investigadora del Conicet, cree que esa valorización tiene mucho de acto reflejo.

"El hecho de que la gente considere la educación como uno de los valores prioritarios tiene que ver con una suerte de ilusión iluminista, muy universal, que primó en todo el siglo XX. Siendo un valor muy universal, se pone ahí la confianza en el cambio de la sociedad, en el mejoramiento del ser humano, en las creencias. Y eso se potencia en momentos como el actual, de tanta crisis social. Pero en el caso particular de la sociedad argentina se relaciona con una tradición propia, una aspiración legítima a que haya un proceso de educación formal permanente."

Democracia, honestidad, bien común, solidaridad, educación, patriotismo, trabajo... El filósofo francés Alain Badiou dice que lo que más lo entusiasma de la Argentina es su vitalidad y también algo que no es un valor en sí, pero es valioso: "Lo interesante de estos momentos es que por fin la Argentina empieza a abandonar sus viejas mitologías."

Se sabe: cuando se abandona una mitología sólo queda enfrentarse con uno mismo. $\mathrm{Y}$ es en esos momentos cuando pueden producirse cambios cualitativos más allá de una verborrágica expresión de deseos.

\section{Antecedentes en Australia}

Durante la década de 1990, se ha producido un aumento sostenido en la realización de estudios basados en indicadores sociales y comunitarios en Australia. Entre ellos se destaca el proyecto marco que el presente trabajo considera como base para establecer los puntos incluidos en el cuestionario realizado a la población tomada como muestra.

El proyecto se conoció como "Proyecto Nacional de la Ciudadanía". En esta investigación de la comunidad se exploraron cuestiones relacionadas con la ciudadanía y la democracia, los indicadores sociales y de la comunidad desarrollo.

Se inició en 1995 a través de la Universidad Tecnológica de Swinburne, Melbourne (SUT) y el Consejo de Victoria de Servicio Social (VCOSS), con la financiación del Consejo Australiano de Investigación y la Fundación Myer, que 
ha reunido a varios socios de la comunidad y de otras universidades, entre ellas Deakin, RMIT, y las universidades de Nueva Gales del Sur y Tasmania.

El objetivo general del proyecto fue el desarrollo de puntos de referencia e indicadores para una "buena sociedad" (a nivel nacional) y "buenas comunidades" (a nivel local); procurando que se combinen en "estándares de mejores prácticas" (como los derechos humanos) con un fuerte desarrollo de la comunidad democrática y elementos de participación ciudadana (es decir, las comunidades y los ciudadanos se pronuncian sobre las metas y prioridades que consideran importantes para su comunidad). Por lo tanto, es a la vez una investigación social, un desarrollo comunitario y una creación de redes de trabajo.

La idea que subyace en el proyecto es que en la sociedad australiana contemporánea ( $\mathrm{y}$ en muchas otras) las formas más influyentes de la descripción de "progreso" y "bienestar", y los indicadores y puntos de referencia que la mayor parte de desarrollo de políticas de influencia se centran son los que se relacionan principalmente en el desarrollo económico de salida (por ejemplo, el Producto Bruto Interno). Estos indicadores establecen efectivamente las prioridades políticas y sociales y definen los términos del debate público, pero no se corresponden necesariamente con los valores y aspiraciones de la gente de la comunidad en cuanto a la clase de sociedad que quieren - por lo que no es un problema democrático. Al mismo tiempo, no crean una precisa o una imagen veraz del estado de salud de la sociedad en su conjunto, especialmente en áreas como la salud de la comunidad, la equidad y la justicia, el capital social y la confianza, la justicia, etc., por lo que son limitados para ser utilizados en la política y el debate público. El problema puede ser resumido en el título de un famoso artículo americano de 1995 (adaptado ligeramente): "Si la economía va tan bien, ¿por qué son tantos los australianos infelices?".

Los indicadores basados en la comunidad pueden ser un vehículo importante para identificar, y si es necesario reafirmar de manera concreta, lo que se considera importante y valioso en la sociedad.

El "Proyecto Nacional de la Ciudadanía" se inició con una revisión exhaustiva de los diferentes modelos de política de los indicadores y puntos de referencia para una buena sociedad.

Examinando a través de muchos ejemplos a nivel internacional, nacional, estatal y regional, lo que se analizó fue: la forma en que fueron diseñados (por comités o comunidades, por consenso o experiencia); qué tipo de problemas se incluyeron (salud social, así como también física), también bienestar ambiental; valores y conceptos generales en los que estaban enmarcados, ¿cuáles fueron los elementos clave en el "mapa" de una buena sociedad? ¿Incluye cultura y valores espirituales pesados en la balanza con el bienestar material? esa "felicidad nacional bruta" ¿cuenta tanto como el 
"Producto Bruto Nacional"?; la forma en que se han aplicado (como controles de gestión, como herramientas de planificación, como instrumentos de cambio social o, simplemente, fueron utilizados para una mejor presentación de informes); y el éxito que han tenido en la práctica.

Al final, no se encontró un solo modelo que satisfaga todas las necesidades exactamente - por lo tanto se asumió que el modelo australiano a desarrollar debía ser integral, basado en la democracia y demostrado en la práctica.

\subsection{Bases Teóricas}

\section{Desarrollo y valores culturales}

El desarrollo de una sociedad debe contemplar diversas variables, donde lo económico cumple un rol importante pero no puede dejar de considerarse los aspectos sociales, ambientales y culturales como generadores de la sinergia necesaria en pos de ese desarrollo.

Los conceptos cultura y desarrollo no siempre han sido vinculados, ni se han trabajado en el mismo contexto. Sin embargo, en los últimos años se han encontrado nuevas acciones e ideas que promueven cada vez una mayor atención hacia estos conceptos. Poco se duda ya acerca de su importancia como generadora de desarrollo y cohesión social, de su relevante papel ante la cuestión de la diversidad cultural, la integración de comunidades minoritarias, los procesos de igualdad y la problemática de las poblaciones marginadas.

En la Declaración de México sobre las Políticas Culturales, aprobada por la Conferencia Mundial sobre las Políticas Culturales, ha quedado plasmado el trabajo realizado para llegar a una definición de cultura. Ésta ha sido ampliamente aceptada y, hasta la actualidad, es adoptada por UNESCO:

- "En su sentido más amplio, la cultura puede considerarse actualmente como el conjunto de los rasgos distintivos, espirituales y materiales, intelectuales y afectivos que caracterizan a una sociedad o un grupo social. Ella engloba, además de las artes y las letras, los modos de vida, los derechos fundamentales al ser humano, los sistemas de valores, las tradiciones y las creencias.

- La cultura da al ser humano la capacidad de reflexionar sobre sí mismo. Es ella la que hace de nosotros seres específicamente humanos, racionales, críticos y éticamente comprometidos. A través de ella discernimos los valores y efectuamos opciones. A través de ella el ser humano expresa, toma conciencia de sí mismo, se reconoce como un proyecto inacabado, pone en cuestión sus propias realizaciones, busca incansablemente nuevas significaciones, y crea obras que lo trascienden." (1982 p.7) 
Definido así, la cultura no es un conjunto estático de valores y prácticas: se recrea constantemente de manera natural en la medida en que las personas cuestionan, adaptan y redefinen sus valores y prácticas ante el cambio de la realidad y el intercambio de ideas.

Esta definición de cultura contempla además la idea de complementariedad y dinamismo en las culturas y de la generación de diversificación en las identidades culturales no excluyentes entre sí.

Sin embargo, la definición de cultura no fue la misma a lo largo del tiempo, fue evolucionando fundamentalmente en las últimas décadas. Esta indefinición, sumada a una visión economicista del desarrollo, dificultaron aún más su consideración dentro de las políticas públicas de los gobiernos.

Otra cuestión a resaltar en el análisis de cultura y desarrollo, es que por mucho tiempo, la concepción más extendida vinculaba a la cultura con las bellas artes y el elitismo; de esta forma, el patrimonio inmaterial (las lenguas, tradiciones orales, artes del espectáculo, las costumbres, usos sociales, rituales, actos festivos, conocimientos y prácticas relativos a la naturaleza y el universo, saberes y técnicas vinculados a la artesanía tradicional, entre otras) no se concebía como elemento a ser promovidos.

Sobre esta evolución en la definición del término cultura, la UNESCO señala cuatro etapas:

- La primera se da entre la década del '50 y '60. En este momento se da la ampliación del concepto de cultura desde una definición más ligada a la producción artística hasta el concepto de la identidad cultural. Durante este periodo, UNESCO defiende las culturas en respuesta a situaciones concretas como la descolonización, reconociendo la igualdad de todas las culturas. Fue UNESCO quien ya en 1966 señaló en la Declaración de los Principios de la Cooperación Cultural Internacional la inevitable necesidad de contemplar la cultura dentro de la cooperación internacional.

- En la segunda etapa, durante las décadas del '70 y ' 80 , se toma de conciencia de la unión vital entre cultura y desarrollo, que se tomará como base de la cooperación y solidaridad internacional. La relación entre cultura y desarrollo comienza a ser defendida por diferentes expertos en estas décadas, aunque no es hasta finales de los 80 o incluso en los 90 cuando los organismos internacionales y las agencias de cooperación al desarrollo comienzan a impulsar los estudios y trabajos que analizan cómo los factores culturales podían incidir en los procesos de desarrollo. 
- Luego, durante los '80 y '90, se toma de conciencia sobre las aspiraciones y bases culturales en la construcción de democracias. Se trabaja sobre la exclusión y discriminación de minorías, pueblos autóctonos y poblaciones inmigrantes.

- Por último, en los años '90 y 2000 , se orienta hacia la puesta en valor del diálogo de culturas y civilizaciones en su riqueza, designada como patrimonio común de la humanidad por la Declaración Universal de la UNESCO sobre la diversidad cultural. Señala, además, las dos ramas de la diversidad: la primera basada en asegurar una interacción armoniosa de las diversas identidades culturales, variadas y dinámicas; mientras que la otra, reclama por la defensa de la diversidad creativa, la diversidad de las múltiples formas y expresiones culturales inherentes a las culturas.

Se profundizó en el concepto de desarrollo y con la aparición en 1990 del desarrollo humano, que no atiende sólo al crecimiento económico, sino que, fomenta el desarrollo como un proceso para fortalecer las capacidades y ampliar las opciones de las personas.

En 1990, el PNUD (Programa de las Naciones Unidas para el Desarrollo) publicó el primer Informe sobre Desarrollo Humano, en el cual se generó una breve definición de desarrollo humano, que con el tiempo se fue generalizando: "Ofrecer a las personas mayores oportunidades"

En el Informe se planteaba renovar la atención en las personas, considerando el dispar progreso de los países en materia de desarrollo humano durante la década del ochenta, caracterizada por crisis económicas, estabilización y ajustes.

Esta definición es fundamental, pero no suficiente para contener todo lo que implica el desarrollo humano. Éste trata de ser sostenible en el tiempo, de evitar el empobrecimiento de la gente y de frenar la dominación y la injusticia estructural. Para ello, son esenciales los principios de equidad, sustentabilidad y respeto por los derechos humanos.

Otro elemento esencial del desarrollo es su naturaleza dinámica. Por lo tanto, 20 años después, en un siguiente Informe de Desarrollo humano, se plantea una reformulación en la definición, quedando expresada de la siguiente manera:

"El desarrollo humano supone la expresión de la libertad de las personas para vivir una vida prolongada, saludable y creativa; perseguir objetivos que ellas mismas consideren valorables; y participar activamente en el desarrollo sostenible y equitativo del planeta que comparten. Las personas son los beneficiarios e impulsores del desarrollo humano, ya sea como individuos o en grupo." 
Esta nueva definición destaca los fundamentos básicos del desarrollo humano: su naturaleza sustentable, equitativa y empoderadora y su inherente flexibilidad. Según este planteamiento, el desarrollo humano se compone de tres factores:

- Bienestar, ampliando las libertades reales de la gente, para que puedan prosperar.

- Empoderamiento y agencia. Es decir, permitir que la capacidad de decidir y de participar de personas y grupos, permitan dar forma y beneficiarse de los procesos que le competen en el plano personal, comunitario y nacional.

- Justicia. Por último, este enfoque insiste en mantener la deliberación y el debate y en dejar siempre la puerta abierta a la discusión. Mejorar la equidad, mantener los resultados en el tiempo y respetar los derechos humanos y otros objetivos planteados por la sociedad.

Kliksberg (2000) analiza al desarrollo desde una perspectiva que se despega del pensamiento económico convencional. Incluye al capital social y a la cultura como impulsores fundamentales para el desarrollo.

Plantea un nuevo concepto a tener en cuenta, no incluido en el pensamiento económico tradicional, que gira en torno de la idea de capital social. Explora las relaciones entre la cultura y el desarrollo, buscando nuevas formas efectivas de medir el desarrollo. Resalta que hay aspectos en la cultura de cada pueblo que pueden favorecer a su desarrollo económico y social. Se plantea descubrirlos, potenciarlos, apoyarse en ellos, y hacer que sean incluidos en la agenda del desarrollo.

Por otro lado, destaca que no deben confundirse medios con fines en cuanto se refiere a desarrollo y enfatiza que los fines tienen que ver con la ampliación de las oportunidades reales de los seres humanos, de desenvolver sus potencialidades. Y para medir el progreso de una sociedad, hay que ver que los indicadores claves, como años que la gente vive, calidad de su vida, y desarrollo de su potencial mejoren.

Las personas, las familias, los grupos, son capital social y cultura por esencia, y esa cultura incluye valores, tradiciones, actitudes de cooperación, percepciones, visiones de la realidad, formas de expresión y comunicación, entre otros aspectos que definen la identidad de las personas y las naciones, si ello es ignorado, se inhabilitarán importantes capacidades aplicables al desarrollo. Si, por el contrario, se reconoce y potencia su aporte, puede ser muy relevante y propiciar círculos virtuosos con las dimensiones del desarrollo. 
Se asigna a los valores un peso decisivo en el desarrollo. Hace una distinción de los efectos que puede producir la prevalencia de valores que considera adversos al progreso, de los que considera positivos:

- $\quad$ "Si los valores dominantes se concentran en el individualismo, la indiferencia frente al destino del otro, la falta de responsabilidad colectiva, el desinterés por el bienestar general, la búsqueda como valor central del enriquecimiento personal, el consumismo, y otros semejantes, puede esperarse que estas conductas debilitarán seriamente el tejido social y pueden conducir a todo orden de impactos regresivos. Ellos pueden ir desde fuerte inequidades económicas que, según indican múltiples investigaciones, generan poderosas trabas a un desarrollo económico sostenido hasta, como ya se mencionó, descensos en la cohesión social que puede, incluso, influir negativamente sobre la esperanza de vida promedio. Uno de los efectos visibles de la vigencia de valores antisolidarios, es la extensión de la corrupción en diversas sociedades.

- Valores positivos conducen en direcciones diferentes. Así, por ejemplo, sociedades que han estimulado y cultivado valores favorables a la equidad, y los han reflejado en múltiples expresiones, desde sus sistemas fiscales hasta la universalización de servicios de salud, y educación de buena calidad, tienen actualmente buenos niveles en ese campo que, a su vez, facilitan su progreso económico y tecnológico, y su competitividad. Se mencionan con frecuencia, al respecto, casos como los de los países nórdicos, Canadá, Japón, Israel, entre otros.” (2000, p. 29,30).

En este sentido observa importantes falencias en América Latina. Junto a grandes esfuerzos de algunos sectores por avanzar la cultura e importantes concreciones, se observan reservas y marginaciones por parte de otros en incorporar la cultura a la agenda central del desarrollo. Se le restan recursos, se la hace objeto preferencial de recortes presupuestarios, se la somete a continuos cambios sin permitir la estabilidad necesaria para asentar actividades e instituciones. Se argumenta, asimismo, con frecuencia, que se trataría de una especie de necesidad secundaria que tendría su lugar cuando otras previas se hubieran satisfecho.

Retomando el concepto de capital social, el mismo se convierte en un elemento clave de análisis y estudio, para comprender cómo se comportan las sociedades en su conjunto, tanto desarrolladas como en vías de desarrollo. En este marco, el capital social comunitario, es decir aquella forma de capital referida a la capacidad que tiene un grupo humano de emprender acciones colectivas que redunden en beneficio de todos sus miembros, se presenta como un factor relevante para el desarrollo (Lorenzelli, 2003; Cacciutto 2010). De tal manera, se presentará al concepto como un cuerpo de conocimientos que considera a los miembros de comunidad no como sujetos pasivos sino 
como agentes, es decir actores con capacidad para generar cambios empoderamiento- (Sen, 2009).

Entonces el capital social debe estudiarse a nivel regional (en este caso La Plata, Berisso y Ensenada) ya que el desarrollo sólo es posible y sustentable en la medida que la sociedad o grupo son los diseñadores y actores de ese proceso (Sandoval Forero, 2002). Y es aquí donde radica la importancia del capital social, como medidor estratégico del estado de cohesión social de un territorio y factor relevante de la sustentabilidad social y, por ende, insumo clave para la toma de decisiones de políticas estratégicas vinculadas al desarrollo de una sociedad en su conjunto.

Como expresa Comparato (2012) en su artículo "Capital Social: consideraciones metódicas-conceptuales del rol de las comunidades locales", existe un mayor consenso en que fue recién con los postulados de Bourdieu y Coleman, en la década de 1980, donde se hace un uso más sistemático de lo que hoy se conoce como capital social (Portes, 1998; Durston, 2000; Lorenzelli, 2003).

Pierre Bourdieu (1986) lo define como "el agregado de los recursos reales o potenciales ligados a la posesión de una red durable de relaciones más o menos institucionalizadas de reconocimiento mutuo". En este sentido, el autor plantea que a diferencia del capital económico y cultural en posesión de las personas, que podían ser perfectamente inteligibles desde el individuo, el capital social demanda la existencia de un grupo o una red de relaciones sociales (Ramírez Plascencia, 2005). Hablamos por ello de una forma de capital en la cual no es existe dueño. Es decir, el capital total que poseen los miembros individuales del grupo les sirve a todos, conjuntamente.

Por otro lado, también se reconoce a James Coleman como uno de los primeros formuladores sistemáticos del concepto de capital social (Ramírez Plascencia, 2005). Sin dejar de mencionar la característica inmaterial, define a esta forma de capital por su función, mencionando que "no es una sola entidad, sino una variedad de distintas entidades que tienen dos características en común: todas consisten de algún aspecto de una estructura social y facilitan ciertas acciones de los individuos que están dentro de la estructura" (Coleman, 1990, citado en Millán y Gordon, 2004).

Como sucede con toda construcción empírica, existen corrientes detractoras y respecto al capital social es preciso mencionar aquellas posturas críticas respecto al concepto. En este sentido, Durston (2000) considera que si bien el capital social es el conjunto de relaciones de confianza y cooperación "no necesariamente produce altos niveles de participación ni sociedades civiles altamente democráticas, ni necesariamente resulta en aumentos de la productividad y producto económico de empresas o economías". Desde esta perspectiva intervienen diversas variables adicionales. Siguiendo esta línea de 
pensamiento, Portes (1998), habla sobre un lado oscuro o "downside" del capital social. Argumenta que dicha forma de capital también puede llevar a la discriminación, la explotación y la corrupción, tomando el ejemplo de grupos mafiosos o prácticas clientelares. En definitiva, grupos con altos niveles de confianza, cooperación e incluso reciprocidad pueden resultar perjudiciales en términos comunitarios.

Continuando con la contextualización de este concepto, se aprecia que no existe una unívoca concepción del capital social. Diversos organismos tales como el PNUD, la CEPAL o el mismo Banco Mundial han abordado este tema pero aún no existe un consenso claro en definirlo de una manera específica (Arriagada, 2001).

De esta forma, cobra sentido repasar algunas de las definiciones más aceptadas en torno al capital social. Primero, rever la importancia de conceptualizar el capital social, tanto para sus fines teóricos pero también de sus implicancias empíricas. Cabe citarse así, la definición de Cacciutto (2010) "Aquellas capacidades y habilidades que poseen los actores de una comunidad para obtener determinados recursos, cumplir objetivos y resolver problemas colectivos, como producto de su pertenencia a redes de relaciones sociales más o menos institucionalizadas, con cualidades de confianza, reciprocidad y cooperación, que incentiven la creación de identidad y valores, y promuevan el desarrollo de las comunidades a las que pertenecen". Definirlo como capacidad resuelve, por lo menos en parte, el problema de abarcar variables muy interrelacionadas pero a la vez distintas. Es decir, las cualidades de confianza, reciprocidad, cooperación y de compromiso cívico son las fuentes o factores que influyen pero no que no son el capital social. El capital social bajo esta postura es una capacidad, en tanto dinámica, que puede ser "mejorada" -como también reducida o disminuida-. En otras palabras no hablamos de la existencia o la inexistencia absoluta de capital social, o de que sea algo estrictamente positivo o negativo, sino que es una capacidad que dependiendo de cómo se interrelacione con otros sistemas y, en definitiva, cómo se construya puede ser útil para favorecer el desarrollo de un territorio (Comparato, 2012).

Ahora bien, así como coexiste una diversidad de definiciones del capital social- $y$ de los diferentes componentes que lo conforman- también hay diferentes formas de medirlo (Arriagada, 2003). Pero aun así existe consenso académico en que hay una necesidad creciente de hacer operativo el concepto en lo que respecta con fines relacionados con la investigación y para programas y proyectos públicos y privados (Lorenzelli, 2003; lisakka, 2007).

De esta manera, dentro de las formas de medición más populares, se puede identificar la propuesta del Banco Mundial (2002) denominada "Cuestionario Integrado para la Medición del Capital Social". Dicha metodología fue diseñada en el 2002 y se aplicó en diversos países tales como Ghana, 
Bolivia, Tanzania, entre otros. Consiste en una serie de preguntas para posteriormente integrarlas al sistema de Encuestas de Niveles de Vida (ENV). Otro antecedente interesante es el denominado "Measuring Social Capital. An Australian Framework and Indicators" realizado por el "Australian Bureau of Statistics (ABS)". Dicha metodología fue aplicada a mediados del 2004 y posteriormente desarrolló un marco estadístico en función de indicadores (Australian Bureau of Statistics, 2004).

Finalmente, Comparato (2012) realiza una interesante clasificación del capital social, otorgándoles categorías y que se sintetizan en el siguiente cuadro:

Tabla 2: Tipos de Capital Social

\begin{tabular}{|l|l|}
\hline Tipos de Capital Social & Significado \\
\hline $\begin{array}{l}\text { Capital social lazo, aglutinante o } \\
\text { también conocido como "bonding" }\end{array}$ & $\begin{array}{l}\text { Se trata de un tipo de capital social } \\
\text { cuya característica principal es que } \\
\text { las relaciones se dan entre grupos } \\
\text { homogéneos. Su utilización abarca en } \\
\text { general grupos excluyentes cuya } \\
\text { forma de capital se asemeja más bien } \\
\text { a un capital privado. Asimismo, está } \\
\text { representado generalmente por las } \\
\text { relaciones entre familia, vecinos y } \\
\text { amigos (Eduardo Jorge, 2008; } \\
\text { Lorenzelli, 2003; Camarero Rioja, } \\
\text { 2010) }\end{array}$ \\
\hline Capital social puente, vinculante o \\
"bridging" & $\begin{array}{l}\text { Con esta categoría se hace referencia } \\
\text { a las conexiones entre individuos y } \\
\text { grupos heterogéneos de una misma } \\
\text { comunidad. Se tratan, en general, de } \\
\text { grupos incluyentes cuya figura del } \\
\text { capital social se asemeja más a un } \\
\text { bien público. Se trata entonces, de un } \\
\text { capital social que "tiene puentes". En } \\
\text { tal sentido, y pensando en términos } \\
\text { comunitarios, el capital social lazo o } \\
\text { "bonding" debe ser visto como un } \\
\text { primer paso pero no suficiente. Para } \\
\text { el desarrollo comunitario se debe } \\
\text { fortalecer también el capital social que } \\
\text { vinculante o "bridging" (Obs. Cit.). }\end{array}$ \\
\hline Capital social eslabón o "linking" \\
$\begin{array}{l}\text { Michael Woolcok agrega esta } \\
\text { categoría. Justifica que en el capital }\end{array}$ \\
\hline
\end{tabular}

Página 23 


\begin{tabular}{|c|c|}
\hline & $\begin{array}{l}\text { social vinculante o "bridging", a pesar } \\
\text { de haber interacciones entre grupos } \\
\text { heterogéneos, existe una distribución } \\
\text { simétrica de poder entre esos grupos. } \\
\text { Agrega, por ello, una categoría que } \\
\text { engloba a aquella red de relaciones } \\
\text { en donde existen grupos en distintos } \\
\text { espacios de acción y de poder. Se } \\
\text { utiliza generalmente para designar las } \\
\text { conexiones externas } \\
\text { extracomunitarias o aquellas dentro } \\
\text { de una misma comunidad pero con } \\
\text { relación asimétrica de poder (Atria, } \\
2003 \text {; y Michael Woolcok (1998) } \\
\text { citado en Lorenzelli, 2003). }\end{array}$ \\
\hline Capital Social Formal & $\begin{array}{l}\text { Refiere a las redes y asociaciones } \\
\text { constituidas sobre bases } \\
\text { organizativas identificables. Se } \\
\text { caracterizan por tener una estructura, } \\
\text { procedimientos, autoridades, normas } \\
\text { formales, etc. (Ramírez Plascencia, } \\
2008 \text { ). }\end{array}$ \\
\hline Capital Social Informal & $\begin{array}{l}\text { En oposición al anterior, remite al } \\
\text { amplio espectro de la convivencia } \\
\text { social que carece de formalidades. Es } \\
\text { el caso de comidas familiares, una } \\
\text { charla entre vecinos, etc. (Ob. Cit.) }\end{array}$ \\
\hline Capital Social vuelto hacia adentro & $\begin{array}{l}\text { Se tratan de redes egocentradas que } \\
\text { apoyan específicamente los intereses } \\
\text { particulares de los miembros que } \\
\text { integran una estructura social (Ob. } \\
\text { Cit.). }\end{array}$ \\
\hline Capital Social vuelto hacia afuera & $\begin{array}{l}\text { Se tratan de las relaciones existentes } \\
\text { en un grupo caracterizadas por ser } \\
\text { abiertas y permeables a otros. Como } \\
\text { tal pretenden promover el interés } \\
\text { público. Son incluyentes (Ob Cit). }\end{array}$ \\
\hline $\begin{array}{l}\text { Forma particularizada o "Close-tie } \\
\text { social de capital" }\end{array}$ & $\begin{array}{l}\text { Definición similar al capital social } \\
\text { aglutinante o "bonding". En otras } \\
\text { palabras, se trata de una forma de } \\
\text { capital que se da en grupos similares }\end{array}$ \\
\hline
\end{tabular}




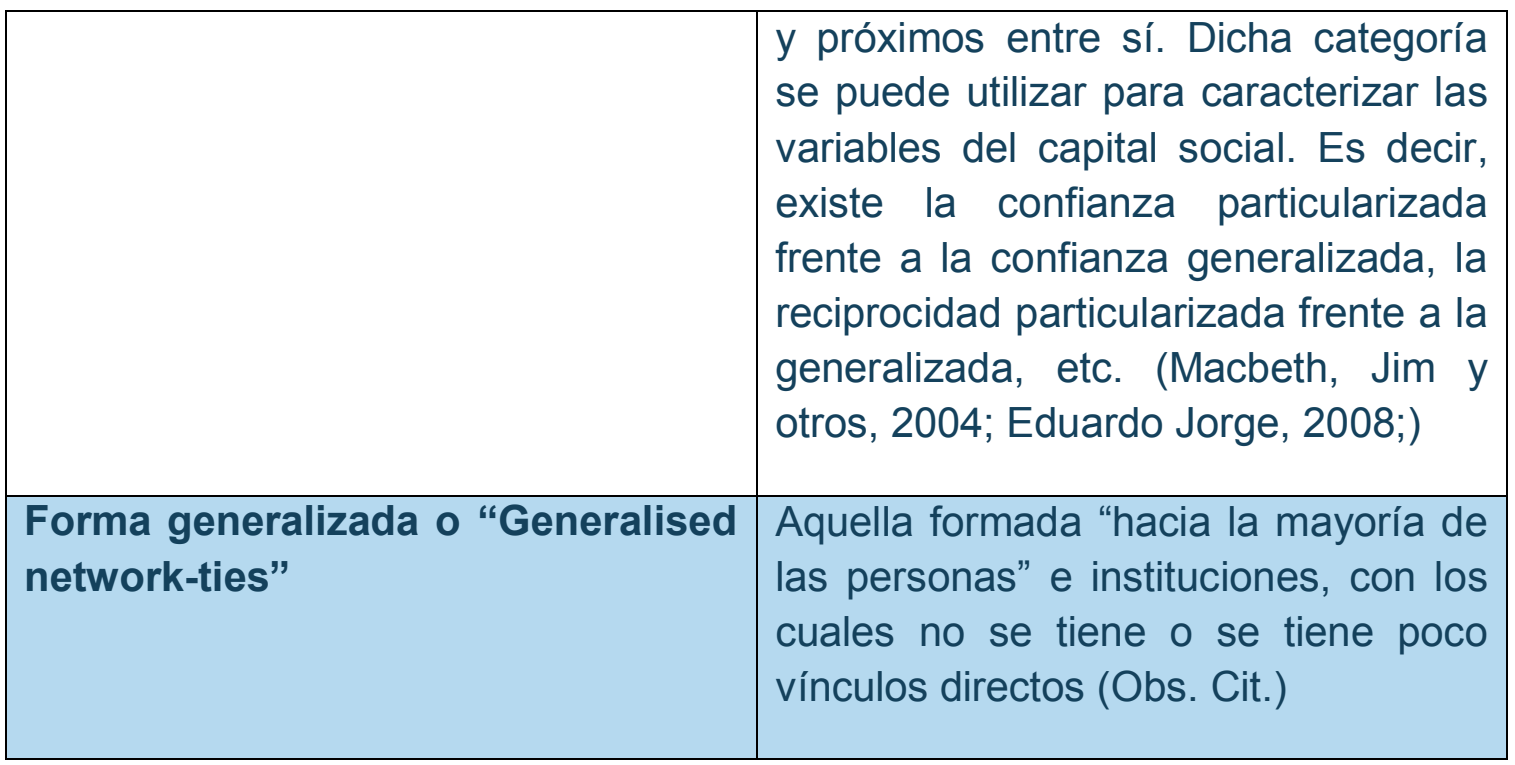

Fuente: Comparato (2012).

\section{El desarrollo económico desde la visión de la Escuela Institucionalista}

La teoría económica tradicional considera a las instituciones como parte del contexto o supone que éstas se adaptarán a las condiciones que fijen los mercados. Asume que los mercados a largo plazo alcanzan siempre a resultados eficientes, que todos los intervinientes poseen información completa y gratuita, y considera a los procesos políticos externos. De esta forma, los agentes económicos pueden tomar decisiones sin la necesidad de un arreglo institucional.

Este análisis es al menos incompleto, dado que considera que el mercado es lo único que permite mejorar la asignación de los recursos, olvidando que los mecanismos reales de asignación de recursos son operados por las instituciones y especialmente las estructuras de poder que organizan a los mercados.

La escuela institucionalista para cubrir estas ausencias, introduce a las instituciones al análisis económico como variables internas.

Los institucionalistas afirman que el diseño institucional puede modificar la equidad en la sociedad, y que el esquema de incentivos puede ser cambiado por quienes ejercen la autoridad, favoreciendo o motivando un comportamiento racional en una dirección determinada y modificando los resultados obtenidos. El comportamiento de los actores es influido por las conductas oportunistas, individuales, por la cultura de cada país o por los valores de las personas.

Las grandes instituciones que ordenan y facilitan a la vez las vidas de los ciudadanos, desde el lenguaje hasta las instituciones del Estado de Derecho, no son el producto de una persona individual, sino el de un largo proceso de

Página 25 
interacción histórica entre los miembros de una sociedad. Por lo tanto, es factible afectar o guiar el cambio institucional en la misma medida en que se puede orientar e influir la acción colectiva.

Tal como expresa Popper (1985, p. 70-71) "las instituciones son humanas no en el sentido de que han sido conscientemente construidas por determinados hombres y mujeres, sino en el de que los hombres siempre podemos valorarlas y modificarlas, que es lo mismo que decir que la responsabilidad por su vigencia es sólo nuestra"

Las instituciones son el principal capital de cada sociedad. Son ellas quienes determinan principalmente el tipo de organizaciones e interacciones permitidas a la libertad del individuo en cada sociedad. Es bien sabido que la suma de individuos brillantes no hace de por sí a una sociedad brillante. La eficiencia y la equidad de un orden social dependen sobre todo de su sistema institucional y, a su vez, de la calidad de sus organizaciones. Es por esto que se da una creciente referencia a la cultura como responsable del nivel o del tipo de desarrollo.

El Instituto Internacional de Gobernabilidad Barcelona (1998) se plantea "¿Por qué personas de alta competencia intelectual y moral no rinden en un país y sí en otro? Sencillamente porque las personas se adaptan al medio no en base a sus competencias personales sino al conocimiento y cumplimiento de las normas institucionales".

North ha formulado la distinción entre instituciones y organizaciones como el supuesto conceptual básico para la comprensión de la historia económica $\mathrm{y}$, consiguientemente, para la formulación de una teoría del desarrollo históricamente fundada. Las instituciones son, para él, las reglas del juego o las restricciones convencionalmente construidas para enmarcar la interacción humana en una sociedad determinada. Las instituciones son normas, pero no son la legislación.

En consecuencia, investigar el sistema institucional de un país es tarea que excede, con mucho, el estudio de sus instituciones formales, ya que exige el averiguamiento de las convicciones, valores, principios o creencias que pautan el comportamiento real, determinan la interpretación de las normas formales, las completan o hasta producen in extremis su inaplicación. En conclusión, quien no conoce las instituciones informales no puede pretender conocer un país. La dificultad está en que uno de los efectos del subdesarrollo consiste en bloquear o censurar con más fuerza la emergencia o visibilidad de lo informal.

En otras palabras, el institucionalismo plantea que potencial de eficiencia económica y equidad social de cada sociedad viene en gran parte determinado por la clase de conformación institucional en ella vigente. $Y$ toda mejora de eficiencia y equidad que desborde el potencial y no se corresponda con el 
avance institucional requerido, está condenada de antemano al fracaso inmediato o a la fugacidad de resultados.

La fortaleza o debilidad del marco institucional de un país debe evaluarse en relación al grado en que incentiva la eficiencia económica y la equidad social. Ahora bien, mientras en América Latina existe una conciencia suficiente de la debilidad de las instituciones políticas de la democracia, todavía no existe conciencia suficiente de la debilidad de las instituciones económicas y del importante impacto de esta debilidad sobre la equidad social y la sostenibilidad de la propia democracia. Esto se debe, entre otras razones, al manejo perseverante de una teoría del desarrollo insuficiente o inapropiada.

"La insuficiencia de las instituciones políticas de las democracias latinoamericanas es generalmente reconocida: el Estado y el proceso de adopción de decisiones y asignación de recursos públicos sigue, a pesar de los procesos electorales, cautivo de grupos o coaliciones que lo utilizan en su exclusivo beneficio e impiden la participación e integración de grandes masas de excluidos. Y aunque puede refinarse y avanzarse en los diagnósticos, existe ya base suficiente de conocimiento y experiencia para formular líneas claras de desarrollo institucional en el ámbito político." (Instituto Internacional de Gobernabilidad Barcelona, 1998)

La economía institucional no se caracteriza por la uniformidad teórica de las aportaciones de sus autores. No obstante, a pesar de las diferencias existentes entre las distintas corrientes institucionalistas, Pulido, Casero y Mogollón (2007) presentan brevemente los principios básicos de la teoría económica institucional:

(1) "El enfoque cultural de la economía: La teoría económica institucional considera que los procesos económicos están insertados en un entorno social muy complejo (...) Desde esta perspectiva el sistema económico de un país, región o territorio determinado, a pesar de que tiene muchos elementos en común con otros sistemas económicos, es un producto histórico-cultural único y en evolución permanente (Dugger, 1990). En este sentido, Sturgeon (2002) plantea que el concepto de cultura es una parte integral del análisis económico. No es posible separar los fenómenos económicos de los sociales, siendo necesario analizarlos de forma conjunta e integrada.

(2) Crítica a la economía neoclásica: La teoría económica institucional representa un cambio de paradigma del concepto estático y de equilibrio de la economía neoclásica al concepto dinámico de proceso y evolución (...) Así pues, los institucionalistas piensan que, aunque el concepto de equilibrio y el método marginal pueden ser útiles para algunos 
propósitos subordinados de análisis, las explicaciones del fenómeno económico son posibles únicamente con referencia a la naturaleza y a la fuerza efectiva de las instituciones sociales."

Tal como expresa Oliveras (1996) "La visión del desarrollo como una relación mecánica de etapas progresivas consecuencia de la acumulación de capital guiada por agentes maximizadores interactuando en el mercado es, en el mejor de los casos, incompleta. Se trata, en todo caso, de una dinámica coevolutiva de todos los elementos del tejido social: conocimiento, valores, organizaciones, tecnología...

El desarrollo, por tanto, no trata del mercado, aunque éste pueda ser una de las organizaciones que se utilice como medio, sino de la conducta de los agentes de la transformación, es decir, los seres humanos.

Tal conducta, generadora de y a la vez constreñida por las instituciones, es la que coloca a los países en una posición o en otra. La llamada ventaja comparativa no es definida por la dotación de tales o cuales recursos naturales (sin que ello signifique que no cuentan), sino por la certeza y agilidad en el diseño institucional.

La pobreza de la teoría del desarrollo, particularmente en su versión neoclásica, radica precisamente en su vacío institucional. Se limita básicamente a presumir el carácter inhibidor de las instituciones no mercantiles y la acción positiva que supondría el desplazamiento de éstas por el mercado."

\section{Índice de Desarrollo Humano}

El Índice de Desarrollo Humano (IDH) es probablemente uno de los indicadores estadísticos más utilizados para medir y comparar el desarrollo de los países, aunque también es frecuente su uso en otras escalas territoriales. Este instrumento fue presentado por el PNUD en el informe del año 1990. Desde entonces, el concepto de desarrollo humano se ha convertido en un icono en el discurso sobre el desarrollo a nivel mundial.

Para su cálculo se estudian formalmente tres factores clave:

- Un indicador de salud: la esperanza de vida al nacer.

- Un indicador social: la tasa de alfabetización en adultos (más la tasa bruta combinada de matriculación en educación primaria, secundaria y superior y los años de duración de la educación obligatoria).

- Un indicador económico: El Producto Bruto Interno (PBI) en paridad del poder adquisitivo en dólares (PPA en US\$). 
Estos informes incorporan un apartado en el que se detallan elaboradas y útiles clasificaciones estadísticas que hacen referencia a factores vinculados con el desarrollo de los países: el Índice de desarrollo relativo al género, tendencias demográficas, economía y desigualdad, salud y educación o el Índice de pobreza Humana. Siendo la más conocida la correspondiente al Índice de Desarrollo Humano.

La Organización de las Naciones unidas desarrolló este indicador con el fin de examinar las desigualdades existentes entre los diferentes países del mundo y, a la vez, observar la evolución de estos países a lo largo de los años y comprobar si las desigualdades existentes evidentes se acortan o se agravan.

La combinación de estas medidas da un resultado entre 0 y 1 (mínimo y máximo desarrollo humano, respectivamente). Así, por ejemplo, en el informe presentado en 2013, Australia presentaba un valor de 0,938, que la ubicaba en el puesto 2 de la clasificación, mientras que Argentina se encontraba en el puesto 45 , con un valor de 0,811 . Así mismo, en el puesto número 1 se encontraba Noruega y últimos de la clasificación se encontraban Congo, R.D. y Níger con un valor de 0,304 cada uno.

Tabla 3: Índice de Desarrollo Humano y sus componentes

\begin{tabular}{|c|c|c|}
\hline Clasificación según IDH & Australia (puesto 2) & Argentina (puesto 45) \\
\hline IDH (2012) & 0,938 & 0,811 \\
\hline Esperanza de vida al nacer (2012) & 82 & 76,6 \\
\hline Años promedio de escolaridad (2010) & 12 & 9,3 \\
\hline Años esperados de escolaridad (2011) & 19,6 & 19,1 \\
\hline Ingreso Nacional Bruto (INB) per cápita - PPA en U\$S de 2005 (2012) & 34.340 & 15.347 \\
\hline Clasificación según el INB per cápita menos clasificación según el IDH & 15 & 7 \\
\hline IDH no referido a ingresos 2012 & 0,978 & 0,848 \\
\hline
\end{tabular}

Fuente: Informe sobre Desarrollo Humano 2013

- Esperanza de vida al nacer: años que vivirá un recién nacido si los patrones de mortalidad por edades imperantes en el momento de su nacimiento siguieran siendo los mismos a lo largo de toda su vida.

- Años promedio de escolaridad: años promedio de escolaridad que reciben las personas de 25 años y más, según los niveles de logros educacionales de la población de acuerdo con la duración de cada nivel.

- Años esperados de escolarización: años de instrucción que un menor en edad de ingresar a la escuela puede esperar recibir si los patrones vigentes de las tasas de matriculación específicas por edad se mantuvieran constantes durante toda su vida.

- Ingreso nacional bruto (INB) per cápita: el ingreso total de una economía generado por su producción y la propiedad de los factores de producción, menos los ingresos pagados por el uso de los factores de 
producción de propiedad del resto del mundo, convertido a dólares estadounidenses usando las tasas de la paridad del poder adquisitivo (PPA), dividido por la población a mitad del año.

- $\quad$ Clasificación según el INB per cápita menos la clasificación según el IDH: diferencia entre la clasificación del INB per cápita y la clasificación del IDH. Una cifra negativa indica que el país tiene una mejor clasificación en el INB que en el IDH.

- $\quad I D H$ no referido a ingresos: valor del IDH calculado sólo a partir de los indicadores de esperanza de vida y educación.

La tendencia del índice desde su creación muestra que el desarrollo humano se ha incrementado a lo largo de los últimos 20 años. El Informe destaca que en la última década todos los países aceleraron sus logros en las dimensiones de educación, salud e ingresos, según mediciones del Índice de Desarrollo Humano (IDH); en tanto que ningún país sobre el cual había datos disponibles tuvo un valor del IDH más bajo en 2012 que en 2000; en contraposición con lo ocurrido en la década anterior, en la que 18 países registraron en 2000 valores del IDH inferiores a los de 1990.

Entre 1990 y 2012, prácticamente todos los países mejoraron su estado de desarrollo humano. De 132 países de los que se dispone series de datos completos, solo 2 registraron en 2012 un IDH inferior al de 1990.

El IDH mundial promedio en el año de 1980 era de 0,455, mientras que en el año 2012 subió hasta 0,694.

\section{Medición de indicadores de la comunidad}

Al momento de generarse la necesidad de establecer la medición de indicadores de la comunidad, se plantea la convergencia de tres fenómenos separados:

En primer lugar, se reconoce que existen problemas económicos y sociales que necesitan soluciones para toda la comunidad.

El segundo factor es la forma de gobierno democrática. La democracia, la comunidad y la ciudadanía han sido percibidas como instituciones débiles, en muchos otros países industrializados en los últimos años.

En la literatura de investigación, esto es visto como un producto de muchos factores: el tamaño y la complejidad del gobierno y la sociedad; la globalización y una percepción de pérdida de la autonomía de la política nacional; falta de confianza en los principales partidos políticos; y los efectos de una década o más de los recortes del gobierno en infraestructura social y 
comunitaria. Este problema se puede medir de varias maneras: en la apatía de los votantes y la alienación pública a los procesos políticos, la creciente desigualdad social, la disminución de la confianza social y la participación ciudadana, más corporaciones y modelos empresariales con orientación comercial de los gobiernos que han generado cambios en el lenguaje y la cultura de la democracia. Tal vez el ejemplo más claro de este último es la transformación gradual de los ciudadanos en "clientes" (Saul, 1997).

No existe una solución única a los problemas de este tipo, pero hay un cierto acuerdo sobre los remedios más obvios, tales como ${ }^{9}$ :

- Nuevos procesos participativos locales.

- Énfasis en la inclusión social.

- Un enfoque holístico de la "salud comunitaria", no sólo uno basado en la igualdad formal del tratamiento o mejora de "servicio al cliente".

- $\quad$ El desarrollo de las tareas más significativas y de cooperación de gobierno que construyen confianza social y comunidades más fuertes.

- La necesidad de crear procesos y foros más abiertos y democráticos, para la resolución de los intereses en conflicto, la creación de una mayor rendición de cuentas y la ampliación de oportunidades para la participación ciudadana en la gestión pública.

El tercer y más potente ingrediente ha sido el desafío global de aceptar las maneras por las que el gobierno y las sociedades han de definir y medir el "progreso" y el "bienestar".

Los debates sobre el progreso y su significado y la forma de medirlo no son nuevos. Hace más de 2000 años, Aristóteles consideraba que la definición de la "buena sociedad" es la tarea central de la filosofía.

Pero es más que un debate teórico. Los economistas políticos desde Hobbes hasta Marx han observado que "el instrumento más poderoso de la autoridad política es el poder de dar nombres y forzar las definiciones" (Chorover, 1979); y en la sociedad occidental desde la Revolución Industrial, no ha habido ninguna idea más potente para ser definida ( $\mathrm{y}$ por lo tanto aprovechada) que la idea de progreso. Esta idea, con sus connotaciones de destino y fatalidad, se ha convertido en casi "la narrativa meta de la historia" (MacLintock, 1992) - la legitimación del poder político, elevando a los que definen e interpretan, y proporcionando un tema unificador para las políticas de las Naciones.

Desde finales de 1950, el debate sobre el significado del progreso se ha realizado más en formas técnicas (tales como estadísticas), pero no menos apasionada, y a través de diferentes fases y los foros: internacional, a través de las Naciones Unidas, el Programa de Desarrollo de las Naciones Unidas de la OCDE (el "Proyecto de Indicadores Sociales"), y más recientemente, los

\footnotetext{
9 Mike Salvaris: Community and social indicators: How citizens can measure progress, Noviembre 2000
} 
movimientos en por lo menos seis naciones desarrolladas para desarrollar indicadores nacionales generales de bienestar, como el GPI, o "Indicador de Progreso Genuino". (Eckersley, 1998).

El principal promotor de este debate ha sido una preocupación creciente acerca de la influencia de los indicadores económicos de producción, en particular el Producto Bruto Interno (PBI), según las mediciones aproximadas del progreso humano. (EI PBI es esencialmente el valor total de todos los bienes y servicios intercambiados de dinero en la economía nacional).

En la era posterior a la guerra, los indicadores estadísticos han sido cada vez más influyente en las políticas públicas: los mismos generan los debates marco, dirigen la planificación, afectan los presupuestos y motivan a la acción. En un mundo cada vez más complejo, la búsqueda de indicadores debe ser un proceso continuo. Los indicadores estadísticos pueden llegar a ser una especie de medida representativa de los valores de la sociedad y metas, los "códigos de ADN estructurales que se convierten en las unidades fundamentales para analizar las opciones de las economías y tecnológicas" (Henderson, 1996).

Indicadores como el PBI se han convertido en un instrumento clave de la autoridad política moderna por su poder para proporcionar una definición autorizada de "progreso" para comunidades enteras. Por lo tanto, ellos plantean cuestiones democráticas (¿Qué se debe medir? ¿Quién debe decidir?) tanto como cuestiones técnicas (¿Cuál es la medición específica? ¿Cuán exacta es?).

Los opositores al PBI lo han criticado porque es engañoso (es decir, es una mala medida de la real condición de la economía y de la sociedad) y excesivamente potente (influye en la conformación de la comprensión cotidiana de progreso y bienestar).

Estas preocupaciones vinieron originalmente de muchos lugares distintos: ambientalistas, los movimientos de mujeres, los países en desarrollo, los activistas de derechos humanos e incluso economistas. Con el tiempo, comenzaron a converger en un movimiento de gran alcance y de amplia base.

El argumento central que la mayoría de estos grupos acuerdan es simple: "medir el valor de mercado de la producción económica dice muy poco acerca de la salud general de la comunidad o el medio ambiente, y nada acerca de los costos sociales de lo que se ha producido en la economía, o sobre su utilidad o la sostenibilidad". Como explica John Ralston Saul, "los productores de acero no tienen ningún incentivo para reducir la contaminación, en la medida en que no pagan las facturas de lavandería o de salud que generan". Como resultado, el mecanismo de mercado no sirve con precisión a uno de los fines que se pretende cumplir - a saber, la presentación de la sociedad con una evaluación precisa de los costos relativos de la producción de las cosas". (Saúl, 1997). 
La crítica elocuente de Robert Kennedy hacia 1960 se convirtió en la plataforma de lanzamiento para uno de los proyectos de indicadores comunitarios más conocidos de EE.UU, "Seattle Sostenible". Kennedy destacó la debilidad fundamental del PBI como medida del "progreso". No puede distinguir entre "crecimiento" (un aumento de la cantidad) y el "desarrollo" (una mejora en calidad) (Atkisson, 2000).

"El Producto Bruto Nacional incluye la contaminación del aire y la publicidad de los cigarrillos, y las ambulancias para despejar nuestras carreteras. Cuenta cerraduras especiales para nuestras puertas y las cárceles para las personas que las rompen. El Producto Bruto Nacional incluye la destrucción de los bosques de secuoyas y la muerte del Lago Superior. Crece con la producción de napalm y misiles para guerras nucleares.... Y si el Producto Bruto Nacional incluye todo esto, hay mucho que no comprende. No incluye la salud de nuestras familias, la calidad de su educación, o la alegría de su juego. Es indiferente a la decencia de nuestras fábricas y la seguridad de las calles por igual. No incluye la belleza de nuestra poesía o la fortaleza de nuestros matrimonios, la inteligencia de nuestro debate público o la integridad de nuestros funcionarios públicos.... El Producto Bruto tampoco mide nuestro ingenio ni nuestro coraje, ni nuestra sabiduría ni nuestro aprendizaje, ni nuestra compasión ni nuestra devoción a otro. Se mide todo, en definitiva, excepto lo que hace que la vida valga la pena; y nos puede decir todo sobre América excepto si estamos orgullosos de ser estadounidenses". (Atkisson, 1995).

Hacia el 2000 se acordó que los indicadores como el PBI necesitan tener un marco de medición más amplio y equilibrado, que refleje con mayor precisión las aspiraciones democráticas de la gente y las cosas que valoran, así como también la compleja y multifacética naturaleza del bienestar social, económico y ambiental. Para ello se planteó la necesidad de nuevas medidas y nuevos procesos.

Así es que se decidió incluir algunas medidas importantes de bienestar social y comunitario que se pasan por alto en las cuentas nacionales: por ejemplo, el capital social, ambiental, la sostenibilidad, la salud de la comunidad, la participación y la ciudadanía, la equidad social y la justicia, e incluso la salud de la democracia misma. Por ejemplo, en Reino Unido y países escandinavos, los indicadores de la democracia y la participación, incluyendo la honestidad, la apertura en el gobierno y la burocracia, se han desarrollado como parte de la más amplia "auditoría social". Sólo por poner todos estos indicadores en conjunto, estas diferentes dimensiones de un todo complejo, permiten construir una medida más precisa de una buena sociedad.

\section{Indicadores Comunitarios}

"Muchas comunidades, inspiradas por el objetivo de lograr la salud y la sostenibilidad a largo plazo, dan buenos pasos hacia la búsqueda de mejores 
medidas de progreso... Al convocar a los ciudadanos a considerar cómo medir su bienestar general, la comunidad en su conjunto es estimulada para crear nuevas visiones del futuro, desarrollar nuevas relaciones de trabajo a través de límites de edad, y definir sus activos, los problemas y las oportunidades de nuevas maneras" (Redefiniendo el Progreso 1997).

Tanto las comunidades pequeñas como las grandes naciones necesitan buenas medidas de progreso. El valor de los derechos económicos de producción puede ser una de esas medidas para la mayoría de las comunidades; pero una mejor vista de la salud general de la comunidad se puede tener al mirar más ampliamente: en las escuelas y parques; el estado de los ríos y lagos locales; la calidad de los barrios; el tipo de puestos de trabajo que la economía local genera; el nivel de participación de los ciudadanos locales en las actividades de voluntariado; el grado de confianza que tienen en sus vecinos y el gobierno local; el porcentaje de los jóvenes que tienen trabajo, o que están gravemente deprimidos o han dejado las ciudades; e incluso el estado de la calle principal.

Lo antes expuesto da lugar a los llamados "Indicadores Comunitarios", los cuales son un intento de poner las ideas sobre el progreso y la participación en la acción a nivel local o regional. Son esencialmente herramientas para el desarrollo de la comunidad.

La tarea de desarrollar indicadores de la comunidad, si se hace correctamente, proporciona una oportunidad para ampliar la participación significativa en la gestión pública; los ciudadanos se reúnen para decidir qué medidas simbolizan el aumento del bienestar social de sus comunidades.

Los indicadores requieren que "las personas con diferentes orígenes trabajen juntos hacia una meta común, que todos pueden estar de acuerdo, a pesar de las diferencias políticas o culturales. De hecho, el dibujo de forma creativa en su diversidad - en profesiones, orígenes y experiencias de la vida es lo que hace el esfuerzo exitoso" (Redefiniendo Progreso, 1997:8).

El proceso podría comenzar con las personas que se unen para expresar sus ideas acerca de qué tipo de sociedad o de comunidad les gustaría vivir en el futuro. Esta visión amplia es luego trabajada pese a una serie de objetivos concretos en las esferas clave, que luego deben ser ordenados por orden de importancia. El siguiente paso es definir las normas que se deben cumplir para el logro de los objetivos (los «puntos de referencia») y las medidas o estadísticas (los "indicadores") específicas que demuestran el progreso en el logro de ellos. El vínculo entre los puntos de referencia e indicadores es crucial: al igual que un viajero necesita tanto un mapa y una brújula, así también las comunidades necesitan saber hacia dónde van (los puntos de referencia 0 "mapa") y dónde están ahora (los indicadores o "brújula").

Los indicadores y puntos de referencia de la comunidad son específicos del contexto. En el proceso de desarrollo de ellos, los ciudadanos tendrán que 
seleccionar, de muchas opciones posibles, las que mejor capten las aspiraciones de su comunidad.

El valor de la clave del desarrollo de indicadores de la comunidad es que los ciudadanos trabajen juntos para determinar las metas para su futuro y participar en la medición del progreso hacia esas metas, que estén mejor informados acerca de los recursos necesarios y las limitaciones confrontadas.

En estas tareas los ciudadanos a menudo trabajan con el gobierno local y tal vez con los expertos de algún tipo, pero fundamentalmente, será una colaboración, no una dependencia, la relación. Generalmente no hay garantía que los indicadores comunitarios desarrollados de esta manera sean adoptados en procesos formales de gobernanza política y, sino por su legitimidad crearán una poderosa presión para los sistemas institucionales que compran en el servicio las prioridades de la comunidad.

"Los indicadores de una sociedad reflejan valores colectivos $y$ fundamentan las decisiones colectivas. Una nación que mantiene un ojo vigilante sobre el funcionamiento de la educación o la seguridad de sus calles hace diferentes opciones en comparación a una nación que sólo presta atención a su Producto Bruto Nacional (PBN). La idea de los ciudadanos de elegir sus propios indicadores es algo nuevo bajo el sol - algo intensamente democrático". (Seattle Sostenible - 1998. Indicadores de la Comunidad Sostenible. Seattle, EE.UU.)

Los puntos de referencia e indicadores comunitarios no deben ser vistos ya sea como una nueva herramienta de gestión ni como un fin en sí mismos: son lo ideal y un medio para mejorar los resultados de la democracia, de la comunidad y la gobernabilidad.

El éxito de los proyectos de indicadores de la comunidad apunta a crear cambios duraderos en los valores y capacidades, en la comunidad y las agencias gubernamentales. Los resultados deben ser, no sólo los puntos de referencia e indicadores en sí mismos, sino que deben generar el aumento de la actividad de la comunidad (proyectos y estrategias locales, comités y reuniones, etc.); mejora de los niveles en los procesos de gobierno (¿por qué no ser estándares de "las mejores prácticas globales" que consulte la comunidad y que el gobierno considere en su planificación interdisciplinaria?); aumento de la conciencia y la comprensión (del gobierno y de las prioridades de la comunidad); y con el tiempo, una capacidad ampliada para la participación y por tanto más comunidades empoderadas. Estas metas más grandes son más complejas y utilizan muchos recursos en la técnica de identificar los puntos de referencia e indicadores específicos, pero en el largo plazo son más importantes. Sin atención a los procesos, y para los problemas de fondo que los puntos de referencia e indicadores señalan, existe el riesgo de que los puntos de referencia e indicadores terminen convirtiéndose en una nueva forma de tiranía de dirección o de un mero truco político. 
Puede decirse que, al final del día, "medir el progreso no es lo mismo que hacer que se haga". (Besleme et al 1998:245). 


\section{Metodología.}

\subsection{Población y muestra.}

La población analizada fueron las ciudades de La Plata, Berisso y Ensenada. Con el dato del tamaño de la población seleccionada, obtenido del Censo 2010, realizado por el Instituto Nacional de Estadísticas y Censos, se determinó el tamaño de la muestra en trescientos (300) habitantes, a través de la fórmula de muestreo de proporciones con «N» conocido:

$$
n=\frac{Z_{\alpha}^{2} \cdot N \cdot p \cdot q}{e^{2} \cdot(N-1)+Z_{\alpha}^{2} \cdot p \cdot q}
$$

Dónde:

$\mathrm{N}=654.324$ habitantes (población total de las ciudades de La Plata, Berisso y Ensenada)

$\mathrm{p}$ = prevalencia esperada del parámetro a evaluar, que en caso de desconocerse, se aplica la opción más desfavorable $(p=0,5)$, que hace mayor el tamaño muestral

$\mathrm{q}=$ complemento de la prevalencia esperada del parámetro a evaluar, es decir $1-p=0,5$

$Z_{\alpha}=1,96$ para $\alpha=5 \%$, o sea un nivel de confianza del $95 \%$

e $\quad=5,66 \%$ error de muestreo

El casco urbano de la ciudad de La Plata fue dividido en cuatro zonas con similar cantidad de habitantes, utilizando datos provenientes de los radios censales de la ciudad, utilizados para la realización de los censos nacionales, que proveen información poblacional y geográfica. Sumando las localidades de Berisso y Ensenada, como zonas adicionales, la muestra total de trescientas (300) encuestas se dividió por afijación simple, lo que dio por resultado cincuenta (50) encuestas en cada subzona (en la imagen se ve con un color distinto cada una). 


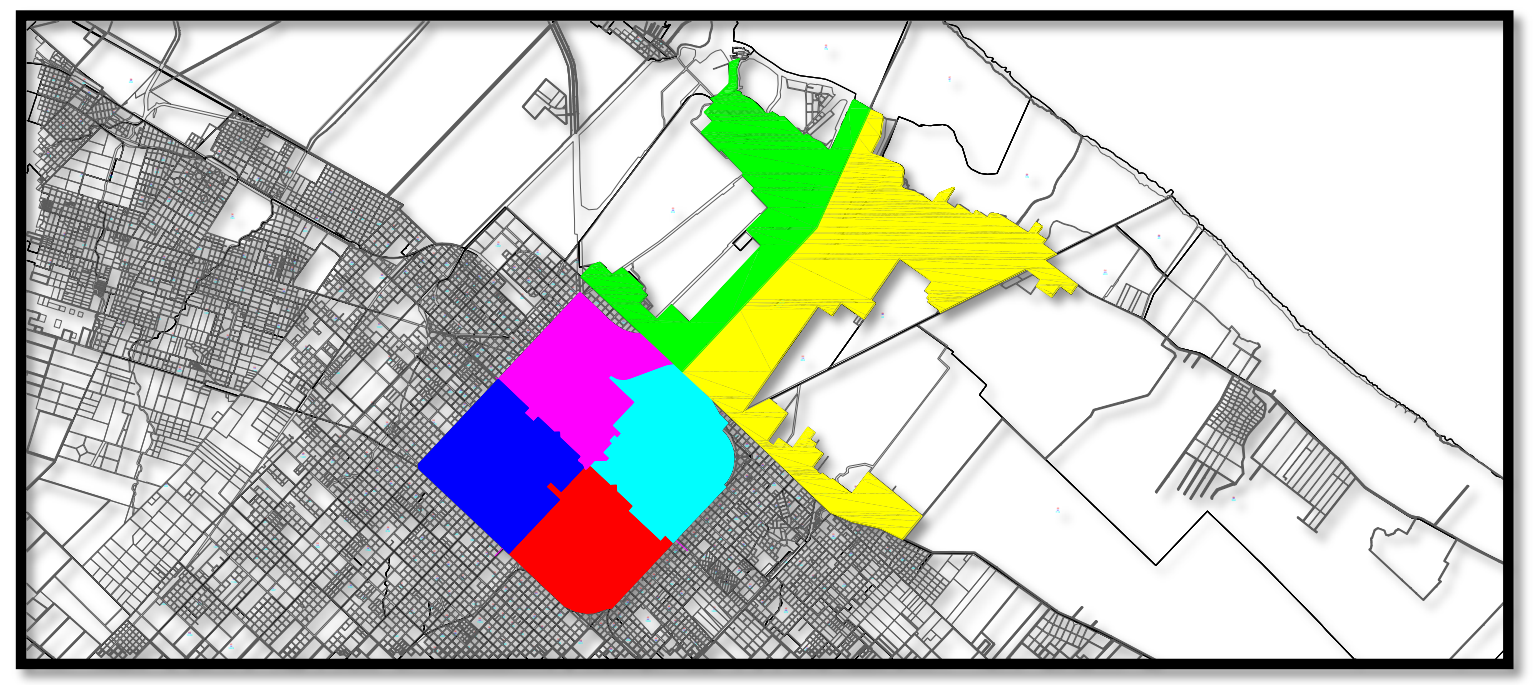

- Color magenta: zona norte de la ciudad de La Plata, comprendida entre las calles $120,51,13$ y 32, con 54.034 habitantes.

- Color celeste: zona este de la ciudad de La Plata, comprendida entre las calles $120,72,13$ y 51 , con 56.080 habitantes.

- Color rojo: zona sur de la ciudad de La Plata, comprendida entre las calles 13, 72, 31 y 51 , con 50.372 habitantes.

- Color azul: zona oeste de la ciudad de La Plata, comprendida entre las calles 13, 51, 31 y 32, con 52.731 habitantes.

- Color amarillo: ciudad de Berisso, donde se circunscribieron las encuestas al centro y alrededores, con 88.123 habitantes.

- Color verde: ciudad de Ensenada, con 55.629 habitantes.

En función de la distribución poblacional que tienen estas ciudades, se determinó qué cantidad de personas por edad y sexo debían ser encuestadas en cada subzona para que la muestra sea representativa.

La Tabla 4 fue desarrollada por el Instituto de Estadísticas y Censos para el partido de La Plata con los datos del censo 2010. Si bien la información reflejada pertenece al partido de La Plata en su conjunto, en el presente estudio el foco de análisis ha sido puesto en la distribución por edades y sexo dentro de la población activa (desde los 20 a los 64 años).

Tabla 4: Provincia de Buenos Aires, partido La Plata. Población total por sexo e índice de masculinidad, según edad en años simples y grupos quinquenales de edad. Año 2010. 
Tabla 4: Población total en La Plata

\begin{tabular}{|c|c|c|c|c|c|}
\hline \multirow{2}{*}{ Edad } & \multirow{2}{*}{ Población total } & \multicolumn{2}{|c|}{ Sexo } & \multirow{2}{*}{$\begin{array}{c}\text { Índice de } \\
\text { masculinidad }\end{array}$} & \\
\hline & & Varones & Mujeres & & \\
\hline Total & 654,324 & 315,263 & 339,061 & 93.0 & \\
\hline $20-24$ & 61,433 & 30,630 & 30,803 & 99.4 & $16.01 \%$ \\
\hline $25-29$ & 55,898 & 27,904 & 27,994 & 99.7 & $14.56 \%$ \\
\hline $30-34$ & 53,465 & 26,311 & 27,154 & 96.9 & $13.93 \%$ \\
\hline $35-39$ & 46,612 & 22,887 & 23,725 & 96.5 & 12. $14 \%$ \\
\hline $40-44$ & 39,148 & 19,284 & 19,864 & 97.1 & $10.20 \%$ \\
\hline $45-49$ & 35,908 & 17,565 & 18,343 & 95.8 & $9.36 \%$ \\
\hline $50-54$ & 33,455 & 15,796 & 17,659 & 89.5 & $8.72 \%$ \\
\hline $55-59$ & 30,535 & 14,122 & 16,413 & 86.0 & $7.96 \%$ \\
\hline $60-64$ & 27,344 & 12,476 & 14,868 & 83.9 & $7.12 \%$ \\
\hline TOTAL TOTAL & 383,798 & 186,975 & 196,823 & & \\
\hline
\end{tabular}

Nota: la población total incluye a las personas viviendo en situación de calle. $58.7 \%$

$\boxminus$ índice de masculinidad indica la cantidad de varones por cada 100 mujeres.

Fuente: INDEC. Censo Nacional de Población, Hogares y Viviendas 2010.

EI INDEC divide a las edades en intervalos de 5 años y establece qué cantidad de personas existen en el partido en ese intervalo. En la última columna de la derecha se puede ver los porcentajes de participación en el total de la población de cada intervalo de edades.

\subsection{Tipo de investigación.}

El presente trabajo de investigación es de carácter exploratorio.

\subsection{Técnicas de Recolección de Datos}

El instrumento principal de recolección de datos ha sido una adaptación del proyecto hecho en Australia ${ }^{10}$, que se encuentra dividido en tres secciones, cada una basada en la anterior: dos cuestionarios (el primero sobre ciudadanía, comunidad y valores sociales, y el segundo sobre valores y prioridades nacionales, el buen gobierno y la Constitución), y una actividad de focus group para realizar un relevamiento cualitativo con la participación de voluntarios que fueron encuestados previamente.

En esta investigación, se replicó la primera sección (ciudadanía, comunidad y valores sociales), reduciendo la misma de 38 a 35 aspectos evaluados, quedando eliminados:

\footnotetext{
${ }^{10}$ Proyecto Nacional de la Ciudadanía - Región de Victoria. Julio 1999
} 
- Cuidado especial en proteger las comunidades rurales y lejanas.

- Respeto por la cultura de los indígenas.

- Aceptar refugiados, incluso con algún costo para nosotros.

En cada ítem se asignó una valoración de cuán importante era lo expresado para una sociedad desarrollada (variable Importancia), y luego otra valoración calificando en qué medida sucedía lo expresado en la sociedad (variable Desempeño). Las preguntas fueron del tipo "cerrado", solicitando a cada encuestado que calificara de 1 (nada importante) a 10 (muy importante).

Las encuestas fueron personales y anónimas, pero para analizar la existencia o no de relación entre las respuestas obtenidas y el perfil demográfico de los encuestados, se solicitaron datos referidos al perfil: edad, sexo, nivel de educación y situación laboral.

La selección de participantes ha sido puerta a puerta en las subzonas previamente definidas. En cada situación de contacto, se explicó al potencial encuestado sobre el origen y temática del cuestionario, informando que sus respuestas serían para un estudio realizado por la Maestría en Dirección de Empresas de la Universidad de La Plata. Con el consentimiento de la persona, se leyó el cuestionario al mismo tiempo que se fueron registrando las valoraciones otorgadas por el encuestado en cada planilla. El tiempo promedio de contacto fue de aproximadamente veinticinco (25) minutos por encuesta.

Las variables objeto de la encuesta por ser consideradas relevantes para definir las características culturales de la sociedad son las siguientes:

1. Eficiente.

2. Ética.

3. Económicamente fuerte y pujante.

4. Segura.

5. Medioambientalmente responsable.

6. Satisfecha.

7. Creativa.

8. Internacionalmente (regionalmente) responsable.

9. Comunitariamente inclusiva.

10. Políticamente potente.

11. Diversa y tolerante.

12. Propensa a la tecnología.

13. Justa.

14. Competitiva.

15. Democrática.

16. De alto nivel de vida. 


\subsection{Técnicas de Análisis.}

El procesamiento de los datos se llevó a cabo a partir de la clasificación, registro y codificación de los mismos. Todas las encuestas obtenidas se cargaron en una matriz donde en las columnas se situaron las valoraciones y datos demográficos, y las filas se correspondían con cada individuo encuestado. Las respuestas a los datos demográficos fueron codificadas numéricamente para facilitar su carga en la base de datos.

Se crearon dos variables adicionales a la de Importancia y Desempeño obtenidas con las respuestas de las encuestas, combinándolas de la siguiente manera:

1. Discrepancia $=$ Desempeño - Importancia

2. Gravedad Percibida $=-1$ * Discrepancia * Importancia

De todas las variables numéricas se obtuvieron los promedios para poder jerarquizarlas, y así determinar los valores más importantes para la sociedad y compararlos con los resultados obtenidos en Australia.

En la tabla 5 se muestra en la columna (a) la valoración promedio que los encuestados dieron a la Importancia de los 35 atributos que hacen a una sociedad exitosa, y en la columna (b) la jerarquización de las mismas.

Tabla 5: Tabla modelo Importancia

\begin{tabular}{|l|l|l|l|}
\hline \multirow{2}{*}{ Item $\mathrm{N}^{\circ}$} & Características & \multicolumn{2}{|c|}{ Importancia } \\
\cline { 3 - 4 } & & Calificación 1-10 (a) & Jerarquía 1 - 35 (b) \\
\hline & & & \\
\hline
\end{tabular}

Fuente: Community and social indicators: How citizens can measure progress. (Noviembre 2000)

En la tabla 6, la columna (c), muestra la valoración promedio que los encuestados dieron al Desempeño de los 35 atributos que hacen a una sociedad exitosa.

Tabla 6: Tabla modelo de Desempeño

\begin{tabular}{|l|c|c|}
\hline \multirow{2}{*}{ Item $\mathrm{N}^{\circ}$} & Características & Desempeño \\
\cline { 3 - 3 } & & Calificación 1-10 (c) \\
\hline
\end{tabular}

Fuente: Community and social indicators: How citizens can measure progress. (Noviembre 2000)

En la tabla 7, la columna (d), muestra la Discrepancia entre la Importancia y el Desempeño. 
Tabla 7: Tabla modelo Discrepancia

\begin{tabular}{|c|c|c|}
\hline \multirow{2}{*}{ Item $\mathbf{N}^{\circ}$} & Características & Discrepancia \\
\cline { 3 - 3 } & & $(\mathrm{d}=\mathrm{c}-\mathrm{a})$ \\
\hline & & \\
\hline
\end{tabular}

Fuente: Community and social indicators: How citizens can measure progress. (Noviembre 2000)

En la tabla 8 se muestra en la columna (e) la ponderación de la Discrepancia de cada atributo con la Importancia asignada al mismo, dando una idea de la Gravedad Percibida en cada uno, y en la columna (f) la jerarquización de las mismas.

Tabla 8: Tabla modelo Gravedad Percibida

\begin{tabular}{|l|l|l|l|}
\hline \multirow{2}{*}{ Item $\mathbf{N}^{\circ}$} & Características & \multicolumn{2}{|c|}{ Gravedad Percibida } \\
\cline { 3 - 4 } & & $\begin{array}{c}\text { Ponderación } \\
\left(\mathrm{e}=-\mathrm{d}^{*} \mathrm{a}\right)\end{array}$ & Jerarquía 1-35 (f) \\
\hline & & & \\
\hline
\end{tabular}

Fuente: Community and social indicators: How citizens can measure progress. (Noviembre 2000)

Adicionalmente, se analizó la existencia de relación entre las respuestas y los distintos grupos demográficos encuestados. Para esto se realizó la prueba etha-cuadrado que mide la correlación entre una variable categórica y una real:

$$
\eta=\sqrt{\frac{V_{\text {entre }}}{V}}
$$

Dónde:

$\mu \quad=\frac{1}{N} \sum N_{k} \mu_{k} \quad$ La media de la variable sobre el conjunto de la variable cualitativa es la media de las medias de los grupos $\left(\mu_{k}\right)$, ponderados por las frecuencias absolutas de los grupos $\left(N_{k}\right)$.

$V_{\text {entre }}=\frac{1}{N} \sum N_{k} \mu_{k}^{2}-\mu^{2}$

La varianza entre los grupos (o entre las clases) es la varianza de las medias.

$V_{\text {dentro }}=\frac{1}{N} \sum N_{k} V_{k} \quad$ La varianza dentro de los grupos (o dentro de las 
clases) es la media de las varianzas.

$V=V_{\text {entre }}+V_{\text {dentro }} \quad$ La varianza total es la sumatoria de la varianza entre con la varianza dentro.

Los valores de este índice están comprendidos entre 0 y 1 .Este índice vale cero cuando la varianza entre es nula, lo cual evidencia la ausencia de vínculo entre ambas variables. Por el contrario, vale uno cuando la varianza entre es igual a la varianza total, demostrando un fuerte vínculo entre ambas variables. 


\section{Resultados de la Investigación}

\subsection{Perfil de los encuestados en Berisso}

\subsubsection{Sexo}

El procesamiento de resultados arrojó un Índice de Sexo de 50\%. Este índice demográfico expresa la razón de hombres frente a mujeres en un determinado territorio (expresada en tanto por ciento).

La participación porcentual de cada género es expresada en la siguiente gráfica:

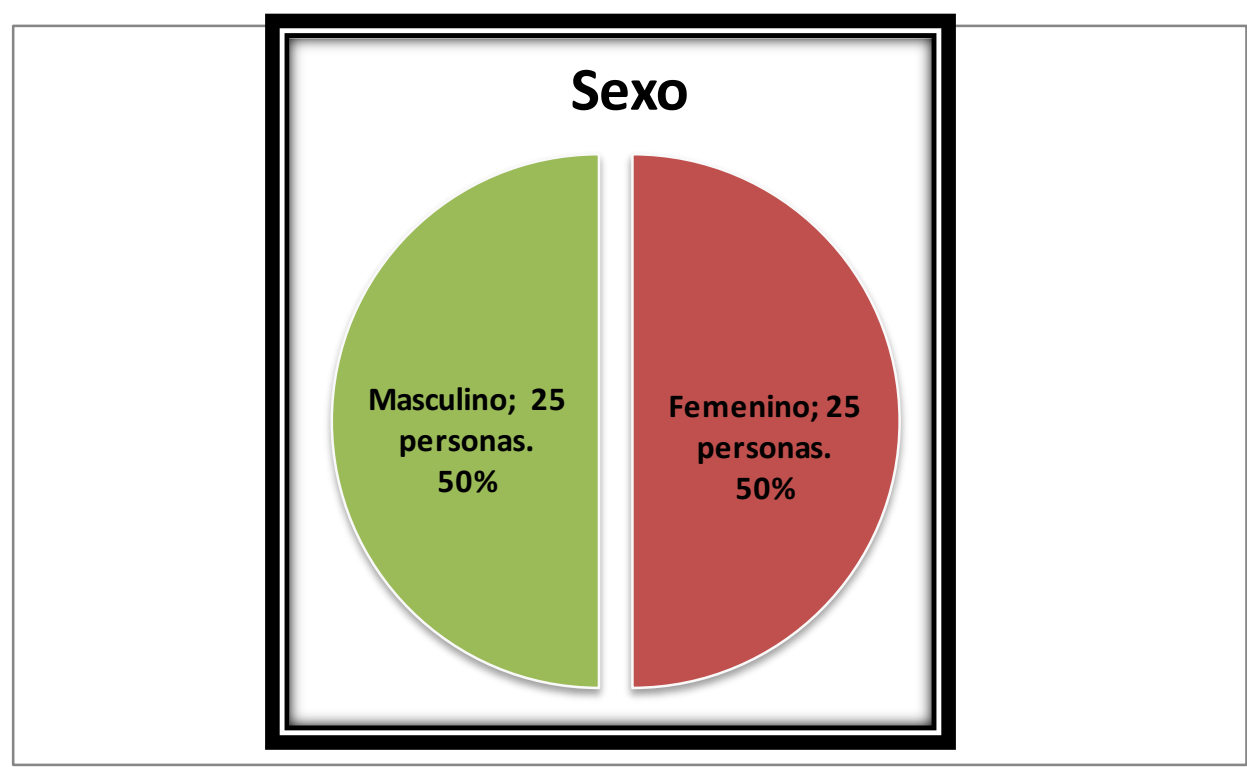

\subsubsection{Edad}

La edad promedio de la población encuestada en Berisso es de 36,4 años. La siguiente gráfica expone la distribución de edades de los encuestados obtenida para el estudio realizado, y la compara con los datos poblacionales del censo 2010. Puede apreciarse que los resultados de la encuesta se condicen con los de la población. 


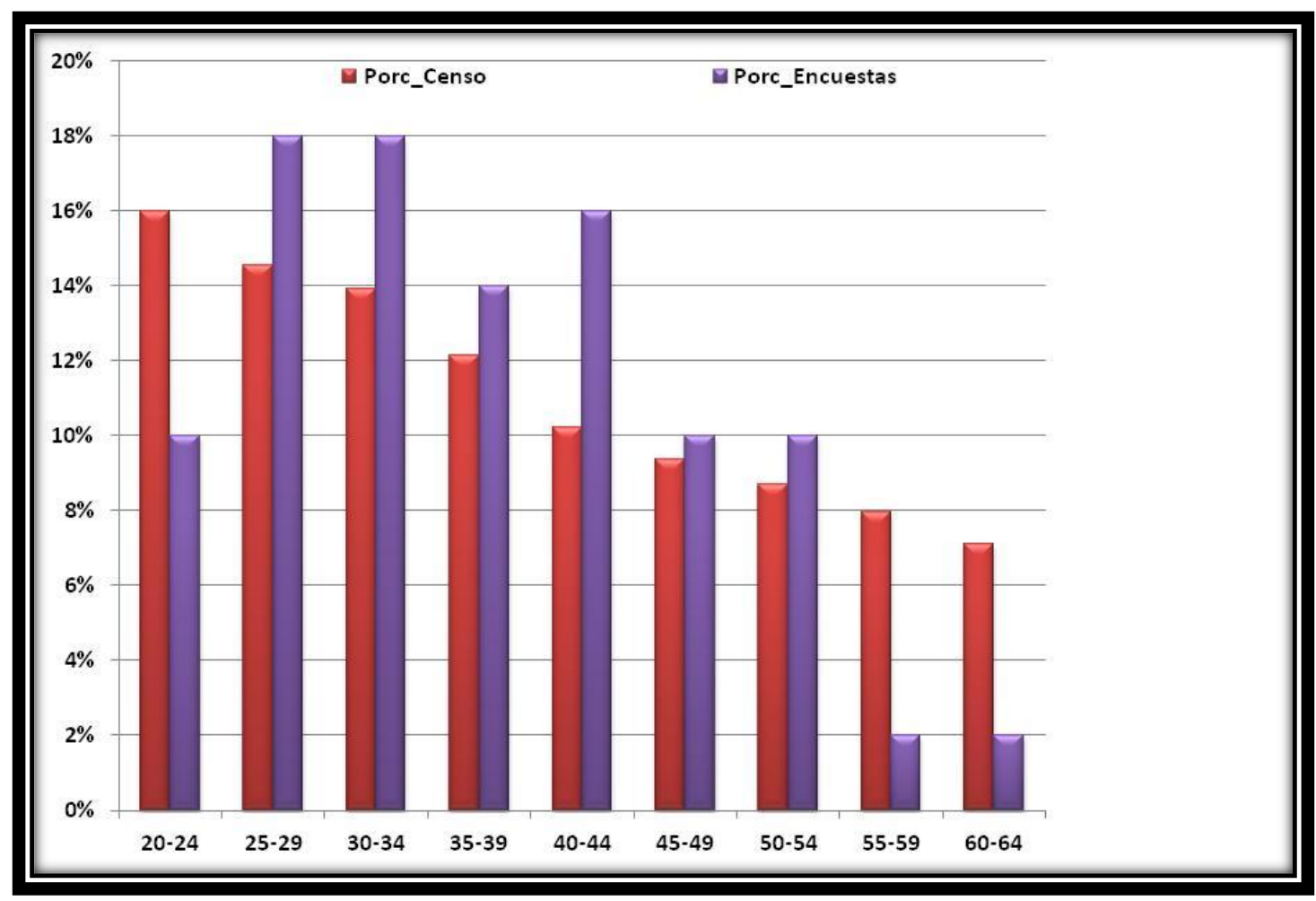

\subsubsection{Educación}

La siguiente gráfica muestra la participación porcentual según la educación de los encuestados.

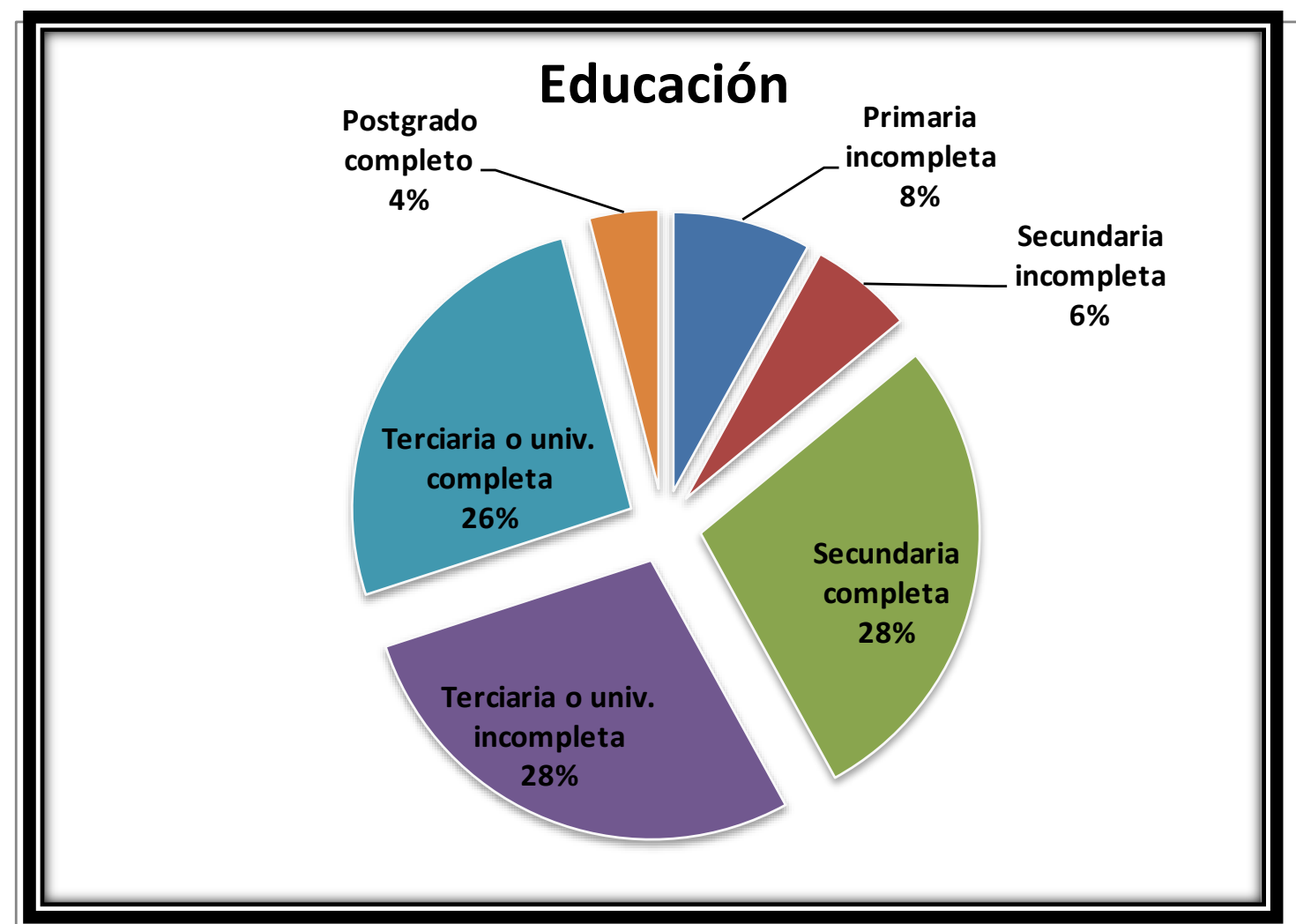

Página 45 
Los grupos más representantes tienen algún nivel de estudio finalizado, siendo los más representativos, con un $28 \%$ cada uno, quienes tienen un estudio terciario o universitario incompleto y quienes tienen la secundaria incompleta.

\subsubsection{Situación laboral}

A continuación se exponen las participaciones en cuanto a la situación laboral de los encuestados.

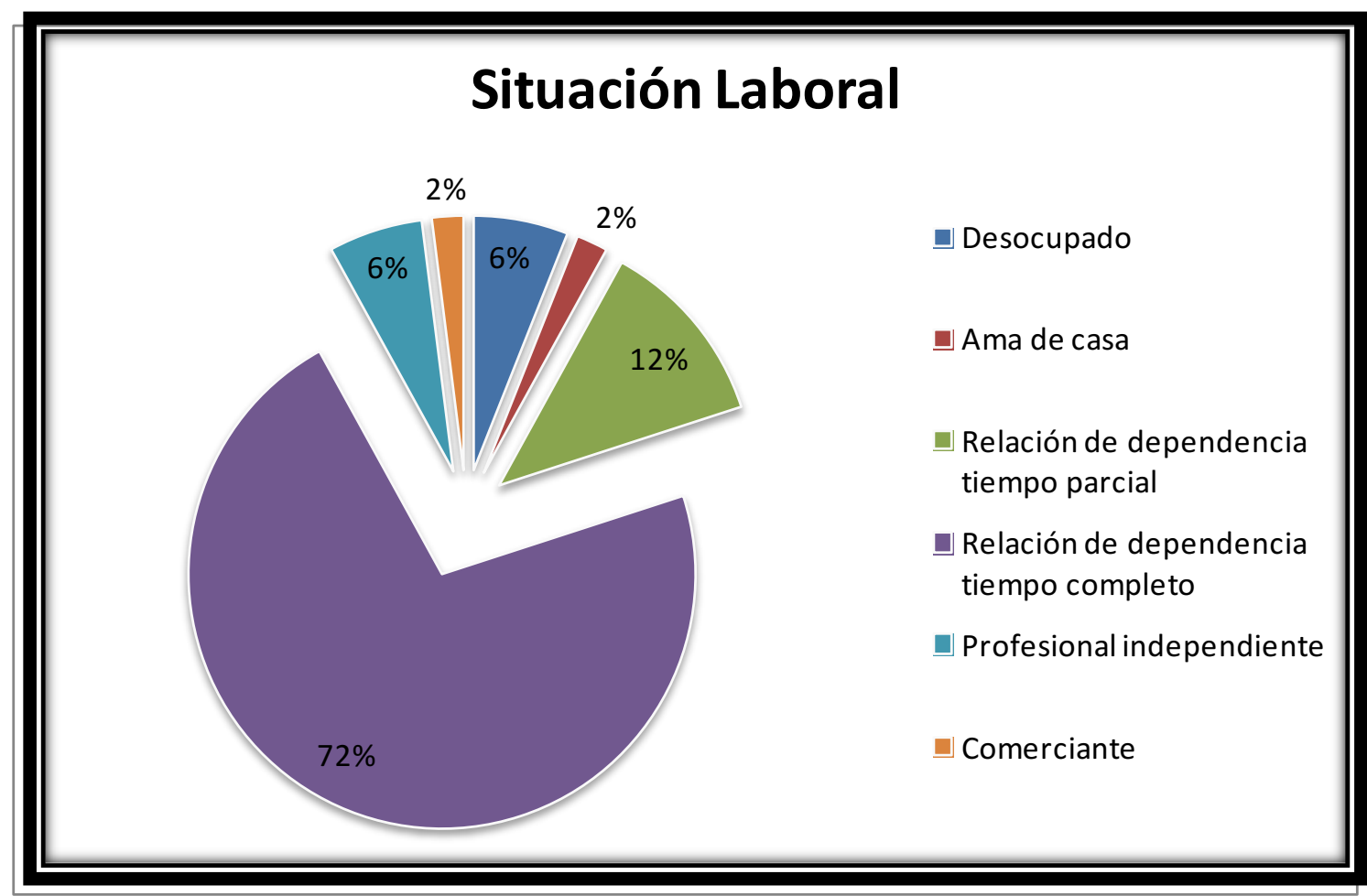

Poco más de 7 de cada 10 encuestados son trabajadores en relación de dependencia de tiempo completo, siendo el grupo más representativo.

7.2. Situación comparativa: Berisso con la Región de La Plata, Berisso y Ensenada

\subsubsection{Importancia asignada a las características relevadas}

La tabla a continuación expone los resultados obtenidos en las encuestas realizadas en Berisso en comparación al resultado arrojado por el total de la Región de La Plata, Berisso y Ensenada. 
Tabla 9: Berisso vs. Región La Plata, Berisso y Ensenada. Importancia.

\begin{tabular}{|c|c|c|c|c|c|}
\hline \multirow{3}{*}{ Item } & \multirow{3}{*}{ Características } & \multicolumn{4}{|c|}{ Importancia: Jerarquía según calificación otorgada } \\
\hline & & \multicolumn{2}{|c|}{ Berisso } & \multicolumn{2}{|c|}{ La Plata, Berisso y Ensenada } \\
\hline & & Importancia & Calificación otorgada & Importancia & Calificación otorgada \\
\hline 2 & Todos son tratados igualitaria y equitativamente por la ley & 1 & 9,80 & 1 & 9,71 \\
\hline 4 & Buena calidad de los servicios básicos (salud, educación, etc.) para todos & 2 & 9,78 & 2 & 9,66 \\
\hline 3 & Los derechos humanos básicos de todos los ciudadanos están fuertemente protegidos & 4 & 9,54 & 3 & 9,61 \\
\hline 5 & Eliminación del crimen y la violencia & 9 & 9,42 & 4 & 9,52 \\
\hline 1 & Altos niveles de honestidad en la política y la vida pública & 3 & 9,64 & 5 & 9,47 \\
\hline 26 & Vigorosa libertad de opinión, múltiples opiniones públicas (disensos) & 5 & 9,52 & 6 & 9,43 \\
\hline 9 & Confianza justificada en que las instituciones públicas actúan con limpieza y justicia & 6 & 9,48 & 7 & 9,42 \\
\hline 7 & Igualdad de oportunidades para hombres y mujeres & 8 & 9,44 & 8 & 9,33 \\
\hline 18 & Respeto por, y estricta aplicación de las leyes & 11 & 9,34 & 9 & 9,28 \\
\hline 15 & Se alienta la vida familiar y los valores de la familia & 7 & 9,46 & 10 & 9,24 \\
\hline 20 & Fuerte protección social (edad, enfermedad, desempleo, etc.) & 12 & 9,32 & 11 & 9,20 \\
\hline 30 & Libertad para hacer lo que nos gusta siempre que no perjudiquemos a otros & 13 & 9,30 & 12 & 9,19 \\
\hline 11 & Buena atención a las personas vulnerables, disminuidos y de clase baja & 15 & 9,18 & 13 & 9,16 \\
\hline 17 & Eliminación de la pobreza & 14 & 9,20 & 14 & 9,14 \\
\hline 31 & Generosidad en ayudar a regiones perjudicadas & 10 & 9,40 & 15 & 9,13 \\
\hline 10 & Las comunidades locales tienen buena calidad de servicios públicos (transporte, luz, etc.) & 16 & 9,16 & 16 & 9,12 \\
\hline 19 & Trabajos seguros, satisfactorios y equitativamente pagados para todos los que quieren trabajar & 19 & 9,04 & 17 & 9,07 \\
\hline 6 & Protección del medioambiente, recursos y fauna & 20 & 9,02 & 18 & 9,01 \\
\hline 8 & Todos pagan impuestos equitativamente, acorde con el ingreso y riqueza & 17 & 9,10 & 19 & 8,99 \\
\hline 12 & Reducción de la contaminación medioambiental, desarrollo de fuentes de energía renovables & 21 & 8,98 & 20 & 8,93 \\
\hline 25 & Altos niveles de progreso científico y tecnológico & 18 & 9,08 & 21 & 8,84 \\
\hline 27 & Las personas participan en la toma de decisiones de hechos que los afectan & 24 & 8,62 & 22 & 8,76 \\
\hline 16 & Las personas jóvenes son valoradas, y tienen perspectivas de futuro seguras & 22 & 8,70 & 23 & 8,67 \\
\hline 23 & Protección de la libertad religiosa & 29 & 8,44 & 24 & 8,60 \\
\hline 24 & Relaciones justas, limpias e independientes con otras naciones & 27 & 8,52 & 25 & 8,56 \\
\hline 13 & Las personas se sienten responsables por cada uno de los demás y por la comunidad & 30 & 8,32 & 26 & 8,50 \\
\hline 14 & Las personas que trabajan duramente pueden tener éxito en la vida & 26 & 8,56 & 27 & 8,47 \\
\hline 33 & Una fuerte economía de libre empresa y un gobierno eficiente en sus tareas básicas & 23 & 8,64 & 28 & 8,46 \\
\hline 32 & No hay grandes diferencias en la riqueza y poder entre las personas & 25 & 8,60 & 29 & 8,43 \\
\hline 29 & Comunidades y organizaciones locales fuertes & 28 & 8,48 & 30 & 8,33 \\
\hline 21 & Capacidad para confiar en otras personas, incluso extraños & 31 & 8,24 & 31 & 8,22 \\
\hline 22 & Ciudad atractiva y bien planificada & 32 & 8,10 & 32 & 8,03 \\
\hline 28 & Atomización en la propiedad y control de los medios de comunicación & 33 & 7,38 & 33 & 7,55 \\
\hline 35 & Las personas tienen valores sociales y estilos de vida similares & 35 & 6,48 & 34 & 6,58 \\
\hline 34 & Establecer una economía fuerte antes que la equidad y las metas medioambientales & 34 & 6,92 & 35 & 6,51 \\
\hline
\end{tabular}

Es importante destacar que en 4 de los 5 factores considerados como más importantes en la región de La Plata, Berisso y Ensenada coinciden con aquellos que la población de Berisso destaca entre los 5 más importantes. La diferencia radica que en Berisso colocan en el 9no lugar a la "Eliminación del crimen y la violencia" que para la región de La Plata, Berisso y Ensenada ocupa el 4to lugar y, a su vez, en Berisso "Vigorosa libertad..." se encuentra entre las 5 primeras y en la región de La Plata está en el puesto 6. Esto permite apreciar una clara similitud entre la ciudad de Berisso y la región de La Plata, Berisso y Ensenada en cuanto a la jerarquía que sus poblaciones le otorgan a cada uno de los atributos.

Entonces, los atributos que mayor relevancia se les ha dado en la región de La Plata, Berisso y Ensenada, son:

- Todos son tratados igualitaria y equitativamente por la ley.

* Buena calidad de los servicios básicos (salud, educación, etc.) para todos. 
Los derechos humanos básicos de todos los ciudadanos están fuertemente protegidos.

* Eliminación del crimen y la violencia.

* Altos niveles de honestidad en la política y la vida pública.

Los atributos que mayor relevancia se les ha dado en Berisso, son:

* Todos son tratados igualitaria y equitativamente por la ley.

* Buena calidad de los servicios básicos (salud, educación, etc.) para todos.

* Altos niveles de honestidad en la política y la vida pública.

* Los derechos humanos básicos de todos los ciudadanos están fuertemente protegidos.

* Vigorosa libertad de opinión, múltiples opiniones públicas (disensos).

Entre los cinco atributos que menor relevancia poseen, se evidencia que:

En ambas muestras los puestos de menor importancia coinciden en los 5 atributos, que se detallan a continuación:

* Capacidad para confiar en otras personas, incluso extraños

* Ciudad atractiva y bien planificada

- Atomización en la propiedad y control de los medios de comunicación

* Las personas tienen valores sociales y estilos de vida similares.

* Establecer una economía fuerte antes que la equidad y las metas medioambientales.

Solamente varía la jerarquía de "Atomización de la propiedad..." y "Las personas tienen valores...".

$\rightarrow$ Por otro lado si observamos los primeros diez atributos en importancia para La Plata, Berisso y Ensenada en su conjunto, 9 de esos 10 atributos también han sido elegidos como más importantes por la sociedad de Berisso. El que está entre los 10 primeros en la región de La Plata pero no en Berisso es "Respeto por y estricta...". 


\subsubsection{Desempeño real percibido para las características relevadas}

En esta sección, el análisis comparativo dio como resultado:

Tabla 10: Berisso vs. Región La Plata, Berisso y Ensenada. Desempeño Real

\begin{tabular}{|c|c|c|c|c|}
\hline & & $\begin{array}{c}\text { Desempeño } \\
\text { Región LP, } \\
\text { Berisso y } \\
\text { Ensenada } \\
\end{array}$ & $\begin{array}{c}\text { Desempeño } \\
\text { Berisso }\end{array}$ & \\
\hline Item & Características & $\begin{array}{c}\text { Calificación } \\
1-10 \text { (c) }\end{array}$ & $\begin{array}{l}\text { Calificación } \\
1-10\left(c^{*}\right)\end{array}$ & $\begin{array}{c}\Delta \% \text { Berisso vs } \\
\text { Región LP, Ber y } \\
\text { Ens }\end{array}$ \\
\hline 1 & Altos niveles de honestidad en la política y la vida pública & 3,68 & 3,20 & $-13 \%$ \\
\hline 2 & Todos son tratados igualitaria y equitativamente por la ley & 4,32 & 3,94 & $-9 \%$ \\
\hline 3 & Los derechos humanos básicos de todos los ciudadanos están fuertemente protegidos & 5,01 & 4,74 & $-5 \%$ \\
\hline 4 & Buena calidad de los servicios básicos (salud, educación, etc.) para todos & 4,98 & 5,02 & $1 \%$ \\
\hline 5 & Eliminación del crimen y la violencia & 3,52 & 3,08 & $-13 \%$ \\
\hline 6 & Protección del medioambiente, recursos y fauna & 4,70 & 4,50 & $-4 \%$ \\
\hline 7 & Igualdad de oportunidades para hombres y mujeres & 6,89 & 6,88 & $0 \%$ \\
\hline 8 & Todos pagan impuestos equitativamente, acorde con el ingreso y riqueza & 4,34 & 4,08 & $-6 \%$ \\
\hline 9 & Confianza justificada en que las instituciones públicas actúan con limpieza y justicia & 3,81 & 3,42 & $-10 \%$ \\
\hline 10 & Las comunidades locales tienen buena calidad de servicios públicos (transporte, luz, etc.) & 4,66 & 4,56 & $-2 \%$ \\
\hline 11 & Buena atención a las personas vulnerables, disminuidos y de clase baja & 5,00 & 4,82 & $-4 \%$ \\
\hline 12 & Reducción de la contaminación medioambiental, desarrollo de fuentes de energía renovables & 4,08 & 3,60 & $-12 \%$ \\
\hline 13 & Las personas se sienten responsables por cada uno de los demás y por la comunidad & 4,23 & 3,98 & $-6 \%$ \\
\hline 14 & Las personas que trabajan duramente pueden tener éxito en la vida & 4,94 & 4,98 & $1 \%$ \\
\hline 15 & Se alienta la vida familiar y los valores de la familia & 5,78 & 5,08 & $-12 \%$ \\
\hline 16 & Las personas jóvenes son valoradas, y tienen perspectivas de futuro seguras & 4,79 & 4,26 & $-11 \%$ \\
\hline 17 & Eliminación de la pobreza & 4,47 & 4,30 & $-4 \%$ \\
\hline 18 & Respeto por, y estricta aplicación de las leyes & 3,89 & 3,62 & $-7 \%$ \\
\hline 19 & Trabajos seguros, satisfactorios y equitativamente pagados para todos los que quieren trabajar & 4,38 & 4,18 & $-4 \%$ \\
\hline 20 & Fuerte protección social (edad, enfermedad, desempleo, etc.) & 4,80 & 4,30 & $-10 \%$ \\
\hline 21 & Capacidad para confiar en otras personas, incluso extraños & 3,60 & 3,20 & $-11 \%$ \\
\hline 22 & Ciudad atractiva y bien planificada & 5,04 & 4,64 & $-8 \%$ \\
\hline 23 & Protección de la libertad religiosa & 7,78 & 7,88 & $1 \%$ \\
\hline 24 & Relaciones justas, limpias e independientes con otras naciones & 5,48 & 4,84 & $-12 \%$ \\
\hline 25 & Altos niveles de progreso científico y tecnológico & 5,47 & 4,80 & $-12 \%$ \\
\hline 26 & Vigorosa libertad de opinión, múltiples opiniones públicas (disensos) & 6,26 & 6,10 & $-3 \%$ \\
\hline 27 & Las personas participan en la toma de decisiones de hechos que los afectan & 4,82 & 4,34 & $-10 \%$ \\
\hline 28 & Atomización en la propiedad y control de los medios de comunicación & 5,06 & 4,58 & $-9 \%$ \\
\hline 29 & Comunidades y organizaciones locales fuertes & 4,94 & 4,46 & $-10 \%$ \\
\hline 30 & Libertad para hacer lo que nos gusta siempre que no perjudiquemos a otros & 5,11 & 4,28 & $-16 \%$ \\
\hline 31 & Generosidad en ayudar a regiones perjudicadas & 6,58 & 6,28 & $-5 \%$ \\
\hline 32 & No hay grandes diferencias en la riqueza y poder entre las personas & 3,28 & 2,94 & $-10 \%$ \\
\hline 33 & Una fuerte economía de libre empresa y un gobierno eficiente en sus tareas básicas & 3,96 & 3,88 & $-2 \%$ \\
\hline 34 & Establecer una economía fuerte antes que la equidad y las metas medioambientales & 4,93 & 4,78 & $-3 \%$ \\
\hline 35 & Las personas tienen valores sociales y estilos de vida similares & 4,10 & 3,78 & $-8 \%$ \\
\hline
\end{tabular}

Si se realiza un análisis general, se evidencia que el promedio total del desempeño de los atributos evaluados en Berisso es menor en relación al desempeño en la región de La Plata, Berisso y Ensenada. Esto implica que los encuestados de Berisso consideran que los aspectos para ellos de importancia, en la realidad se ven concretados un $7 \%$ menos en promedio que en la región de La Plata. 
Cuando se profundiza el análisis y se observa el desempeño promedio para las cinco características más importantes, la tendencia se mantiene ya que Berisso tiene 4 puntos en promedio, mientras que para la región de La Plata, Berisso y Ensenada el promedio es de 4.3 puntos (entonces, el desempeño es un 7,5\% menor en Berisso). Si se extiende el análisis a las diez primeras características Berisso tiene un promedio de 4,3 puntos mientras que La Plata, Berisso y Ensenada en su conjunto tienen un promedio de 4,59 puntos, o sea, un 5,5\% menor en Berisso.

Las características que mejor desempeño percibido presentan según los resultados de la encuesta a la sociedad la región de La Plata, Berisso y Ensenada y en la ciudad de Berisso son:

Tabla 11: Desempeño Región La Plata, Berisso y Ensenada y de la ciudad de Berisso

\begin{tabular}{|c|c|c|c|}
\hline & & $\begin{array}{c}\text { Desempeño } \\
\text { Región LP, } \\
\text { Berisso y } \\
\text { Ensenada }\end{array}$ & $\begin{array}{c}\text { Desempeño } \\
\text { Berisso }\end{array}$ \\
\hline Item & Características & $\begin{array}{c}\text { Calificación } \\
1-10 \text { (c) }\end{array}$ & $\begin{array}{c}\text { Calificación } \\
1-10\left(c^{*}\right)\end{array}$ \\
\hline 23 & Protección de la libertad religiosa & 7,78 & 7,88 \\
\hline 7 & Igualdad de oportunidades para hombres y mujeres & 6,89 & 6,88 \\
\hline 31 & Generosidad en ayudar a regiones perjudicadas & 6,58 & 6,28 \\
\hline 26 & Vigorosa libertad de opinión, múltiples opiniones públicas (disensos) & 6,26 & 6,10 \\
\hline 15 & Se alienta la vida familiar y los valores de la familia & 5,78 & 5,08 \\
\hline
\end{tabular}

* Protección de la libertad religiosa.

* Igualdad de oportunidades para hombres y mujeres.

* Generosidad en ayudar a regiones perjudicadas.

Vigorosa libertad de opinión, múltiples opiniones públicas (disensos).

Se alienta la vida familiar y los valores de la familia.

$\rightarrow$ De las características que mejor puntuación han recibido en materia de desempeño, "Igualdad de oportunidades...", "Vigorosa libertad de opinión...", "Generosidad en ayudar a regiones..." y "Se alienta la vida 
familiar..." se encuentran entre las consideradas diez más importantes para esa sociedad.

Por su parte, las características en que la población percibe un peor desempeño resultaron ser:

* Confianza justificada en que las instituciones públicas actúan con limpieza y justicia.

* Altos niveles de honestidad en la política y la vida pública.

* Capacidad para confiar en otras personas, incluso extraños.

* Eliminación del crimen y la violencia.

* No hay grandes diferencias en la riqueza y poder entre las personas.

$\rightarrow$ De las características que peor puntuación ha recibido en materia de desempeño, están presente entre las 10 consideradas más importantes para Berisso "Confianza justificada en que las instituciones públicas..." (puesto 6), "Altos niveles de honestidad en la política..." (puesto 3) y "Eliminación del crimen..." (puesto 9).

\subsubsection{Discrepancia entre importancia asignada y desempeño percibido}

Cuando se realiza la comparación de las brechas existentes entre la importancia asignada a los diferentes atributos y el desempeño real de los mismos, según las percepciones de la sociedad, se observan los siguientes valores para las características relevadas: 
Tabla 12: Discrepancia entre Importancia y Desempeño en la ciudad de Berisso y en la Región de La Plata, Berisso y Ensenada.

\begin{tabular}{|c|c|c|c|c|c|c|c|}
\hline \multirow{3}{*}{ Item } & \multirow{3}{*}{ Características } & \multicolumn{2}{|c|}{ Importancia Asignada } & \multicolumn{2}{|c|}{ Desempeño Percibido } & \multirow{2}{*}{\multicolumn{2}{|c|}{\begin{tabular}{|c} 
Discrepancia entre \\
desempeño percibido e \\
importancia asignada (Ber v \\
Ber y Región vs Región)
\end{tabular}}} \\
\hline & & \multirow{2}{*}{\begin{tabular}{|c|} 
Región \\
Berisso, LP y \\
Ens. \\
$\begin{array}{c}\text { Calificación 1- } \\
10\end{array}$ \\
\end{tabular}} & \multirow{2}{*}{\begin{tabular}{|c|} 
Berisso \\
$\begin{array}{c}\text { Calificación 1- } \\
10\end{array}$ \\
\end{tabular}} & \multirow{2}{*}{\begin{tabular}{|c|} 
Región Berisso, \\
LP y Ens. \\
$\begin{array}{c}\text { Calificación 1- } \\
10\end{array}$
\end{tabular}} & \multirow{2}{*}{\begin{tabular}{|c|} 
Berisso \\
$\begin{array}{c}\text { Calificación 1- } \\
10\end{array}$ \\
\end{tabular}} & & \\
\hline & & & & & & $\begin{array}{c}\text { Región Berisso, } \\
\text { LP y Ens. }\end{array}$ & Berisso \\
\hline 1 & Altos niveles de honestidad en la política y la vida pública & 9,47 & 9,64 & 3,68 & 3,20 & $-5,80$ & $-6,44$ \\
\hline 5 & Eliminación del crimen y la violencia & 9,52 & 9,42 & 3,52 & 3,08 & $-6,00$ & $-6,34$ \\
\hline 9 & Confianza justificada en que las instituciones públicas actúan con limpieza y justicia & 9,42 & 9,48 & 3,81 & 3,42 & $-5,61$ & $-6,06$ \\
\hline 2 & Todos son tratados igualitaria y equitativamente por la ley & 9,71 & 9,80 & 4,32 & 3,94 & $-5,39$ & $-5,86$ \\
\hline 18 & Respeto por, y estricta aplicación de las leyes & 9,28 & 9,34 & 3,89 & 3,62 & $-5,39$ & $-5,72$ \\
\hline 32 & No hay grandes diferencias en la riqueza y poder entre las personas & 8,43 & 8,60 & 3,28 & 2,94 & $-5,15$ & $-5,66$ \\
\hline 12 & Reducción de la contaminación medioambiental, desarrollo de fuentes de energía renovables & 8,93 & 8,98 & 4,08 & 3,60 & $-4,85$ & $-5,38$ \\
\hline 21 & Capacidad para confiar en otras personas, incluso extraños & 8,22 & 8,24 & 3,60 & 3,20 & $-4,62$ & $-5,04$ \\
\hline 30 & Libertad para hacer lo que nos gusta siempre que no perjudiquemos a otros & 9,19 & 9,30 & 5,11 & 4,28 & $-4,08$ & $-5,02$ \\
\hline 20 & Fuerte protección social (edad, enfermedad, desempleo, etc.) & 9,20 & 9,32 & 4,80 & 4,30 & $-4,41$ & $-5,02$ \\
\hline 8 & Todos pagan impuestos equitativamente, acorde con el ingreso y riqueza & 8,99 & 9,10 & 4,34 & 4,08 & $-4,64$ & $-5,02$ \\
\hline 17 & Eliminación de la pobreza & 9,14 & 9,20 & 4,47 & 4,30 & $-4,67$ & $-4,90$ \\
\hline 19 & Trabajos seguros, satisfactorios y equitativamente pagados para todos los que quieren trabajar & 9,07 & 9,04 & 4,38 & 4,18 & $-4,70$ & $-4,86$ \\
\hline 3 & Los derechos humanos básicos de todos los ciudadanos están fuertemente protegidos & 9,61 & 9,54 & 5,01 & 4,74 & $-4,60$ & $-4,80$ \\
\hline 33 & Una fuerte economía de libre empresa y un gobierno eficiente en sus tareas básicas & 8,46 & 8,64 & 3,96 & 3,88 & $-4,50$ & $-4,76$ \\
\hline 4 & Buena calidad de los servicios básicos (salud, educación, etc.) para todos & 9,66 & 9,78 & 4,98 & 5,02 & $-4,68$ & $-4,76$ \\
\hline 10 & Las comunidades locales tienen buena calidad de servicios públicos (transporte, luz, etc.) & 9,12 & 9,16 & 4,66 & 4,56 & $-4,46$ & $-4,60$ \\
\hline 6 & Protección del medioambiente, recursos y fauna & 9,01 & 9,02 & 4,70 & 4,50 & $-4,31$ & $-4,52$ \\
\hline 16 & Las personas jóvenes son valoradas, y tienen perspectivas de futuro seguras & 8,67 & 8,70 & 4,79 & 4,26 & $-3,89$ & $-4,44$ \\
\hline 15 & Se alienta la vida familiar y los valores de la familia & 9,24 & 9,46 & 5,78 & 5,08 & $-3,46$ & $-4,38$ \\
\hline 11 & Buena atención a las personas vulnerables, disminuidos y de clase baja & 9,16 & 9,18 & 5,00 & 4,82 & $-4,16$ & $-4,36$ \\
\hline 13 & Las personas se sienten responsables por cada uno de los demás y por la comunidad & 8,50 & 8,32 & 4,23 & 3,98 & $-4,27$ & $-4,34$ \\
\hline 25 & Altos niveles de progreso científico y tecnológico & 8,84 & 9,08 & 5,47 & 4,80 & $-3,37$ & $-4,28$ \\
\hline 27 & Las personas participan en la toma de decisiones de hechos que los afectan & 8,76 & 8,62 & 4,82 & 4,34 & $-3,95$ & $-4,28$ \\
\hline 29 & Comunidades y organizaciones locales fuertes & 8,33 & 8,48 & 4,94 & 4,46 & $-3,39$ & $-4,02$ \\
\hline 24 & Relaciones justas, limpias e independientes con otras naciones & 8,56 & 8,52 & 5,48 & 4,84 & $-3,08$ & $-3,68$ \\
\hline 14 & Las personas que trabajan duramente pueden tener éxito en la vida & 8,47 & 8,56 & 4,94 & 4,98 & $-3,53$ & $-3,58$ \\
\hline 22 & Ciudad atractiva y bien planificada & 8,03 & 8,10 & 5,04 & 4,64 & $-2,99$ & $-3,46$ \\
\hline 26 & Vigorosa libertad de opinión, múltiples opiniones públicas (disensos) & 9,43 & 9,52 & 6,26 & 6,10 & $-3,17$ & $-3,42$ \\
\hline 31 & Generosidad en ayudar a regiones perjudicadas & 9,13 & 9,40 & 6,58 & 6,28 & $-2,55$ & $-3,12$ \\
\hline 28 & Atomización en la propiedad y control de los medios de comunicación & 7,55 & 7,38 & 5,06 & 4,58 & $-2,49$ & $-2,80$ \\
\hline 35 & Las personas tienen valores sociales y estilos de vida similares & 6,58 & 6,48 & 4,10 & 3,78 & $-2,48$ & $-2,70$ \\
\hline 7 & Igualdad de oportunidades para hombres y mujeres & 9,33 & 9,44 & 6,89 & 6,88 & $-2,43$ & $-2,56$ \\
\hline 34 & Establecer una economía fuerte antes que la equidad y las metas medioambientales & 6,51 & 6,92 & 4,93 & 4,78 & $-1,58$ & $-2,14$ \\
\hline 23 & Protección de la libertad religiosa & 8,60 & 8,44 & 7,78 & 7,88 & $-0,82$ & $-0,56$ \\
\hline & & & & PROI & MEDIO TOTAL & $-3,99$ & $-4,37$ \\
\hline
\end{tabular}

En el análisis general de la discrepancia entre la importancia asignada y el desempeño percibido de cada uno de los atributos, se observa que el promedio total tanto para la ciudad de Berisso como para la región de La Plata, Berisso y Ensenada se encuentra por debajo de lo esperado. En el caso de la Región, el desempeño real se aleja en un promedio de 3,99 puntos en función de lo que la gente espera de esos atributos. $Y$ en el caso de la ciudad de Berisso el desempeño promedio se aleja en 4,37 puntos de lo esperado. 
En el siguiente cuadro se destacan los 5 atributos que mayor diferencia presentan en la discrepancia entre la importancia asignada y su desempeño real para la ciudad de Berisso y la región de La Plata, Berisso y Ensenada.

Tabla 13: Discrepancia entre importancia asignada y desempeño. Ciudad de Berisso y Región de La Plata, Berisso y Ensenada.

\begin{tabular}{|c|c|c|c|c|c|c|c|}
\hline \multirow{3}{*}{ Item } & \multirow{3}{*}{ Características } & \multicolumn{2}{|c|}{ Importancia Asignada } & \multicolumn{2}{|c|}{ Desempeño Percibido } & \multirow{2}{*}{\multicolumn{2}{|c|}{\begin{tabular}{|c} 
Discrepancia entre \\
desempeño percibido e \\
importancia asignada (Ber vs \\
Ber y Región vs Región)
\end{tabular}}} \\
\hline & & \multirow{2}{*}{\begin{tabular}{|c|}
$\begin{array}{c}\text { Región } \\
\text { Berisso, LP y } \\
\text { Ens. }\end{array}$ \\
$\begin{array}{c}\text { Calificación 1- } \\
10\end{array}$ \\
\end{tabular}} & \multirow{2}{*}{\begin{tabular}{|c|} 
Berisso \\
$\begin{array}{c}\text { Calificación 1- } \\
10\end{array}$ \\
\end{tabular}} & \multirow{2}{*}{\begin{tabular}{|c} 
Región Berisso, \\
LP y Ens. \\
$\begin{array}{c}\text { Calificación 1- } \\
10\end{array}$
\end{tabular}} & \multirow{2}{*}{\begin{tabular}{|c|} 
Berisso \\
$\begin{array}{c}\text { Calificación 1- } \\
10\end{array}$
\end{tabular}} & & \\
\hline & & & & & & $\begin{array}{l}\text { Región } \\
\text { Berisso, LP y } \\
\text { Ens. }\end{array}$ & Berisso \\
\hline 1 & Altos niveles de honestidad en la política y la vida pública & 9,47 & 9,64 & 3,68 & 3,20 & $-5,80$ & $-6,44$ \\
\hline 5 & Eliminación del crimen y la violencia & 9,52 & 9,42 & 3,52 & 3,08 & $-6,00$ & $-6,34$ \\
\hline 9 & Confianza justificada en que las instituciones públicas actúan con limpieza y justicia & 9,42 & 9,48 & 3,81 & 3,42 & $-5,61$ & $-6,06$ \\
\hline 2 & Todos son tratados igualitaria y equitativamente por la ley & 9,71 & 9,80 & 4,32 & 3,94 & $-5,39$ & $-5,86$ \\
\hline 18 & Respeto por, y estricta aplicación de las leyes & 9,28 & 9,34 & 3,89 & 3,62 & $-5,39$ & $-5,72$ \\
\hline
\end{tabular}

Las mayores discrepancias se dan en los atributos que resultan de mayor importancia. 4 de los 5 de mayor diferencia están dentro de los 10 atributos de mayor importancia para la ciudad de Berisso.

\subsubsection{Gravedad de la situación de las características analizadas}

En esta sección veremos cuál es la mirada respecto a la gravedad de la situación en que se encuentra cada característica bajo estudio según la percepción de la muestra, comparando Berisso con la región de La Plata. 
Tabla 14: Gravedad percibida. Región de La Plata, Berisso y Ensenada y de la ciudad de Berisso.

\begin{tabular}{|c|c|c|c|c|c|c|c|}
\hline \multirow{3}{*}{ Item } & \multirow{3}{*}{ Características } & \multicolumn{2}{|c|}{ Importancia Asignada } & \multicolumn{2}{|c|}{ Discrepancia } & \multicolumn{2}{|c|}{ Gravedad Percibida } \\
\hline & & $\begin{array}{l}\text { Región } \\
\text { Berisso, LP y } \\
\text { Ens. }\end{array}$ & Berisso & $\begin{array}{c}\text { Región Berisso, } \\
\text { LP y Ens. }\end{array}$ & Berisso & $\begin{array}{c}\text { Región Berisso, } \\
\text { LP y Ens. }\end{array}$ & Berisso \\
\hline & & \begin{tabular}{|c} 
Calificación 1- \\
10
\end{tabular} & \begin{tabular}{|c} 
Calificación 1- \\
10
\end{tabular} & Calificación 1-10 & \begin{tabular}{|c|} 
Calificación 1- \\
10 \\
\end{tabular} & $-1 * D * 1$ & $-1 * D * 1$ \\
\hline 1 & Altos rivedes de honestidad en la política y la vida pública & 9,47 & 9,64 & $-5,80$ & $-6,44$ & 54,91 & 62,08 \\
\hline 5 & Elimnación del crimen y la violencia & 9,52 & 9,42 & $-6,00$ & $-6,34$ & 57,12 & 59,72 \\
\hline 9 & Confianza justificada en que las instituciones públicas actúan con limpieza y justicia & 9,42 & 9,48 & $-5,61$ & $-6,06$ & 52,88 & 57,45 \\
\hline 2 & Todos son tratados igualitaria y equitativarnente por la ley & 9,71 & 9,80 & $-5,39$ & $-5,86$ & 52,37 & 57,43 \\
\hline 18 & Respeto por, y estricta aplicación de las leyes & 9,28 & 9,34 & $-5,39$ & $-5,72$ & 50,05 & 53,42 \\
\hline 32 & No hay grandes diferencias en la riqueza y poder entre las personas & 8,43 & 8,60 & $-5,15$ & $-5,66$ & 43,41 & 48,68 \\
\hline 12 & Reducción de la contarninación medioarnbiental, desarrollo de fuentes de energia renovables & 8,93 & 8,98 & $-4,85$ & $-5,38$ & 43,31 & 48,31 \\
\hline $20 \mid$ & Fuerte proteción social (edad, enfermedad, desernpleo, etc) & 9,20 & 9,32 & $-4,41$ & $-5,02$ & 40,56 & 46,79 \\
\hline 30 - & Libertad para hacer lo que nos gusta siempre que no pejudiquernos a otros & 9,19 & 9,30 & $-4,08$ & $-5,02$ & $\mathbf{3 7 , 5 3}$ & 46,69 \\
\hline 4 & Buena calidad de los servicios básicos (salud, educación, etc) para todos & 9,66 & 9,78 & $-4,68$ & $-4,76$ & 45,16 & 46,55 \\
\hline 3 & Los derechos hurnanos báscos de todos los ciudadanos están fuerternente protegidos & 9,61 & 9,54 & $-4,60$ & $-4,80$ & 44,25 & 45,79 \\
\hline 8 & Todos pagan impuestos equitativamente, acorde con ed ingreso y riqueza & 8,99 & 9,10 & $-4,64$ & $-5,02$ & $\mathbf{4 1 , 7 3}$ & 45,68 \\
\hline $17 \mid$ & Gimnación de la pobreza & 9,14 & 9,20 & $-4,67$ & $-4,90$ & 42,68 & 45,08 \\
\hline 19 & Trabajos seguros, satisfactorios y equitativarnente pagados para todos los que quieren trabajar & 9,07 & 9,04 & $-4,70$ & $-4,86$ & 42,61 & 43,93 \\
\hline 10 & Las comunidades locales tienen buena calidad de servicios públicos (transporte, luz, etc) & 9,12 & 9,16 & $-4,46$ & $-4,60$ & 40,72 & 42,14 \\
\hline 21 & Capadidad para confiar en otras personas, induso extraños & 8,22 & 8,24 & $-4,62$ & $-5,04$ & 37,93 & 41,53 \\
\hline 15 & Se alienta la vida farniliar y los valores de la farnilia & 9,24 & 9,46 & $-3,46$ & $-4,38$ & 31,93 & 41,43 \\
\hline 33 & Una fuerte economia de libre empresa y un gobiemo eficiente en sus tareas básicas & 8,46 & 8,64 & $-4,50$ & $-4,76$ & 38,03 & $\mathbf{4 1 , 1 3}$ \\
\hline 6 & Protección del medioarnbiente, recursos y fauna & 9,01 & 9,02 & $-4,31$ & $-4,52$ & 38,88 & 40,77 \\
\hline 11 & Buena atención a las personas vulnerables, disninuidos y de dase baja & 9,16 & 9,18 & $-4,16$ & $-4,36$ & 38,15 & 40,02 \\
\hline 25 & Altos niveles de progreso científico y tecnológico & $\mathbf{8 , 8 4}$ & 9,08 & $-3,37$ & $-4,28$ & 29,76 & 38,86 \\
\hline 16 | & Las personas jóvenes son valoradas, y tienen perspectivas de futuro seguras & 8,67 & 8,70 & $-3,89$ & $-4,44$ & $\mathbf{3 3 , 7 1}$ & 38,63 \\
\hline 27 & Las personas participan en la torna de decisiones de hechos que los afectan & 8,76 & 8,62 & $-3,95$ & $-4,28$ & 34,59 & 36,89 \\
\hline 13 & Las personas se sienten responsables por cada uno de los dernás y por la cornunidad & 8,50 & 8,32 & $-4,27$ & $-4,34$ & 36,34 & 36,11 \\
\hline 29 & Comunidades y organizaciones locales fuertes & 8,33 & 8,48 & $-3,39$ & $-4,02$ & 28,25 & 34,09 \\
\hline 26 & Vigorosa libertad de opinión, múltiples opìniones públicas (disensos) & 9,43 & 9,52 & $-3,17$ & $-3,42$ & 29,90 & 32,56 \\
\hline $24 \mid$ & Relaciones justas, limpias e independientes con otras naciones & 8,56 & 8,52 & $-3,08$ & $-3,68$ & 26,35 & 31,35 \\
\hline 14 & Las personas que trabajan durarnente pueden tener éxito en la vida & 8,47 & 8,56 & $-3,53$ & $-3,58$ & 29,87 & 30,64 \\
\hline 31 & Generosidad en ayudar a regiones perjudicadas & 9,13 & 9,40 & $-2,55$ & $-3,12$ & 23,31 & 29,33 \\
\hline 22 & Cudad atractiva y bien planificada & 8,03 & 8,10 & $-2,99$ & $-3,46$ & $\mathbf{2 4 , 0 1}$ & 28,03 \\
\hline $7 \mid$ & Igualdad de oportunidades para horntres y mujeres & 9,33 & 9,44 & $-2,43$ & $-2,56$ & 22,69 & $\mathbf{2 4 , 1 7}$ \\
\hline 28 & Atornización en la propiedad y control de los medios de comunicación & 7,55 & 7,38 & $-2,49$ & $-2,80$ & 18,82 & 20,66 \\
\hline 35 & Las personas tienen valores sociales y estios de vida similares & 6,58 & 6,48 & $-2,48$ & $-2,70$ & 16,31 & 17,50 \\
\hline 34 & Establecer una economía fuerte antes quela equidad y las metas medioambientales & 6,51 & 6,92 & $-1,58$ & $-2,14$ & 10,29 & 14,81 \\
\hline $23 \mid$ & Protección de la libertad religiosa & 8,60 & $8, \mathbf{4 4}$ & $-0,82$ & $-0,56$ & 7,08 & 4,73 \\
\hline & & & & & DIO TOT & 35,59 & 39,23 \\
\hline
\end{tabular}

La gravedad promedio en cuanto al estado general de las diferentes características para Berisso es de 39,23 puntos; mientras que para La Plata, Berisso y Ensenada es de 35,59 puntos (un 10,2\% mayor para Berisso).

La gravedad promedio para las cinco características más importantes es de 58,02 puntos para Berisso contra 53,47 puntos en el caso de La Plata, Berisso y Ensenada (un 8,5\% mayor para Berisso). Si el análisis se lleva a las diez características de mayor relevancia, la gravedad promedia 52,71 puntos para Berisso versus 48,62 puntos para la región de La Plata, Berisso y Ensenada (un 8,5\% mayor para Berisso).

Según los resultados obtenidos, las características que la sociedad de Berisso entiende que están en una situación más crítica son:

* Altos niveles de honestidad en la política y la vida pública $(62,08$ puntos). 
* Eliminación del crimen y la violencia (59,72 puntos).

* Confianza justificada en que las instituciones públicas actúan con limpieza y justicia (57,45 puntos).

* Todos son tratados igualitaria y equitativamente por la ley $(57,43$ puntos).

* Respeto por y estricta aplicación de las leyes (53,42 puntos).

$\rightarrow$ Cuatro de las características que se plantean como críticas en esta sección aparecen entre las diez más importantes para la zona estudiada. La única que no está entre las 10 primeras en importancia es "Respeto por y estricta aplicación de las leyes", que de todas formas se encuentra en el puesto 11.

En cambio, las siguientes características se presentan con un menor nivel de gravedad en la ciudad de Berisso:

* Protección de la libertad religiosa (4,73 puntos).

* Establecer una economía fuerte antes que la equidad y las metas medioambientales (14,81 puntos).

* Las personas tienen valores sociales y estilos de vida similares $(17,50$ puntos).

* Atomización en la propiedad y control de los medios de comunicación (20,66 puntos).

* Igualdad de oportunidades para hombres y mujeres (24,17 puntos).

$\rightarrow$ Solamente una de las características se encuentra dentro de las diez más importantes para la población bajo análisis. Ella es: "Igualdad de oportunidades para..." (puesto 8 en la jerarquía).

\subsection{Situación comparativa: Berisso con Australia}

\subsubsection{Importancia asignada a las características relevadas}

La tabla a continuación expone los resultados obtenidos en las encuestas realizadas en Berisso en comparación al resultado arrojado por la sociedad de Australia. 
Tabla 15: Importancia. Berisso y Australia

\begin{tabular}{|c|c|c|c|}
\hline \multirow{2}{*}{ Item } & \multirow{2}{*}{ Características } & \multicolumn{2}{|c|}{ Importancia } \\
\hline & & Berisso & Australia \\
\hline 1 & Altos niveles de honestidad en la política y la vida pública & 3 & 1 \\
\hline 2 & Todos son tratados igualitaria y equitativamente por la ley & 1 & 2 \\
\hline 3 & Los derechos humanos básicos de todos los ciudadanos están fuertemente protegidos & 4 & 3 \\
\hline 4 & Buena calidad de los servicios básicos (salud, educación, etc.) para todos & 2 & 4 \\
\hline 5 & Eliminación del crimen y la violencia & 9 & 5 \\
\hline 6 & Protección del medioambiente, recursos y fauna & 20 & 6 \\
\hline 7 & Igualdad de oportunidades para hombres y mujeres & 8 & 7 \\
\hline 8 & Todos pagan impuestos equitativamente, acorde con el ingreso y riqueza & 17 & 8 \\
\hline 9 & Confianza justificada en que las instituciones públicas actúan con limpieza y justicia & 6 & 9 \\
\hline 10 & Las comunidades locales tienen buena calidad de servicios públicos (transporte, luz, etc.) & 16 & 10 \\
\hline 11 & Buena atención a las personas vulnerables, disminuidos y de clase baja & 15 & 11 \\
\hline 12 & Reducción de la contaminación medioambiental, desarrollo de fuentes de energía renovables & 21 & 12 \\
\hline 13 & Las personas se sienten responsables por cada uno de los demás y por la comunidad & 30 & 13 \\
\hline 14 & Las personas que trabajan duramente pueden tener éxito en la vida & 26 & 14 \\
\hline 15 & Se alienta la vida familiar y los valores de la familia & 7 & 15 \\
\hline 16 & Las personas jóvenes son valoradas, y tienen perspectivas de futuro seguras & 22 & 16 \\
\hline 17 & Eliminación de la pobreza & 14 & 17 \\
\hline 18 & Respeto por y estricta aplicación de las leyes & 11 & 18 \\
\hline 19 & Trabajos seguros, satisfactorios y equitativamente pagados para todos los que quieren trabajar & 19 & 19 \\
\hline 20 & Fuerte protección social (edad, enfermedad, desempleo, etc.) & 12 & 20 \\
\hline 21 & Capacidad para confiar en otras personas, incluso extraños & 31 & 21 \\
\hline 22 & Ciudad atractiva y bien planificada & 32 & 22 \\
\hline 23 & Protección de la libertad religiosa & 29 & 23 \\
\hline 24 & Relaciones justas, limpias e independientes con otras naciones & 27 & 24 \\
\hline 25 & Altos niveles de progreso científico y tecnológico & 18 & 25 \\
\hline 26 & Vigorosa libertad de opinión, múltiples opiniones públicas (disensos) & 5 & 26 \\
\hline 27 & Las personas participan en la toma de decisiones de hechos que los afectan & 24 & 27 \\
\hline 28 & Atomización en la propiedad y control de los medios de comunicación & 33 & 28 \\
\hline 29 & Comunidades y organizaciones locales fuertes & 28 & 29 \\
\hline 30 & Libertad para hacer lo que nos gusta siempre que no perjudiquemos a otros & 13 & 30 \\
\hline 31 & Generosidad en ayudar a regiones perjudicadas & 10 & 31 \\
\hline 32 & No hay grandes diferencias en la riqueza y poder entre las personas & 25 & 32 \\
\hline 33 & Una fuerte economía de libre empresa y un gobierno eficiente en sus tareas básicas & 23 & 33 \\
\hline 34 & Establecer una economía fuerte antes que la equidad y las metas medioambientales & 34 & 34 \\
\hline 35 & Las personas tienen valores sociales y estilos de vida similares & 35 & 35 \\
\hline
\end{tabular}

Es importante destacar que en 4 de los 5 factores considerados como más importantes en Australia, coinciden con aquellos que la población de Berisso destaca entre los 5 más importantes. La diferencia radica que en Berisso colocan en el 9no lugar a la "Eliminación del crimen y la violencia" que para la sociedad de Australia ocupa el 5to lugar y, a su vez, en Berisso "Vigorosa libertad de opinión..." se encuentra entre las 5 primeras y para los australianos ocupa el puesto 26 .

Por su lado, la "Protección del medio ambiente, recursos y fauna" en Australia ocupa el 6to lugar y en Berisso el puesto 20. A su vez, "Todos pagan 
impuestos equitativamente, acorde con el ingreso y la riqueza" en Berisso ocupa el puesto 17 y en Australia el 8.

Entonces, los atributos que mayor relevancia se les ha dado en Australia, son:

* Altos niveles de honestidad en la política y la vida pública.

* Todos son tratados igualitaria y equitativamente por la ley.

* Los derechos humanos básicos de todos los ciudadanos están fuertemente protegidos.

* Buena calidad de los servicios básicos (salud, educación, etc.) para todos.

* Eliminación del crimen y la violencia.

Los atributos que mayor relevancia se les ha dado en Berisso, son:

* Todos son tratados igualitaria y equitativamente por la ley.

* Buena calidad de los servicios básicos (salud, educación, etc.) para todos.

* Altos niveles de honestidad en la política y la vida pública.

* Los derechos humanos básicos de todos los ciudadanos están fuertemente protegidos.

* Vigorosa libertad de opinión, múltiples opiniones públicas (disensos).

Entre los cinco atributos que menor relevancia poseen, se evidencia que:

En ambas muestras los puestos de menor importancia coinciden en 2 atributos, que se detallan a continuación:

* Establecer una economía fuerte antes que la equidad y las metas medioambientales (puesto 34 en ambos casos).

* Las personas tienen valores sociales y estilos de vida similares (puesto 35 en ambos casos).

\subsubsection{Desempeño real percibido para las características relevadas}

En esta sección, el análisis comparativo dio como resultado: 
Tabla 16: Desempeño. Berisso y Australia

\begin{tabular}{|c|c|c|c|c|}
\hline \multirow{2}{*}{ Item } & \multirow{2}{*}{ Características } & \multirow{2}{*}{\begin{tabular}{|c|} 
Desempeño Australia \\
Calificación 1-10 (c) \\
\end{tabular}} & \multirow{2}{*}{\begin{tabular}{|l|} 
Desempeño Berisso \\
Calificación 1-10 (c) \\
\end{tabular}} & \multirow{2}{*}{$\Delta \%$ (Australia vs. Berisso) } \\
\hline & & & & \\
\hline 1 & Altos niveles de honestidad en la política y la vida pública & 4,30 & 3,20 & $-34,38 \%$ \\
\hline 2 & Todos son tratados igualitaria y equitativamente por la ley & 5,40 & 3,94 & $-37,06 \%$ \\
\hline 3 & Los derechos humanos básicos de todos los ciudadanos están fuertemente protegidos & 6,60 & 4,74 & $-39,24 \%$ \\
\hline 4 & Buena calidad de los servicios básicos (salud, educación, etc.) para todos & 5,50 & 5,02 & $-9,56 \%$ \\
\hline 5 & Eliminación del crimen y la violencia & 3,40 & 3,08 & $-10,39 \%$ \\
\hline 6 & Protección del medioambiente, recursos y fauna & 5,60 & 4,50 & $-24,44 \%$ \\
\hline 7 & Igualdad de oportunidades para hombres y mujeres & 6,40 & 6,88 & $6,98 \%$ \\
\hline 8 & Todos pagan impuestos equitativamente, acorde con el ingreso y riqueza & 3,40 & 4,08 & $16,67 \%$ \\
\hline 9 & Confianza justificada en que las instituciones públicas actúan con limpieza y justicia & 5,10 & 3,42 & $-49,12 \%$ \\
\hline 10 & Las comunidades locales tienen buena calidad de servicios públicos (transporte, luz, etc.) & 4,80 & 4,56 & $-5,26 \%$ \\
\hline 11 & Buena atención a las personas vulnerables, disminuidos y de clase baja & 5,60 & 4,82 & $-16,18 \%$ \\
\hline 12 & Reducción de la contaminación medioambiental, desarrollo de fuentes de energía renovables & 4,80 & 3,60 & $-33,33 \%$ \\
\hline 13 & Las personas se sienten responsables por cada uno de los demás y por la comunidad & 5,10 & 3,98 & $-28,14 \%$ \\
\hline 14 & Las personas que trabajan duramente pueden tener éxito en la vida & 6,80 & 4,98 & $-36,55 \%$ \\
\hline 15 & Se alienta la vida familiar y los valores de la familia & 5,80 & 5,08 & $-14,17 \%$ \\
\hline 16 & Las personas jóvenes son valoradas, y tienen perspectivas de futuro seguras & 4,30 & 4,26 & $-0,94 \%$ \\
\hline 17 & Eliminación de la pobreza & 3,80 & 4,30 & $11,63 \%$ \\
\hline 18 & Respeto por, y estricta aplicación de las leyes & 5,50 & 3,62 & $-51,93 \%$ \\
\hline 19 & Trabajos seguros, satisfactorios y equitativamente pagados para todos los que quieren trabajar & 4,20 & 4,18 & $-0,48 \%$ \\
\hline 20 & Fuerte protección social (edad, enfermedad, desempleo, etc.) & 5,40 & 4,30 & $-25,58 \%$ \\
\hline 21 & Capacidad para confiar en otras personas, incluso extraños & 3,90 & 3,20 & $-21,88 \%$ \\
\hline 22 & Ciudad atractiva y bien planificada & 6,60 & 4,64 & $-42,24 \%$ \\
\hline 23 & Protección de la libertad religiosa & 7,50 & 7,88 & $4,82 \%$ \\
\hline 24 & Relaciones justas, limpias e independientes con otras naciones & 6,10 & 4,84 & $-26,03 \%$ \\
\hline 25 & Altos niveles de progreso científico y tecnológico & 6,80 & 4,80 & $-41,67 \%$ \\
\hline 26 & Vigorosa libertad de opinión, múltiples opiniones públicas (disensos) & 6,30 & 6,10 & $-3,28 \%$ \\
\hline 27 & Las personas participan en la toma de decisiones de hechos que los afectan & 5,10 & 4,34 & $-17,51 \%$ \\
\hline 28 & Atomización en la propiedad y control de los medios de comunicación & 3,70 & 4,58 & $19,21 \%$ \\
\hline 29 & Comunidades y organizaciones locales fuertes & 6,00 & 4,46 & $-34,53 \%$ \\
\hline 30 & Libertad para hacer lo que nos gusta siempre que no perjudiquemos a otros & 7,10 & 4,28 & $-65,89 \%$ \\
\hline 31 & Generosidad en ayudar a regiones perjudicadas & 6,20 & 6,28 & $1,27 \%$ \\
\hline 32 & No hay grandes diferencias en la riqueza y poder entre las personas & 3,30 & 2,94 & $-12,24 \%$ \\
\hline 33 & Una fuerte economía de libre empresa y un gobierno eficiente en sus tareas básicas & 6,10 & 3,88 & $-57,22 \%$ \\
\hline 34 & Establecer una economía fuerte antes que la equidad y las metas medioambientales & 6,80 & 4,78 & $-42,26 \%$ \\
\hline \multirow[t]{2}{*}{35} & Las personas tienen valores sociales y estilos de vida similares & 4,60 & 3,78 & $-21,69 \%$ \\
\hline & & & PROMEDIO & $-21,22 \%$ \\
\hline
\end{tabular}

Del cuadro se desprende que el promedio total del desempeño de los atributos evaluados en Berisso es menor en relación al desempeño Australia. Esto implica que los encuestados de Berisso consideran que los aspectos para ellos de importancia, en la realidad se ven concretados un $21 \%$ menos en promedio respecto a lo que la sociedad australiana ha evaluado sobre esos mismos atributos en su país.

Cuando se profundiza el análisis y se observa el desempeño promedio para las cinco características más importantes, la tendencia se mantiene ya que Berisso tiene 4 puntos en promedio, mientras que para Australia el promedio es de 5,04 puntos (entonces, el desempeño es un 26\% menor en Berisso). Si se extiende el análisis a las diez primeras características Berisso tiene un promedio de 4,34 puntos mientras que Australia tiene 5,05, o sea, un $13 \%$ menor en Berisso. 
Las características que mejor desempeño percibido presentan según los

resultados de la encuesta a la sociedad de Berisso son:

Tabla 17: Mejores desempeños. Berisso y Australia

\begin{tabular}{|c|c|c|c|c|}
\hline \multirow{2}{*}{ Item } & \multirow{2}{*}{ Características } & $\begin{array}{c}\text { Desempeño } \\
\text { Australia }\end{array}$ & $\begin{array}{c}\text { Desempeño } \\
\text { Berisso }\end{array}$ & \\
\hline & & $\begin{array}{c}\text { Calificación 1- } \\
10 \text { (c) }\end{array}$ & $\begin{array}{c}\text { Calificación 1-10 } \\
\text { (c) }\end{array}$ & $\begin{array}{c}\Delta \% \text { (Ber vs } \\
\text { AUS) }\end{array}$ \\
\hline 23 & Protección de la libertad religiosa & 7,50 & 7,88 & $5 \%$ \\
\hline 7 & Igualdad de oportunidades para hombres y mujeres & 6,40 & 6,88 & $8 \%$ \\
\hline 31 & Generosidad en ayudar a regiones perjudicadas & 6,20 & 6,28 & $1 \%$ \\
\hline 26 & Vigorosa libertad de opinión, múltiples opiniones públicas (disensos) & 6,30 & 6,10 & $-3 \%$ \\
\hline 15 & Se alienta la vida familiar y los valores de la familia & 5,80 & 5,08 & $-12 \%$ \\
\hline
\end{tabular}

Aquí se enumeran cada uno de ellos:

- Protección de la libertad religiosa (7,88 puntos).

- Igualdad de oportunidades para hombres y mujeres (6,88 puntos).

* Generosidad en ayudar a regiones perjudicadas (6,28 puntos).

* Vigorosa libertad de opinión, múltiples opiniones públicas (disensos) (6,10 puntos).

* Se alienta la vida familiar y los valores de la familia (5,08 puntos).

$\rightarrow$ De estos atributos, "Vigorosa libertad de..." es el único que se encuentra dentro de los 5 más importantes para la comunidad de Berisso.

Pero si se analizan las diferencias entre los atributos que mejor desempeño han tenido en Berisso en relación a lo que sucede en Australia, se notara que son diferentes a aquellos que se mencionaron en el apartado anterior.

Entonces, de este análisis se desprende el siguiente cuadro:

Tabla 18: Diferencias en Desempeño entre Australia y Berisso

\begin{tabular}{|c|c|c|c|c|}
\hline \multirow{2}{*}{ Item } & \multirow{2}{*}{ Características } & $\begin{array}{c}\text { Desempeño } \\
\text { Australia }\end{array}$ & $\begin{array}{c}\text { Desempeño } \\
\text { Berisso }\end{array}$ & \\
\hline & & $\begin{array}{c}\text { Calificación 1- } \\
10 \text { (c) }\end{array}$ & $\begin{array}{c}\text { Calificación 1-10 } \\
\text { (c) }\end{array}$ & $\begin{array}{c}\Delta \% \text { (Ber vs } \\
\text { AUS) }\end{array}$ \\
\hline 28 & Atomización en la propiedad y control de los medios de comunicación & 3,70 & 4,58 & $24 \%$ \\
\hline 8 & Todos pagan impuestos equitativamente, acorde con el ingreso y riqueza & 3,40 & 4,08 & $20 \%$ \\
\hline 17 & Eliminación de la pobreza & 3,80 & 4,30 & $13 \%$ \\
\hline 7 & Igualdad de oportunidades para hombres y mujeres & 6,40 & 6,88 & $8 \%$ \\
\hline 23 & Protección de la libertad religiosa & 7,50 & 7,88 & $5 \%$ \\
\hline
\end{tabular}


Los atributos que presentan una mejor diferencia porcentual en favor de Berisso cuando se los compara con lo que sucede en Australia, son:

* Atomización en la propiedad y control de los medios de comunicación (24\% de diferencia).

* Todos pagan impuestos equitativamente, acorde con el ingreso y riqueza ( $20 \%$ de diferencia).

* Eliminación de la pobreza (13\% de diferencia).

* Igualdad de oportunidades para hombres y mujeres (8\% de diferencia).

* Protección de la libertad religiosa (5\% de diferencia).

$\rightarrow$ De estos atributos, ninguno de ellos se encuentra dentro de los 5 más importantes para la comunidad de Berisso.

Por su parte, las características en que la población percibe un peor desempeño resultaron ser:

Tabla 19: Peores desempeños. Berisso y Australia

\begin{tabular}{|c|c|c|c|c|}
\hline \multirow[b]{2}{*}{ Item } & \multirow{2}{*}{ Características } & $\begin{array}{c}\text { Desempeño } \\
\text { Australia }\end{array}$ & $\begin{array}{c}\text { Desempeño } \\
\text { Berisso }\end{array}$ & \multirow{2}{*}{ ?\% (Ber vs Aus) } \\
\hline & & $\begin{array}{c}\text { Calificación 1- } \\
10 \text { (c) }\end{array}$ & $\begin{array}{c}\text { Calificación 1- } \\
10 \text { (c) }\end{array}$ & \\
\hline 9 & Confianza justificada en que las instituciones públicas actúan con limpieza y justicia & 5,10 & 3,42 & $-33 \%$ \\
\hline 1 & Altos niveles de honestidad en la política y la vida pública & 4,30 & 3,20 & $-26 \%$ \\
\hline 21 & Capacidad para confiar en otras personas, incluso extraños & 3,90 & 3,20 & $-18 \%$ \\
\hline 32 & No hay grandes diferencias en la riqueza y poder entre las personas & $3, \mathbf{3 0}$ & 2,94 & $-11 \%$ \\
\hline 5 & Eliminación del crimen y la violencia & 3,40 & 3,08 & $-9 \%$ \\
\hline
\end{tabular}

En el cuadro 19 se presentan los atributos de peor desempeño en Berisso y luego se los ordena en función de la diferencia porcentual que los mismos tienen cuando se los compara con el comportamiento en Australia. Entonces, aquí se enumeran de la peor a la mejor diferencia porcentual, tomando como base a la ciudad de Berisso:

* Confianza justificada en que las instituciones públicas actúan con limpieza y justicia (33\% de diferencia).

* Altos niveles de honestidad en la política y la vida pública (26\% de diferencia).

* Capacidad para confiar en otras personas, incluso extraños (18\% de diferencia). 
* No hay grandes diferencias en la riqueza y poder entre las personas (11\% de diferencia).

* Eliminación del crimen y la violencia ( $9 \%$ de diferencia).

$\rightarrow$ De estos atributos, sólo "Altos niveles de..." se encuentra dentro de los 5 más importantes para la comunidad de Berisso.

\subsubsection{Discrepancia entre importancia asignada y desempeño percibido}

Cuando se realiza la comparación de las brechas existentes entre la importancia asignada a los diferentes atributos y el desempeño real de los mismos, según las percepciones de la sociedad, se observan los siguientes valores para las características relevadas: 
Tabla 20: Discrepancia entre importancia asignada y desempeño real, en Berisso y Australia.

\begin{tabular}{|c|c|c|c|c|c|c|c|}
\hline \multirow{3}{*}{ Item } & \multirow{3}{*}{ Características } & \multicolumn{2}{|c|}{ Importancia Asignada } & \multicolumn{2}{|c|}{ Desempeño Percibido } & \multirow{2}{*}{\multicolumn{2}{|c|}{$\begin{array}{c}\text { Discrepancia entre } \\
\text { desempeño percibido e } \\
\text { importancia asignada (Ber vs } \\
\text { Ber y Aus vs Aus) }\end{array}$}} \\
\hline & & \multirow{2}{*}{\begin{tabular}{|c|} 
Australia \\
Calificación 1- \\
10 \\
\end{tabular}} & \multirow{2}{*}{\begin{tabular}{|c|} 
Berisso \\
$\begin{array}{c}\text { Calificación 1- } \\
10\end{array}$ \\
\end{tabular}} & \multirow{2}{*}{\begin{tabular}{c|} 
Australia \\
\\
Calificación 1- \\
10
\end{tabular}} & \multirow{2}{*}{\begin{tabular}{|c|} 
Berisso \\
Calificación 1- \\
10 \\
\end{tabular}} & & \\
\hline & & & & & & Australia & Berisso \\
\hline 1 & Altos niveles de honestidad en la política y la vida pública & 9,30 & 9,64 & 4,30 & 3,20 & $-5,00$ & $-6,44$ \\
\hline 5 & Eliminación del crimen y la violencia & 9,10 & 9,42 & 3,40 & 3,08 & $-5,70$ & $-6,34$ \\
\hline 9 & Confianza justificada en que las instituciones públicas actúan con limpieza y justicia & 9,00 & 9,48 & 5,10 & 3,42 & $-3,90$ & $-6,06$ \\
\hline 2 & Todos son tratados igualitaria y equitativamente por la ley & 9,30 & 9,80 & 5,40 & 3,94 & $-3,90$ & $-5,86$ \\
\hline 18 & Respeto por, y estricta aplicación de las leyes & 8,60 & 9,34 & 5,50 & 3,62 & $-3,10$ & $-5,72$ \\
\hline 32 & No hay grandes diferencias en la riqueza y poder entre las personas & 6,80 & 8,60 & 3,30 & 2,94 & $-3,50$ & $-5,66$ \\
\hline 12 & Reducción de la contaminación medioambiental, desarrollo de fuentes de energía renovables & 8,80 & 8,98 & 4,80 & 3,60 & $-4,00$ & $-5,38$ \\
\hline 21 & Capacidad para confiar en otras personas, incluso extraños & 8,40 & 8,24 & 3,90 & 3,20 & $-4,50$ & $-5,04$ \\
\hline 20 & Fuerte protección social (edad, enfermedad, desempleo, etc.) & 8,50 & 9,32 & 5,40 & 4,30 & $-3,10$ & $-5,02$ \\
\hline 30 & Libertad para hacer lo que nos gusta siempre que no perjudiquemos a otros & 7,40 & 9,30 & 7,10 & 4,28 & $-0,30$ & $-5,02$ \\
\hline 8 & Todos pagan impuestos equitativamente, acorde con el ingreso y riqueza & 9,00 & 9,10 & 3,40 & 4,08 & $-5,60$ & $-5,02$ \\
\hline 17 & Eliminación de la pobreza & 8,60 & 9,20 & 3,80 & 4,30 & $-4,80$ & $-4,90$ \\
\hline 19 & Trabajos seguros, satisfactorios y equitativamente pagados para todos los que quieren trabajar & 8,60 & 9,04 & 4,20 & 4,18 & $-4,40$ & $-4,86$ \\
\hline 3 & Los derechos humanos básicos de todos los ciudadanos están fuertemente protegidos & 9,10 & 9,54 & 6,60 & 4,74 & $-2,50$ & $-4,80$ \\
\hline 33 & Una fuerte economía de libre empresa y un gobierno eficiente en sus tareas básicas & 6,70 & 8,64 & 6,10 & 3,88 & $-0,60$ & $-4,76$ \\
\hline 4 & Buena calidad de los servicios básicos (salud, educación, etc.) para todos & 9,10 & 9,78 & 5,50 & 5,02 & $-3,60$ & $-4,76$ \\
\hline 10 & Las comunidades locales tienen buena calidad de servicios públicos (transporte, luz, etc.) & 9,00 & 9,16 & 4,80 & 4,56 & $-4,20$ & $-4,60$ \\
\hline 6 & Protección del medioambiente, recursos y fauna & 9,10 & 9,02 & 5,60 & 4,50 & $-3,50$ & $-4,52$ \\
\hline 16 & Las personas jóvenes son valoradas, y tienen perspectivas de futuro seguras & 8,60 & 8,70 & 4,30 & 4,26 & $-4,30$ & $-4,44$ \\
\hline 15 & Se alienta la vida familiar y los valores de la familia & 8,60 & 9,46 & 5,80 & 5,08 & $-2,80$ & $-4,38$ \\
\hline 11 & Buena atención a las personas vulnerables, disminuidos y de clase baja & 8,80 & 9,18 & 5,60 & 4,82 & $-3,20$ & $-4,36$ \\
\hline 13 & Las personas se sienten responsables por cada uno de los demás y por la comunidad & 8,70 & 8,32 & 5,10 & 3,98 & $-3,60$ & $-4,34$ \\
\hline 25 & Altos niveles de progreso científico y tecnológico & 8,10 & 9,08 & 6,80 & 4,80 & $-1,30$ & $-4,28$ \\
\hline 27 & Las personas participan en la toma de decisiones de hechos que los afectan & 8,10 & 8,62 & 5,10 & 4,34 & $-3,00$ & $-4,28$ \\
\hline 29 & Comunidades y organizaciones locales fuertes & 7,80 & 8,48 & 6,00 & 4,46 & $-1,80$ & $-4,02$ \\
\hline 24 & Relaciones justas, limpias e independientes con otras naciones & 8,20 & 8,52 & 6,10 & 4,84 & $-2,10$ & $-3,68$ \\
\hline 14 & Las personas que trabajan duramente pueden tener éxito en la vida & 8,60 & 8,56 & 6,80 & 4,98 & $-1,80$ & $-3,58$ \\
\hline 22 & Ciudad atractiva y bien planificada & 8,30 & 8,10 & 6,60 & 4,64 & $-1,70$ & $-3,46$ \\
\hline 26 & Vigorosa libertad de opinión, múltiples opiniones públicas (disensos) & 8,10 & 9,52 & 6,30 & 6,10 & $-1,80$ & $-3,42$ \\
\hline 31 & Generosidad en ayudar a regiones perjudicadas & 7,00 & 9,40 & 6,20 & 6,28 & $-0,80$ & $-3,12$ \\
\hline 28 & Atomización en la propiedad y control de los medios de comunicación & 7,90 & 7,38 & 3,70 & 4,58 & $-4,20$ & $-2,80$ \\
\hline 35 & Las personas tienen valores sociales y estilos de vida similares & 4,50 & 6,48 & 4,60 & 3,78 & 0,10 & $-2,70$ \\
\hline 7 & Igualdad de oportunidades para hombres y mujeres & 9,00 & 9,44 & 6,40 & 6,88 & $-2,60$ & $-2,56$ \\
\hline 34 & Establecer una economía fuerte antes que la equidad y las metas medioambientales & 5,20 & 6,92 & 6,80 & 4,78 & 1,60 & $-2,14$ \\
\hline \multirow[t]{2}{*}{23} & Protección de la libertad religiosa & 8,20 & 8,44 & 7,50 & 7,88 & $-0,70$ & $-0,56$ \\
\hline & & & & & PROMEDIO & $-2,86$ & $-4,37$ \\
\hline
\end{tabular}

En el análisis general de la discrepancia, se observa que el promedio total de los atributos evaluados en Berisso es de $-4,37$ versus los $-2,86$ puntos reflejados en Australia (un 53\% mayor gravedad percibida para la sociedad de Berisso).

Si se profundiza la mirada, se detecta que la gravedad percibida promedio para las cinco características más importantes en Berisso es de -5,28 contra los $-4,14$ puntos en el caso de la región de Australia (un 28\% mayor para Berisso). Si extendemos el análisis a las diez primeras características la brecha es del $17 \%$, ya que en Berisso se observa un promedio de $-4,74$ puntos contra los $-4,05$ de Australia. 


\section{Las características donde la población percibe un desempeño real más cercano}

al nivel de importancia que le asigna son:

Tabla 21: Menores discrepancias. Berisso

\begin{tabular}{|c|c|c|c|c|}
\hline \multirow[t]{2}{*}{ Item } & \multirow[t]{2}{*}{ Características } & $\begin{array}{c}\text { Importancia } \\
\text { Asignada }\end{array}$ & $\begin{array}{c}\text { Desempeño } \\
\text { Percibido }\end{array}$ & $\begin{array}{c}\text { Discrepancia entre } \\
\text { desempeño percibido e } \\
\text { importancia asignada }\end{array}$ \\
\hline & & $\begin{array}{c}\text { Calificación 1- } \\
10\end{array}$ & \begin{tabular}{|c|} 
Calificación 1- \\
10
\end{tabular} & Calificación 1-10 \\
\hline 28 & Atomización en la propiedad y control de los medios de comunicación & 7,38 & 4,58 & $-2,80$ \\
\hline 35 & Las personas tienen valores sociales y estilos de vida similares & 6,48 & 3,78 & $-2,70$ \\
\hline 7 & Igualdad de oportunidades para hombres y mujeres & 9,44 & 6,88 & $-2,56$ \\
\hline 34 & Establecer una economía fuerte antes que la equidad y las metas medioambientales & 6,92 & 4,78 & $-2,14$ \\
\hline 23 & Protección de la libertad religiosa & 8,44 & 7,88 & $-0,56$ \\
\hline & & & PROMEDIO & $-2,15$ \\
\hline
\end{tabular}

Tabla 22: Menores discrepancias. Australia

\begin{tabular}{|c|c|c|c|c|}
\hline \multirow{2}{*}{ Item } & \multirow{2}{*}{ Características } & $\begin{array}{c}\text { Importancia } \\
\text { Asignada } \\
\end{array}$ & \begin{tabular}{|c|} 
Desempeño \\
Percibido
\end{tabular} & $\begin{array}{c}\text { Discrepancia entre } \\
\text { desempeño percibido e }\end{array}$ \\
\hline & & \begin{tabular}{|c|} 
Calificación 1- \\
10 \\
\end{tabular} & \begin{tabular}{|c|} 
Calificación 1- \\
10 \\
\end{tabular} & Calificación 1-10 \\
\hline 31 & Generosidad en ayudar a regiones perjudicadas & 7,00 & 6,20 & $-0,80$ \\
\hline 23 & Protección de la libertad religiosa & 8,20 & 7,50 & $-0,70$ \\
\hline 33 & Una fuerte economía de libre empresa y un gobierno eficiente en sus tareas básicas & 6,70 & 6,10 & $-0,60$ \\
\hline 30 & Libertad para hacer lo que nos gusta siempre que no perjudiquemos a otros & 7,40 & 7,10 & $-0,30$ \\
\hline \multirow[t]{2}{*}{35} & Las personas tienen valores sociales y estilos de vida similares & 4,50 & 4,60 & 0,10 \\
\hline & & & PROMEDIO & $-0,46$ \\
\hline
\end{tabular}

$\rightarrow$ Nótese que tanto para el caso de Berisso como para Australia, ninguna de las características de menor discrepancia son consideradas entre las cinco más importantes por sus sociedades.

$\rightarrow \mathrm{Al}$ analizar los promedios de las 5 características de mejor desempeño para Berisso y para Australia, se aprecia una diferencia a favor de Australia de un $467 \%$ en relación a la discrepancia.

Las mayores brechas se presentan en el siguiente grupo de características:

Tabla 23: Mayores discrepancias. Berisso

\begin{tabular}{|c|c|c|c|c|}
\hline \multirow{2}{*}{ Item } & \multirow{2}{*}{ Características } & \begin{tabular}{|c|} 
Importancia \\
Asignada
\end{tabular} & \begin{tabular}{|c|} 
Desempeño \\
Percibido
\end{tabular} & $\begin{array}{c}\text { Discrepancia entre } \\
\text { desempeño percibido e }\end{array}$ \\
\hline & & \begin{tabular}{|c|} 
Calificación 1- \\
10
\end{tabular} & \begin{tabular}{|c|} 
Calificación 1- \\
10
\end{tabular} & Calificación 1-10 \\
\hline 1 & Altos niveles de honestidad en la política y la vida pública & 9,64 & 3,20 & $-6,44$ \\
\hline 5 & Eliminación del crimen y la violencia & 9,42 & 3,08 & $-6,34$ \\
\hline 9 & Confianza justificada en que las instituciones públicas actúan con limpieza y justicia & 9,48 & 3,42 & $-6,06$ \\
\hline 2 & Todos son tratados igualitaria y equitativamente por la ley & 9,80 & 3,94 & $-5,86$ \\
\hline 18 & Respeto por, y estricta aplicación de las leyes & 9,34 & 3,62 & $-5,72$ \\
\hline & & & PROMEDIO & $-6,08$ \\
\hline
\end{tabular}


Tabla 24: Mayores discrepancias. Australia.

\begin{tabular}{|c|c|c|c|c|}
\hline \multirow{2}{*}{ Item } & \multirow{2}{*}{ Características } & \multirow{2}{*}{\begin{tabular}{|c|}
$\begin{array}{c}\text { Importancia } \\
\text { Asignada }\end{array}$ \\
Calificación 1- \\
10
\end{tabular}} & \multirow{2}{*}{\begin{tabular}{|c|}
$\begin{array}{c}\text { Desempeño } \\
\text { Percibido }\end{array}$ \\
Calificación 1- \\
10
\end{tabular}} & \multirow{2}{*}{\begin{tabular}{|c|}
$\begin{array}{c}\text { Discrepancia entre } \\
\text { desempeño percibido }\end{array}$ \\
Calificación 1-10
\end{tabular}} \\
\hline & & & & \\
\hline 5 & Eliminación del crimen y la violencia & 9,10 & 3,40 & $-5,70$ \\
\hline 8 & Todos pagan impuestos equitativamente, acorde con el ingreso y riqueza & 9,00 & 3,40 & $-5,60$ \\
\hline 1 & Altos niveles de honestidad en la política y la vida pública & 9,30 & 4,30 & $-5,00$ \\
\hline 17 & Eliminación de la pobreza & 8,60 & 3,80 & $-4,80$ \\
\hline \multirow[t]{2}{*}{21} & Capacidad para confiar en otras personas, incluso extraños & 8,40 & 3,90 & $-4,50$ \\
\hline & & & PROMEDIO & $-5,12$ \\
\hline
\end{tabular}

$\rightarrow \mathrm{Al}$ analizar los peores desempeños, en el caso de Berisso, tres de ellos se encuentran entre los cinco atributos más importantes para su sociedad. Ellos son: "Altos niveles de honestidad en la política...", "Eliminación del crimen..." y "Todos son tratados igualitaria y equitativamente por la ley".

$\rightarrow$ En el caso de Australia, dos de los atributos de peor desempeño se encuentran entre los cinco atributos más importantes para su sociedad. Ellos son: "Eliminación del crimen y la violencia" y "Altos niveles de honestidad en la política...".

$\rightarrow \mathrm{Al}$ analizar los promedios de discrepancia de los atributos de peor desempeño de las sociedades de Berisso y la de Australia, se aprecia que hay un $19 \%$ de diferencia a favor de Australia.

\subsubsection{Gravedad de la situación de las características analizadas}

En esta sección veremos cuál es la mirada respecto a la gravedad de la situación en que se encuentra cada característica bajo estudio según la percepción de la muestra, comparando Berisso con Australia. 


\begin{tabular}{|c|c|c|c|c|c|c|c|}
\hline & \multirow{2}{*}{$\begin{array}{c}\text { Importancia } \\
\text { Berisso } \\
\text { Calificación } \\
1-10 \text { (a) }\end{array}$} & \multirow{2}{*}{$\begin{array}{c}\text { Importancia } \\
\text { AUSTRALIA } \\
\text { Calificación } \\
1-10\left(a^{*}\right) \\
\end{array}$} & \multirow{2}{*}{\begin{tabular}{|c|}
$\begin{array}{c}\text { Discrepancia } \\
\text { Berisso }\end{array}$ \\
Valor \\
$(\mathrm{d}=\mathrm{c}-\mathrm{a})$ \\
\end{tabular}} & \multirow{2}{*}{\begin{tabular}{|c|}
$\begin{array}{c}\text { Discrepancia } \\
\text { AUSTRALIA }\end{array}$ \\
$\begin{array}{c}\text { Valor } \\
\left(d^{*}=c^{*}-a^{*}\right)\end{array}$ \\
\end{tabular}} & \multirow{2}{*}{\begin{tabular}{|c|} 
Gravedad \\
Percibida Berisso \\
$\begin{array}{c}\text { Ponderación } \\
(\mathrm{e}=-\mathbf{d} \mathrm{x} \text { a })\end{array}$ \\
\end{tabular}} & \multirow{2}{*}{\begin{tabular}{|c|}
$\begin{array}{c}\text { Gravedad Percibida } \\
\text { AUSTRALIA }\end{array}$ \\
$\begin{array}{c}\text { Ponderación } \\
\left(\mathrm{e}^{*}=-\mathrm{d}^{*} \mathrm{x} \mathrm{a}^{*}\right)\end{array}$ \\
\end{tabular}} \\
\hline Item & Características & & & & & & \\
\hline 1 & Altos niveles de honestidad en la política y la vida pública & 9,64 & 9,30 & $-6,44$ & $-5,00$ & 62,08 & 46,50 \\
\hline 2 & Todos son tratados igualitaria y equitativamente por la ley & 9,80 & 9,30 & $-5,86$ & $-3,90$ & 57,43 & 36,27 \\
\hline 3 & Los derechos humanos básicos de todos los ciudadanos están fuertemente protegidos & 9,54 & 9,10 & $-4,80$ & $-2,50$ & 45,79 & 22,75 \\
\hline 4 & Buena calidad de los servicios básicos (salud, educación, etc.) para todos & 9,78 & 9,10 & $-4,76$ & $-3,60$ & 46,55 & 32,76 \\
\hline 5 & Eliminación del crimen y la violencia & 9,42 & 9,10 & $-6,34$ & $-5,70$ & 59,72 & 51,87 \\
\hline 6 & Protección del medioambiente, recursos y fauna & 9,02 & 9,10 & $-4,52$ & $-3,50$ & 40,77 & 31,85 \\
\hline 7 & Igualdad de oportunidades para hombres y mujeres & 9,44 & 9,00 & $-2,56$ & $-2,60$ & 24,17 & 23,40 \\
\hline 8 & Todos pagan impuestos equitativamente, acorde con el ingreso y riqueza & 9,10 & 9,00 & $-5,02$ & $-5,60$ & 45,68 & 50,40 \\
\hline 9 & Confianza justificada en que las instituciones públicas actúan con limpieza y justicia & 9,48 & 9,00 & $-6,06$ & $-3,90$ & 57,45 & 35,10 \\
\hline 10 & Las comunidades locales tienen buena calidad de servicios públicos (transporte, luz, etc.) & 9,16 & 9,00 & $-4,60$ & $-4,20$ & 42,14 & 37,80 \\
\hline 11 & Buena atención a las personas vulnerables, disminuidos y de clase baja & 9,18 & 8,80 & $-4,36$ & $-3,20$ & 40,02 & 28,16 \\
\hline 12 & Reducción de la contaminación medioambiental, desarrollo de fuentes de energía renovables & 8,98 & 8,80 & $-5,38$ & $-4,00$ & 48,31 & 35,20 \\
\hline 13 & Las personas se sienten responsables por cada uno de los demás y por la comunidad & 8,32 & 8,70 & $-4,34$ & $-3,60$ & 36,11 & 31,32 \\
\hline 14 & Las personas que trabajan duramente pueden tener éxito en la vida & 8,56 & 8,60 & $-3,58$ & $-1,80$ & 30,64 & 15,48 \\
\hline 15 & Se alienta la vida familiar y los valores de la familia & 9,46 & 8,60 & $-4,38$ & $-2,80$ & 41,43 & 24,08 \\
\hline 16 & Las personas jóvenes son valoradas, y tienen perspectivas de futuro seguras & 8,70 & 8,60 & $-4,44$ & $-4,30$ & 38,63 & 36,98 \\
\hline 17 & Eliminación de la pobreza & 9,20 & 8,60 & $-4,90$ & $-4,80$ & 45,08 & 41,28 \\
\hline 18 & Respeto por, y estricta aplicación de las leyes & 9,34 & 8,60 & $-5,72$ & $-3,10$ & 53,42 & 26,66 \\
\hline 19 & Trabajos seguros, satisfactorios y equitativamente pagados para todos los que quieren trabajar & 9,04 & 8,60 & $-4,86$ & $-4,40$ & 43,93 & 37,84 \\
\hline 20 & Fuerte protección social (edad, enfermedad, desempleo, etc.) & 9,32 & 8,50 & $-5,02$ & $-3,10$ & 46,79 & 26,35 \\
\hline 21 & Capacidad para confiar en otras personas, incluso extraños & 8,24 & 8,40 & $-5,04$ & $-4,50$ & 41,53 & 37,80 \\
\hline 22 & Ciudad atractiva y bien planificada & 8,10 & 8,30 & $-3,46$ & $-1,70$ & 28,03 & 14,11 \\
\hline 23 & Protección de la libertad religiosa & 8,44 & 8,20 & $-0,56$ & $-0,70$ & 4,73 & 5,74 \\
\hline 24 & Relaciones justas, limpias e independientes con otras naciones & 8,52 & 8,20 & $-3,68$ & $-2,10$ & 31,35 & 17,22 \\
\hline 25 & Altos niveles de progreso científico y tecnológico & 9,08 & 8,10 & $-4,28$ & $-1,30$ & 38,86 & 10,53 \\
\hline 26 & Vigorosa libertad de opinión, múltiples opiniones públicas (disensos) & 9,52 & 8,10 & $-3,42$ & $-1,80$ & 32,56 & 14,58 \\
\hline 27 & Las personas participan en la toma de decisiones de hechos que los afectan & 8,62 & 8,10 & $-4,28$ & $-3,00$ & 36,89 & 24,30 \\
\hline 28 & Atomización en la propiedad y control de los medios de comunicación & 7,38 & 7,90 & $-2,80$ & $-4,20$ & 20,66 & 33,18 \\
\hline 29 & Comunidades y organizaciones locales fuertes & 8,48 & 7,80 & $-4,02$ & $-1,80$ & 34,09 & 14,04 \\
\hline 30 & Libertad para hacer lo que nos gusta siempre que no perjudiquemos a otros & 9,30 & 7,40 & $-5,02$ & $-0,30$ & 46,69 & 2,22 \\
\hline 31 & Generosidad en ayudar a regiones perjudicadas & 9,40 & 7,00 & $-3,12$ & $-0,80$ & 29,33 & 5,60 \\
\hline 32 & No hay grandes diferencias en la riqueza y poder entre las personas & 8,60 & 6,80 & $-5,66$ & $-3,50$ & 48,68 & 23,80 \\
\hline 33 & Una fuerte economía de libre empresa y un gobierno eficiente en sus tareas básicas & 8,64 & 6,70 & $-4,76$ & $-0,60$ & 41,13 & 4,02 \\
\hline 34 & Establecer una economía fuerte antes que la equidad y las metas medioambientales & 6,92 & 5,20 & $-2,14$ & 1,60 & 14,81 & $-8,32$ \\
\hline \multirow[t]{4}{*}{35} & Las personas tienen valores sociales y estilos de vida similares & 6,48 & 4,50 & $-2,70$ & 0,10 & 17,50 & $-0,45$ \\
\hline & & & \multicolumn{3}{|c|}{ Promedio Total } & 39,23 & 24,87 \\
\hline & & & \multirow{2}{*}{\multicolumn{3}{|c|}{$\begin{array}{l}\text { Promedio } 5 \text { más importantes } \\
\text { Promedio } 10 \text { más importantes }\end{array}$}} & 54,32 & 38,03 \\
\hline & & & & & & 48,18 & 36,87 \\
\hline
\end{tabular}

La gravedad promedio en cuanto al estado general de las diferentes características para Berisso es de 39 puntos; mientras que para Australia, es de 25 puntos (un 58\% mayor para Berisso).

La gravedad promedio para las cinco características más importantes es de 54 puntos para Berisso contra 38 puntos en el caso de Australia (un 52\% mayor para Berisso). Si el análisis se lleva a las diez características de mayor relevancia, la gravedad promedia 48 puntos para Berisso versus 37 puntos para Australia (un 31\% mayor para Berisso). 
Según los resultados obtenidos, las características que la sociedad de Berisso entiende que están en una situación más crítica son:

Tabla 26: Atributos de mayor Gravedad Percibida. Berisso

\begin{tabular}{|c|l|c|}
\cline { 2 - 2 } \multicolumn{2}{l|}{} & $\begin{array}{c}\text { Gravedad } \\
\text { Percibida } \\
\text { Berisso }\end{array}$ \\
\hline Item & \multicolumn{1}{|c|}{ Características } & $\begin{array}{c}\text { Ponderación } \\
(\mathbf{e}=-\mathbf{d} \mathbf{x} \text { a) }\end{array}$ \\
\hline $\mathbf{1}$ & Altos niveles de honestidad en la política y la vida pública & $\mathbf{6 2 , 0 8}$ \\
\hline $\mathbf{5}$ & Eliminación del crimen y la violencia & $\mathbf{5 9 , 7 2}$ \\
\hline $\mathbf{9}$ & Confianza justificada en que las instituciones públicas actúan con limpieza y justicia & $\mathbf{5 7 , 4 5}$ \\
\hline $\mathbf{2}$ & Todos son tratados igualitaria y equitativamente por la ley & $\mathbf{5 7 , 4 3}$ \\
\hline $\mathbf{1 8}$ & Respeto por, y estricta aplicación de las leyes & $\mathbf{5 3 , 4 2}$ \\
\hline
\end{tabular}

$\rightarrow$ De estas características, "Altos niveles de honestidad en la política y la vida pública" y "Todos son tratados igualitaria y equitativamente ante la ley" se encuentran entre las cinco más importantes para la sociedad de Berisso según las puntuaciones asignadas.

Según los resultados obtenidos, las características que la sociedad de Berisso entiende que están en una situación más favorable son:

Tabla 27: Atributos de menor Gravedad Percibida. Berisso

\begin{tabular}{|c|c|c|}
\hline & & $\begin{array}{c}\text { Gravedad } \\
\text { Percibida } \\
\text { Berisso } \\
\end{array}$ \\
\hline Item & Características & $\begin{array}{c}\text { Ponderación } \\
(e=-d x \text { a) }\end{array}$ \\
\hline 7 & Protección de la libertad religiosa & 4,73 \\
\hline 28 & Establecer una economía fuerte antes que la equidad y las metas medioambientales & 14,81 \\
\hline 35 & Las personas tienen valores sociales y estilos de vida similares & 17,50 \\
\hline 34 & Atomización en la propiedad y control de los medios de comunicación & 20,66 \\
\hline 23 & Igualdad de oportunidades para hombres y mujeres & 24,17 \\
\hline
\end{tabular}

$\rightarrow$ De estas características, ninguna se encuentra entre las cinco más importantes para la sociedad de Berisso según las puntuaciones asignadas. Sin embargo, "Igualdad de oportunidades para hombres y mujeres" se encuentra entre las 10 más importantes (puesto 8). 


\subsection{Análisis de correlaciones}

Para verificar si existe relación entre las variables demográficas y las respuestas obtenidas en la encuesta, se llevó a cabo un análisis de etha cuadrado entre cada una de las siguientes variables:

demográficas:

- Importancia de los atributos con las siguientes variables

- Zona: Berisso

- Grupos Etarios: de 20 a 24, de 25 a 29, de 30 a 34, de 35 a 39, de 40 a 44 , de 45 a 49 , de 50 a 54 , de 55 a 59 y de 60 a 64 años de edad.

- Sexo: masculino y femenino.

- Educación: primaria incompleta, secundaria incompleta, terciaria o universitaria incompleta, terciaria o universitaria completa, postgrado completo.

- Ocupación: desocupado, jubilado, ama de casa, relación de dependencia tiempo parcial, relación de dependencia tiempo completo, profesional independiente, comerciante y empresario.

- Desempeño de los atributos con las siguientes variables demográficas:

- Zona: Berisso

- Grupos Etarios: de 20 a 24, de 25 a 29, de 30 a 34, de 35 a 39, de 40 a 44 , de 45 a 49 , de 50 a 54, de 55 a 59 y de 60 a 64 años de edad.

- Sexo: masculino y femenino.

- Educación: primaria incompleta, secundaria incompleta, terciaria o universitaria incompleta, terciaria o universitaria completa, postgrado completo.

- Ocupación: desocupado, jubilado, ama de casa, relación de dependencia tiempo parcial, relación de dependencia tiempo completo, profesional independiente, comerciante y empresario.

- Discrepancia entre la importancia y el desempeño de los atributos con las siguientes variables demográficas:

- Zona: Berisso 
- Grupos Etarios: de 20 a 24, de 25 a 29, de 30 a 34, de 35 a 39, de 40 a 44 , de 45 a 49 , de 50 a 54, de 55 a 59 y de 60 a 64 años de edad.

- Sexo: masculino y femenino.

- Educación: primaria incompleta, secundaria incompleta, terciaria o universitaria incompleta, terciaria o universitaria completa, postgrado completo.

- Ocupación: desocupado, jubilado, ama de casa, relación de dependencia tiempo parcial, relación de dependencia tiempo completo, profesional independiente, comerciante y empresario.

- Gravedad percibida en cada uno de los atributos con las siguientes variable demográficas:

- Zona: Berisso

- Grupos Etarios: de 20 a 24, de 25 a 29, de 30 a 34, de 35 a 39, de 40 a 44 , de 45 a 49 , de 50 a 54 , de 55 a 59 y de 60 a 64 años de edad.

- Sexo: masculino y femenino.

- Educación: primaria incompleta, secundaria incompleta, terciaria o universitaria incompleta, terciaria o universitaria completa, postgrado completo.

- Ocupación: desocupado, jubilado, ama de casa, relación de dependencia tiempo parcial, relación de dependencia tiempo completo, profesional independiente, comerciante y empresario.

Al respecto se pudo observar para cada una de las correlaciones realizadas, que los valores de etha cuadrado se encuentran entre 0 y 0,25 (Ver Anexo 10.2.4), es decir, no existe relación significativa entre las respuestas obtenidas por los encuestados y las variables demográficas analizadas. 


\section{Conclusiones}

En el presente estudio se han analizado diferentes variables para poder identificar similitudes y diferencias entre los componentes culturales de una sociedad desarrollada y otra en vías de desarrollo. Para ello se realizó un estudio sobre la población de Berisso y la población de la región conformada por La Plata, Berisso y Ensenada para luego contrastarlo con un estudio previo realizado sobre la sociedad australiana.

Al comparar los resultados de las jerarquías basadas en la importancia que las poblaciones de Berisso por un lado, y la de Australia por el otro le asignan a las mismas, se observa que dentro del grupo de características bajo estudio, ambas coinciden en cuatro de las cinco de mayor relevancia aunque jerarquizadas de distinta manera, verificando que a pesar de estar en entornos diferentes, las personas reconocen de manera similar aquellos atributos más importantes para el bienestar social.

Esto nos permite comprender que en general las respuestas de la población de Berisso presentan una tendencia similar a las de Australia, es decir, ambas comparten un grupo de valores similares al momento de analizar a sus sociedades.

Al momento de comparar el desempeño promedio para las cinco características más importantes, aparece la primera diferencia significativa entre ambas sociedades, siendo el valor resultante para Australia de un $20 \%$ superior respecto al resultado obtenido para Berisso. Si extendemos el análisis a las diez primeras características, la brecha disminuye, ya que en este caso hay un $13 \%$ de diferencia a favor de Australia. Esto quiere decir, que si bien ambas sociedades desean que se cumplan los mismos atributos, en la realidad el desempeño es muy diferente. Por lo tanto, la situación de estas características en la sociedad australiana es percibida en promedio como mejor por su población, en comparación con lo que sucede en Berisso.

Si profundizamos este análisis, notaremos que el atributo de peor desempeño según la población de Berisso es "Altos niveles de honestidad en la 
política y la vida pública", cuando en la sociedad australiana ocupa el puesto número 8 entre los 35 atributos. Aquí podemos encontrar una de las causas que favorecen o entorpecen el desarrollo de una sociedad.

Siguiendo esta línea, los atributos donde mayor diferencia se observa entre Australia y Berisso son: "Libertad para hacer lo que nos gusta siempre que no perjudiquemos a otros", "Una fuerte economía de libre empresa y un gobierno eficiente en sus tareas básicas", "Respeto por y estricta aplicación de las leyes", "Confianza justificada en que las instituciones públicas actúan con limpieza y justicia" y "Establecer una economía fuerte antes que la equidad y las metas medioambientales". Se aprecia que estos factores al no desempeñarse en la medida que la sociedad espera, se convierten en obstaculizadores para el desarrollo.

Llaman la atención particularmente dos atributos que denotan un mejor desempeño en Berisso que en Australia. Ellos son "Todos pagan impuestos equitativamente, acorde con el ingreso y riqueza" y "Eliminación de la pobreza". Del análisis general se puede inferir que esto se debe a las diferentes percepciones y exigencias que sobre un mismo atributo tiene una sociedad desarrolla y otra en vías de desarrollo.

Por otro lado, cuando se compara a la ciudad de Berisso con la región de La Plata, Berisso y Ensenada, las diferencias son mínimas, ya que entre los 5 atributos de peor desempeño coinciden en todos.

En relación a la discrepancia, al comparar las brechas existentes entre la importancia asignada a las diferentes características y el desempeño de las mismas, según las percepciones de la sociedad, se comienzan a evidenciar los puntos donde la sociedad australiana se encuentra en una mejor posición respecto a la sociedad bajo estudio.

Si se toman los 5 atributos de mayor discrepancia en Berisso y en Australia, hay una brecha de un $12 \%$ superior en Berisso, denotando un escenario menos favorable para el desarrollo humano, en contraposición de lo que sucede en la comunidad australiana. A esta conclusión se llega porque el 
indicador de discrepancia justamente ayuda a comprender cuánto se aleja de la realidad el desempeño de los atributos en función de la importancia que les fue otorgada por la sociedad. Si extendemos el análisis a las diez primeras características, la brecha se profundiza hasta un $22 \%$ promedio, favorable para la sociedad australiana.

En relación al análisis de la gravedad percibida, se vuelve a comprobar lo disímiles de las situaciones en ambas sociedades.

La gravedad promedio en cuanto al estado general de las diferentes características para Berisso es un 58\% mayor respecto a los valores de Australia. Así como se hizo referencia a las escuelas institucionalistas donde se menciona que existen características, capacidades y condiciones que debe tener una sociedad para lograr un entorno que favorezca su desarrollo, aquí se destacan los atributos "Altos niveles de honestidad en la política y la vida pública", "Todos son tratados igualitaria y equitativamente por la ley" y "Eliminación del crimen y la violencia", que tienen altos índices de gravedad percibida y son considerados dentro de las características más importantes para la sociedad de Berisso, convirtiéndose entonces el factores que obstaculizan el desarrollo de esa sociedad.

El análisis de la gravedad de las situaciones de las principales características expone que las condiciones en las que se encuentra la sociedad de Berisso resultan más adversas en comparación a las de Australia.

Siguiendo el análisis y haciendo foco en el índice de desarrollo humano utilizado para medir y comparar el desarrollo de los países y otras escalas territoriales, se ha mencionado que la última actualización del 2012 refleja que Australia se ubica en el segundo puesto mientras que la Argentina aparece en la posición número cuarenta y cinco. Esto se alinea con los resultados alcanzados en la presente investigación dado que si se analizan los atributos que refieren a los factores claves considerados en la medición del índice (indicador social, de salud y económico) se evidencia que en líneas generales la situación argentina se muestra desfavorable respecto a la australiana. 
Cuando se habla de desarrollo, debe tenerse en cuenta que el mismo se hace evidente de diversas maneras, entre ellas en el avance y progreso tecnológico. En este caso la sociedad de Berisso percibe una gravedad de un $284 \%$ mayor. Esto plantea un escenario con mayores obstáculos para lograr las condiciones necesarias para alcanzar el desarrollo esperado.

Sintetizando lo anteriormente expuesto, se observa que a pesar que a nivel individual la población de Berisso y la australiana demuestran intereses similares a la hora de jerarquizar los atributos, cuando se traslada al plano colectivo y se evalúa el desempeño, se evidencian mejores resultados para la sociedad australiana frente a lo que sucede en Berisso. Mientras que cuando se traslada ese mismo análisis a la relación entre la sociedad de Berisso y la sociedad de la Región de La Plata, Berisso y Ensenada, el comportamiento y los intereses son muy similares, sin diferencias significativas.

En definitiva, las anteriormente mencionadas son las características que pueden favorecer $u$ obstaculizar el desarrollo en su conjunto, y de su desempeño dependen las condiciones que permitan el logro de aquellos aspectos más importantes para cada sociedad. 


\section{Bibliografía}

- Australia Bureau of Statistics <http://www.abs.gov.au/>

- Cardoso, F. H., \& Faletto, E. (1979). Dependency and Development in Latin America (Dependencia y Desarrollo en América Latina, Engl.). Univ of California Press, 133.

- Cochrane, P. (1980). Industrialization and dependence: Australia's road to economic development, 1870-1939. University of Queensland Press, 3-4.

- Comparato, G. (2012). Capital Social: consideraciones metódicasconceptuales del rol de las comunidades locales. FCE, UNLP. La Plata, Buenos Aires, Argentina.

- Ferrer, A., \& Wheelwright, E. L. (1966). Industrialization in Argentina and Australia: a comparative study. Instituto Torcuato di Tella, Centro de Investigaciones Económicas, III-V.

- Figueroa Díaz, M. E. (2006). Políticas culturales para el desarrollo en un contexto mundializado.

- Fillol, T. R. (1961). Social factors in economic development: The Argentine case. Cambridge, Mass.: MIT Press, 3.

- Fogarty, J., Gallo, E., \& Diéguez, H. L. (1979). Argentina y Australia (Vol. 201). Buenos Aires, Argentina: Instituto Torcuato Di Tella, 183.

- Harrison, L. E. (1991). El subdesarrollo es un estado de la mente. El caso latinoamericano, Costa Rica, Libro Libre, 207.

- INDEC. Censo Nacional de Población, Hogares y Viviendas 2001 y 2010.

- Instituto Internacional de Gobernabilidad Barcelona (1998). Douglass C. North: La teoría económica neo-institucionalista y el desarrollo latinoamericano. Proyecto PNUD "Red para la Gobernabilidad y el Desarrollo en Desarrollo en América Latina".

- Kliksberg, B. (2000). Capital social y cultura: claves olvidadas del desarrollo. Banco de Intercambio de Desarrollo. Departamento de Integración y Programas Regionales. Publicaciones del Instituto para la Integración de América Latina y el Caribe. Buenos Aires, Argentina.

- Klugman, J. (2010). La verdadera riqueza de las naciones: Caminos al desarrollo humano (Informe sobre desarrollo humano). Edición del Vigésimo Aniversario.

- Mac Gann, T. F. (1966). Argentina: the divided land (Vol. 28). Princeton, $\mathrm{NJ}$ : Van Nostrand, 98, 110-113.

- Maraña, M. (2010). Cultura y desarrollo: evolución y perspectivas. UNESCO Etxea. 
- Marchesi, A., \& Espíndola, E. (2012). Avanzar en la construcción de un espacio cultural compartido: desarrollo de la carta cultural iberoamericana.

- Moran, T. H. (1970). The development of Argentina and Australia: the radical party of Argentina and the labor party of Australia in the process of economic and political development. Comparative Politics, 71-92.

- Oliveras, F. A. C. (1996). Economía heterodoxa: Aportes recientes del institucionalismo. Universidad de Puerto Rico, Recinto de Río Piedras, Departamento de Economía, Unidad de Investigaciones Económicas.

- Popper, S. K. R. (1985). La sociedad abierta y sus enemigos. Orbis.

- Programa de las Naciones Unidas para el Desarrollo. (2013). Informe sobre Desarrollo Humano 2013: El ascenso del Sur: Progreso humano en un mundo diverso.

- Pulido, D. U., Casero, J. C. D., \& Mogollón, R. H. (2007). Evolución y principios de la teoría económica institucional: una propuesta de aplicación para el análisis de los factores condicionantes de la creación de empresas. Investigaciones europeas de dirección y economía de la empresa, 13(3), 183-198.

- Rojas, M. G. (2011). La Medición del Progreso y del Bienestar. Propuestas desde América Latina.

- Salvaris, M. (2000). Community and social indicators: How citizens can measure progress. Institute for Social Research, Swinburne University of Technology, Melbourne.

- Sen, A. (1998). La cultura como base del desarrollo contemporáneo. Instituto Veracruzano de Cultura.

- Smithies, A. (1965). Argentina and Australia. The American Economic Review, 17-30.

- UNESCO (1982). Declaración de México sobre las políticas culturales. Conferencia Mundial sobre las Políticas Culturales. México DF, 26 de julio6 de agosto de 1982.

- United Nations. Development Reports. Countries and HDI ranks in 2013 and change in rank from 2012 to 2013. 2013.

- Vázquez Barquero, A. (1988). Desarrollo Local. Una estrategia de creación de empleo. Ed. Pirámide. Madrid. Pág. 78. 


\section{Anexos}

\subsection{Modelo de Encuestas}

\begin{tabular}{|c|c|c|c|c|}
\hline \multicolumn{4}{|c|}{ Influencia de los valores de la Sociedad en su desarrollo } & \multirow[b]{2}{*}{ Resp } \\
\hline No & ¿Cuán importante es para usted... & Resp & Califique en que medida se da en la realidad... & \\
\hline 1 & $\begin{array}{l}\text { que existan altos niveles de honestidad en la vida } \\
\text { pública y política? }\end{array}$ & & $\begin{array}{l}\text { la existencia de altos niveles de honestidad en la vida } \\
\text { pública y política. }\end{array}$ & \\
\hline 2 & $\begin{array}{l}\text { que todos los ciudadanos sean tratados igualitaria y } \\
\text { equitativamente por la ley? }\end{array}$ & & $\begin{array}{l}\text { que todos los ciudadanos son tratados igualitaria y } \\
\text { equitativamente por la ley. }\end{array}$ & \\
\hline 3 & $\begin{array}{l}\text { que los derechos humanos básicos de todos los } \\
\text { ciudadanos estén fuertemente protegidos? }\end{array}$ & & $\begin{array}{l}\text { que los derechos humanos básicos de todos los } \\
\text { ciudadanos están fuertemente protegidos. }\end{array}$ & \\
\hline 4 & $\begin{array}{l}\text { una buena calidad de los servicios básicos (salud, } \\
\text { educación, etc.) para todos? }\end{array}$ & & $\begin{array}{l}\text { la existencia de una buena calidad de los servicios } \\
\text { básicos (salud, educación, etc.) para todos. }\end{array}$ & \\
\hline 5 & la eliminación del crimen y la violencia? & & $\begin{array}{l}\text { una tendencia a la eliminación del crimen y la } \\
\text { violencia. }\end{array}$ & \\
\hline 6 & $\begin{array}{l}\text { la protección del medioambiente, los recursos y la } \\
\text { fauna? }\end{array}$ & & $\begin{array}{l}\text { la protección del medioambiente, los recursos y la } \\
\text { fauna. }\end{array}$ & \\
\hline 7 & $\begin{array}{l}\text { la igualdad de oportunidades para hombres y } \\
\text { mujeres? }\end{array}$ & & la igualdad de oportunidades para hombres y mujeres. & \\
\hline 8 & $\begin{array}{l}\text { que todos paguen impuestos equitativamente acorde } \\
\text { con el ingreso y la riqueza? }\end{array}$ & & $\begin{array}{l}\text { que todos pagan impuestos equitativamente acorde } \\
\text { con el ingreso y la riqueza. }\end{array}$ & \\
\hline 9 & $\begin{array}{l}\text { que las instituciones públicas actúen con limpieza y } \\
\text { justicia? }\end{array}$ & & $\begin{array}{l}\text { que las instituciones públicas actúan con limpieza y } \\
\text { justicia. }\end{array}$ & \\
\hline 10 & $\begin{array}{l}\text { una buena calidad de servicios públicos (transportes, } \\
\text { luz, etc.)? }\end{array}$ & & $\begin{array}{l}\text { la existencia de una buena calidad de servicios } \\
\text { públicos (transportes, luz, etc.) }\end{array}$ & \\
\hline 11 & $\begin{array}{l}\text { una buena atención a las personas vulnerables, } \\
\text { disminuidas y de clase baja? }\end{array}$ & & $\begin{array}{l}\text { una buena atención a las personas vulnerables, } \\
\text { disminuidas y de clase baja. }\end{array}$ & \\
\hline 12 & $\begin{array}{l}\text { la reducción de la contaminación medioambiental y el } \\
\text { desarrollo de fuentes de energía renovables? }\end{array}$ & & $\begin{array}{l}\text { la reducción de la contaminación medioambiental y el } \\
\text { desarrollo de fuentes de energía renovables. }\end{array}$ & \\
\hline 13 & $\begin{array}{l}\text { que las personas se sientan responsables por cada } \\
\text { uno de los demás y por la comunidad? }\end{array}$ & & $\begin{array}{l}\text { que las personas se sienten responsables por cada } \\
\text { uno de los demás y por la comunidad. }\end{array}$ & \\
\hline 14 & $\begin{array}{l}\text { que se cumpla que las personas que trabajan } \\
\text { duramente puedan tener éxito en la vida? }\end{array}$ & & $\begin{array}{l}\text { que las personas que trabajan duramente tengan éxito } \\
\text { en la vida. }\end{array}$ & \\
\hline 15 & la vida familiar y los valores de la familia? & & $\begin{array}{l}\text { que se dé importancia a la vida familiar y a los valores } \\
\text { de la familia. }\end{array}$ & \\
\hline 16 & $\begin{array}{l}\text { que las personas jóvenes sean valoradas y tengan un } \\
\text { futuro asegurado? }\end{array}$ & & $\begin{array}{l}\text { que las personas jóvenes son valoradas y tienen un } \\
\text { futuro asegurado. }\end{array}$ & \\
\hline 17 & $\begin{array}{l}\text { trabajar para la eliminación de la pobreza en nuestra } \\
\text { zona? }\end{array}$ & & $\begin{array}{l}\text { que se trabaja para la eliminación de la pobreza en } \\
\text { nuestra zona. }\end{array}$ & \\
\hline 18 & el respeto y la estricta aplicación de las leyes? & & el respeto y la estricta aplicación de las leyes. & \\
\hline 19 & $\begin{array}{l}\text { que existan trabajos seguros y equitativamente } \\
\text { pagados para todos los que quieren trabajar? }\end{array}$ & & $\begin{array}{l}\text { la existencia de trabajos seguros y equitativamente } \\
\text { pagados para todos los que quieren trabajar. }\end{array}$ & \\
\hline 20 & $\begin{array}{l}\text { la protección social (edad, enfermedad, desempleo, } \\
\text { etc.)? }\end{array}$ & & $\begin{array}{l}\text { la protección social (edad, enfermedad, desempleo, } \\
\text { etc.) }\end{array}$ & \\
\hline 21 & $\begin{array}{l}\text { que se puede confiar en otras personas, incluso en } \\
\text { extraños? }\end{array}$ & & $\begin{array}{l}\text { que se puede confiar en otras personas, incluso en } \\
\text { extraños. }\end{array}$ & \\
\hline 22 & que la ciudad sea atractiva y bien planificada? & & que la ciudad es atractiva y bien planificada. & \\
\hline 23 & que exista la libertad de religión? & & la existencia de la libertad de religión. & \\
\hline 24 & $\begin{array}{l}\text { que se den relaciones justas, limpias e } \\
\text { independientes con otras naciones? }\end{array}$ & & $\begin{array}{l}\text { que se dan relaciones justas, limpias e } \\
\text { independientes con otras naciones. }\end{array}$ & \\
\hline 25 & $\begin{array}{l}\text { que se den altos niveles de progreso científico y } \\
\text { tecnológico? }\end{array}$ & & $\begin{array}{l}\text { que se dan altos niveles de progreso científico y } \\
\text { tecnológico. }\end{array}$ & \\
\hline 26 & que exista la libertad de opinión y el disenso? & & la existencia de la libertad de opinión y el disenso. & \\
\hline 27 & $\begin{array}{l}\text { que las personas participen en la toma de decisiones } \\
\text { de hechos que las afectan? }\end{array}$ & & $\begin{array}{l}\text { que las personas participan en la toma de decisiones } \\
\text { de hechos que las afectan. }\end{array}$ & \\
\hline 28 & $\begin{array}{l}\text { la atomización en la propiedad y control de los medios } \\
\text { de comunicación? }\end{array}$ & & $\begin{array}{l}\text { la atomización en la propiedad y control de los medios } \\
\text { de comunicación. }\end{array}$ & \\
\hline 29 & $\begin{array}{l}\text { que la comunidad y las organizaciones locales sean } \\
\text { fuertes? }\end{array}$ & & $\begin{array}{l}\text { que la comunidad y las organizaciones locales son } \\
\text { fuertes. }\end{array}$ & \\
\hline 30 & $\begin{array}{l}\text { que no perjudiquemos a otros cuando libremente } \\
\text { hacemos lo que nos gusta? }\end{array}$ & & $\begin{array}{l}\text { que no perjudicamos a otros cuando libremente } \\
\text { hacemos lo que nos gusta. }\end{array}$ & \\
\hline 31 & $\begin{array}{l}\text { que haya generosidad en ayudar a regiones } \\
\text { perjudicadas? }\end{array}$ & & $\begin{array}{l}\text { que hay generosidad en ayudar a regiones } \\
\text { perjudicadas. }\end{array}$ & \\
\hline 32 & $\begin{array}{l}\text { que no haya grandes diferencias en la riqueza y poder } \\
\text { entre las personas? }\end{array}$ & & $\begin{array}{l}\text { que no hay grandes diferencias en la riqueza y poder } \\
\text { entre las personas. }\end{array}$ & \\
\hline 33 & $\begin{array}{l}\text { que exista una fuerte economía de libre empresa y un } \\
\text { gobierno eficiente en sus tareas básicas? }\end{array}$ & & $\begin{array}{l}\text { la existencia de una fuerte economía de libre empresa } \\
\text { y un gobierno eficiente en sus tareas básicas. }\end{array}$ & \\
\hline 34 & $\begin{array}{l}\text { que se establezca una economía fuerte antes que la } \\
\text { equidad y las metas medioambientales? }\end{array}$ & & $\begin{array}{l}\text { el establecimiento de una economía fuerte antes que } \\
\text { la equidad y las metas medioambientales. }\end{array}$ & \\
\hline 35 & $\begin{array}{l}\text { que las personas tengan valores sociales y estilos de } \\
\text { vida similares? }\end{array}$ & & $\begin{array}{l}\text { que las personas tienen valores sociales y estilos de } \\
\text { vida similares. }\end{array}$ & \\
\hline
\end{tabular}




\section{Perfil del respondente}

Sexo: $\quad 1 \square$ Masculino $\quad 2 \square$ Femenino

Edad:

Nivel de Educación

$1 \square$ Sin instrucción

$6 \square$ Terciaria o Univ. Incompleta

$2 \square$ Primaria Incompleta

$7 \square$ Terciaria o Univ. Completa

$3 \square$ Primaria Completa

$4 \square$ Secundaria Incompleta

$8 \square$ Posgrado Completo

$5 \square$ Secundaria Completa

$9 \square \mathrm{Ns} / \mathrm{Nc}$

Trabaja: $1 \square$ Desocupado

$2 \square$ Jubilado

$6 \square$ Profesional independiente

$3 \square$ Ama de casa

$7 \square$ Comerciante

$4 \square$ Relación de dependencia

$8 \square$ Empresario tiempo parcial

$5 \square$ Relación de dependencia tiempo completo 
Anexo II: Resultados obtenidos a través del análisis Etha Cuadrado:

\begin{tabular}{|c|c|c|c|c|}
\hline \multicolumn{5}{|c|}{ RESULTADOS ETHA CUADRADO - ANÁLISIS POR ZONA } \\
\hline Ítem & Importancia & Desempeño & Discrepancia & $\begin{array}{l}\text { Gravedad } \\
\text { Percibida }\end{array}$ \\
\hline 1 & 0,10 & 0,14 & 0,15 & 0,15 \\
\hline 2 & 0,09 & 0,15 & 0,15 & 0,15 \\
\hline 3 & 0,12 & 0,17 & 0,15 & 0,14 \\
\hline 4 & 0,09 & 0,08 & 0,07 & 0,07 \\
\hline 5 & 0,17 & 0,17 & 0,17 & 0,16 \\
\hline 6 & 0,12 & 0,13 & 0,14 & 0,14 \\
\hline 7 & 0,11 & 0,14 & 0,15 & 0,14 \\
\hline 8 & 0,12 & 0,08 & 0,10 & 0,11 \\
\hline 9 & 0,10 & 0,12 & 0,10 & 0,09 \\
\hline 10 & 0,16 & 0,09 & 0,10 & 0,11 \\
\hline 11 & 0,13 & 0,10 & 0,12 & 0,12 \\
\hline 12 & 0,13 & 0,16 & 0,15 & 0,16 \\
\hline 13 & 0,10 & 0,11 & 0,08 & 0,07 \\
\hline 14 & 0,12 & 0,10 & 0,07 & 0,09 \\
\hline 15 & 0,13 & 0,19 & 0,19 & 0,19 \\
\hline 16 & 0,09 & 0,20 & 0,17 & 0,16 \\
\hline 17 & 0,07 & 0,09 & 0,11 & 0,11 \\
\hline 18 & 0,18 & 0,11 & 0,12 & 0,13 \\
\hline 19 & 0,05 & 0,09 & 0,05 & 0,05 \\
\hline 20 & 0,09 & 0,12 & 0,14 & 0,15 \\
\hline 21 & 0,05 & 0,10 & 0,08 & 0,06 \\
\hline 22 & 0,11 & 0,18 & 0,15 & 0,14 \\
\hline 23 & 0,07 & 0,14 & 0,13 & 0,13 \\
\hline 24 & 0,12 & 0,18 & 0,14 & 0,15 \\
\hline 25 & 0,15 & 0,18 & 0,22 & 0,22 \\
\hline 26 & 0,08 & 0,06 & 0,06 & 0,06 \\
\hline 27 & 0,07 & 0,12 & 0,09 & 0,09 \\
\hline 28 & 0,13 & 0,15 & 0,13 & 0,16 \\
\hline 29 & 0,12 & 0,18 & 0,18 & 0,17 \\
\hline 30 & 0,17 & 0,19 & 0,19 & 0,18 \\
\hline 31 & 0,14 & 0,12 & 0,14 & 0,16 \\
\hline 32 & 0,07 & 0,09 & 0,09 & 0,12 \\
\hline 33 & 0,15 & 0,06 & 0,08 & 0,09 \\
\hline 34 & 0,12 & 0,14 & 0,13 & 0,12 \\
\hline 35 & 0,07 & 0,13 & 0,06 & 0,08 \\
\hline
\end{tabular}




\begin{tabular}{|c|c|c|c|c|}
\hline \multicolumn{5}{|c|}{ RESULTADOS ETHA CUADRADO - ANÁLISIS POR EDAD } \\
\hline Ítem & Importancia & Desempeño & Discrepancia & $\begin{array}{l}\text { Gravedad } \\
\text { Percibida }\end{array}$ \\
\hline 1 & 0,22 & 0,15 & 0,19 & 0,21 \\
\hline 2 & 0,15 & 0,20 & 0,23 & 0,23 \\
\hline 3 & 0,13 & 0,22 & 0,24 & 0,23 \\
\hline 4 & 0,15 & 0,15 & 0,17 & 0,17 \\
\hline 5 & 0,20 & 0,14 & 0,17 & 0,18 \\
\hline 6 & 0,17 & 0,15 & 0,18 & 0,18 \\
\hline 7 & 0,19 & 0,21 & 0,22 & 0,21 \\
\hline 8 & 0,17 & 0,18 & 0,20 & 0,20 \\
\hline 9 & 0,24 & 0,17 & 0,22 & 0,23 \\
\hline 10 & 0,21 & 0,17 & 0,21 & 0,22 \\
\hline 11 & 0,12 & 0,15 & 0,17 & 0,17 \\
\hline 12 & 0,19 & 0,12 & 0,12 & 0,14 \\
\hline 13 & 0,19 & 0,18 & 0,18 & 0,19 \\
\hline 14 & 0,13 & 0,08 & 0,12 & 0,12 \\
\hline 15 & 0,14 & 0,17 & 0,18 & 0,18 \\
\hline 16 & 0,16 & 0,14 & 0,16 & 0,17 \\
\hline 17 & 0,14 & 0,22 & 0,20 & 0,19 \\
\hline 18 & 0,23 & 0,19 & 0,23 & 0,23 \\
\hline 19 & 0,17 & 0,19 & 0,20 & 0,18 \\
\hline 20 & 0,09 & 0,16 & 0,16 & 0,15 \\
\hline 21 & 0,20 & 0,14 & 0,23 & 0,23 \\
\hline 22 & 0,12 & 0,11 & 0,11 & 0,12 \\
\hline 23 & 0,17 & 0,08 & 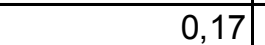 & 0,15 \\
\hline 24 & 0,18 & 0,08 & 0,14 & 0,14 \\
\hline 25 & 0,21 & 0,16 & 0,19 & 0,20 \\
\hline 26 & 0,16 & 0,18 & 0,22 & 0,22 \\
\hline 27 & 0,21 & 0,19 & 0,20 & 0,19 \\
\hline 28 & 0,20 & 0,14 & 0,22 & 0,23 \\
\hline 29 & 0,20 & 0,14 & 0,15 & 0,14 \\
\hline 30 & 0,17 & 0,18 & 0,17 & 0,16 \\
\hline 31 & 0,08 & 0,20 & 0,18 & 0,17 \\
\hline 32 & 0,18 & 0,20 & 0,20 & 0,19 \\
\hline 33 & 0,18 & 0,24 & 0,19 & 0,17 \\
\hline 34 & 0,16 & 0,19 & 0,17 & 0,15 \\
\hline 35 & 0,16 & 0,16 & 0,16 & 0,15 \\
\hline
\end{tabular}




\begin{tabular}{|c|c|c|c|c|}
\hline \multicolumn{5}{|c|}{ RESULTADOS ETHA CUADRADO - ANÁLISIS POR SEXO } \\
\hline Ítem & Importancia & Desempeño & Discrepancia & $\begin{array}{l}\text { Gravedad } \\
\text { Percibida }\end{array}$ \\
\hline 1 & 0,04 & 0,06 & 0,07 & 0,07 \\
\hline 2 & 0,02 & 0,12 & 0,12 & 0,11 \\
\hline 3 & 0,03 & 0,06 & 0,04 & 0,03 \\
\hline 4 & 0,03 & 0,13 & 0,11 & 0,10 \\
\hline 5 & 0,07 & 0,07 & 0,08 & 0,08 \\
\hline 6 & 0,02 & 0,12 & 0,08 & 0,08 \\
\hline 7 & 0,07 & 0,04 & 0,00 & 0,00 \\
\hline 8 & 0,07 & 0,09 & 0,11 & 0,10 \\
\hline 9 & 0,07 & 0,10 & 0,12 & 0,12 \\
\hline 10 & 0,00 & 0,10 & 0,08 & 0,08 \\
\hline 11 & 0,01 & 0,10 & 0,08 & 0,07 \\
\hline 12 & 0,10 & 0,17 & 0,08 & 0,06 \\
\hline 13 & 0,07 & 0,16 & 0,09 & 0,05 \\
\hline 14 & 0,08 & 0,06 & 0,02 & 0,07 \\
\hline 15 & 0,05 & 0,08 & 0,03 & 0,07 \\
\hline 16 & 0,03 & 0,08 & 0,08 & 0,08 \\
\hline 17 & 0,05 & 0,07 & 0,04 & 0,02 \\
\hline 18 & 0,07 & 0,11 & 0,12 & 0,12 \\
\hline 19 & 0,05 & 0,00 & 0,03 & 0,05 \\
\hline 20 & 0,02 & 0,07 & 0,05 & 0,05 \\
\hline 21 & 0,03 & 0,05 & 0,03 & 0,01 \\
\hline 22 & 0,11 & 0,06 & 0,11 & 0,12 \\
\hline 23 & 0,01 & 0,03 & 0,02 & 0,01 \\
\hline 24 & 0,04 & 0,02 & 0,05 & 0,06 \\
\hline 25 & 0,11 & 0,20 & 0,22 & 0,23 \\
\hline 26 & 0,03 & 0,03 & 0,04 & 0,05 \\
\hline 27 & 0,00 & 0,10 & 0,09 & 0,08 \\
\hline 28 & 0,07 & 0,10 & 0,13 & 0,13 \\
\hline 29 & 0,06 & 0,09 & 0,11 & 0,12 \\
\hline 30 & 0,02 & 0,01 & 0,02 & 0,02 \\
\hline 31 & 0,02 & 0,10 & 0,09 & 0,08 \\
\hline 32 & 0,06 & 0,08 & 0,09 & 0,09 \\
\hline 33 & 0,06 & 0,00 & 0,05 & 0,03 \\
\hline 34 & 0,00 & 0,01 & 0,00 & 0,01 \\
\hline 35 & 0,02 & 0,08 & 0,03 & 0,00 \\
\hline
\end{tabular}




\begin{tabular}{|c|c|c|c|c|}
\hline \multicolumn{5}{|c|}{ RESULTADOS ETHA CUADRADO - ANÁLISIS POR NIVEL EDUCATIVO } \\
\hline Ítem & Importancia & Desempeño & Discrepancia & $\begin{array}{l}\text { Gravedad } \\
\text { Percibida }\end{array}$ \\
\hline 1 & 0,24 & 0,14 & 0,20 & 0,22 \\
\hline 2 & 0,08 & 0,18 & 0,21 & 0,21 \\
\hline 3 & 0,13 & 0,16 & 0,16 & 0,17 \\
\hline 4 & 0,17 & 0,15 & 0,18 & 0,19 \\
\hline 5 & 0,18 & 0,22 & 0,25 & 0,25 \\
\hline 6 & 0,10 & 0,14 & 0,16 & 0,16 \\
\hline 7 & 0,18 & 0,17 & 0,18 & 0,17 \\
\hline 8 & 0,10 & 0,18 & 0,19 & 0,20 \\
\hline 9 & 0,14 & 0,15 & 0,15 & 0,15 \\
\hline 10 & 0,19 & 0,17 & 0,20 & 0,20 \\
\hline 11 & 0,12 & 0,23 & 0,23 & 0,23 \\
\hline 12 & 0,10 & 0,17 & 0,18 & 0,17 \\
\hline 13 & 0,14 & 0,20 & 0,24 & 0,23 \\
\hline 14 & 0,16 & 0,05 & 0,15 & 0,14 \\
\hline 15 & 0,13 & 0,18 & 0,19 & 0,19 \\
\hline 16 & 0,19 & 0,18 & 0,23 & 0,23 \\
\hline 17 & 0,08 & 0,18 & 0,18 & 0,18 \\
\hline 18 & 0,16 & 0,18 & 0,22 & 0,22 \\
\hline 19 & 0,23 & 0,14 & 0,18 & 0,19 \\
\hline 20 & 0,14 & 0,13 & 0,14 & 0,14 \\
\hline 21 & 0,19 & 0,13 & 0,21 & 0,23 \\
\hline 22 & 0,22 & 0,14 & 0,21 & 0,22 \\
\hline 23 & 0,13 & 0,18 & 0,19 & 0,18 \\
\hline 24 & 0,17 & 0,18 & 0,20 & 0,21 \\
\hline 25 & 0,09 & 0,14 & 0,16 & 0,15 \\
\hline 26 & 0,15 & 0,15 & 0,16 & 0,17 \\
\hline 27 & 0,09 & 0,19 & 0,14 & 0,12 \\
\hline 28 & 0,17 & 0,09 & 0,14 & 0,15 \\
\hline 29 & 0,12 & 0,08 & 0,15 & 0,17 \\
\hline 30 & 0,14 & 0,17 & 0,16 & 0,15 \\
\hline 31 & 0,18 & 0,10 & 0,10 & 0,10 \\
\hline 32 & 0,16 & 0,14 & 0,20 & 0,22 \\
\hline 33 & 0,19 & 0,12 & 0,21 & 0,24 \\
\hline 34 & 0,17 & 0,11 & 0,13 & 0,22 \\
\hline 35 & 0,18 & 0,13 & 0,21 & 0,22 \\
\hline
\end{tabular}




\begin{tabular}{|c|c|c|c|c|}
\hline \multicolumn{5}{|c|}{ RESULTADOS ETHA CUADRADO - ANÁLISIS POR SITUACIÓN LABORAL } \\
\hline Ítem & Importancia & Desempeño & Discrepancia & $\begin{array}{l}\text { Gravedad } \\
\text { Percibida }\end{array}$ \\
\hline 1 & 0,13 & 0,21 & 0,17 & 0,15 \\
\hline 2 & 0,11 & 0,16 & 0,18 & 0,19 \\
\hline 3 & 0,16 & 0,11 & 0,10 & 0,11 \\
\hline 4 & 0,11 & 0,17 & 0,17 & 0,16 \\
\hline 5 & 0,22 & 0,17 & 0,19 & 0,19 \\
\hline 6 & 0,10 & 0,13 & 0,09 & 0,09 \\
\hline 7 & 0,16 & 0,14 & 0,11 & 0,11 \\
\hline 8 & 0,19 & 0,21 & 0,23 & 0,24 \\
\hline 9 & 0,06 & 0,11 & 0,09 & 0,09 \\
\hline 10 & 0,19 & 0,19 & 0,16 & 0,16 \\
\hline 11 & 0,17 & 0,16 & 0,13 & 0,12 \\
\hline 12 & 0,16 & 0,18 & 0,15 & 0,15 \\
\hline 13 & 0,18 & 0,11 & 0,18 & 0,18 \\
\hline 14 & 0,17 & 0,16 & 0,15 & 0,14 \\
\hline 15 & 0,12 & 0,11 & 0,10 & 0,12 \\
\hline 16 & 0,16 & 0,09 & 0,16 & 0,16 \\
\hline 17 & 0,13 & 0,17 & 0,14 & 0,13 \\
\hline 18 & 0,11 & 0,12 & 0,13 & 0,13 \\
\hline 19 & 0,19 & 0,09 & 0,15 & 0,16 \\
\hline 20 & 0,09 & 0,13 & 0,10 & 0,10 \\
\hline 21 & 0,12 & 0,18 & 0,19 & 0,18 \\
\hline 22 & 0,17 & 0,08 & 0,14 & 0,14 \\
\hline 23 & 0,11 & 0,12 & 0,09 & 0,09 \\
\hline 24 & 0,16 & 0,12 & 0,13 & 0,13 \\
\hline 25 & 0,09 & 0,10 & 0,08 & 0,09 \\
\hline 26 & 0,19 & 0,19 & 0,15 & 0,15 \\
\hline 27 & 0,18 & 0,16 & 0,14 & 0,14 \\
\hline 28 & 0,13 & 0,15 & 0,15 & 0,17 \\
\hline 29 & 0,16 & 0,11 & 0,12 & 0,12 \\
\hline 30 & 0,06 & 0,10 & 0,08 & 0,08 \\
\hline 31 & 0,17 & 0,16 & 0,18 & 0,18 \\
\hline 32 & 0,18 & 0,10 & 0,16 & 0,17 \\
\hline 33 & 0,20 & 0,15 & 0,16 & 0,18 \\
\hline 34 & 0,20 & 0,16 & 0,12 & 0,12 \\
\hline 35 & 0,14 & 0,16 & 0,11 & 0,10 \\
\hline
\end{tabular}


10.2.1 Situación: La Plata, Berisso y Ensenada

\subsubsection{Importancia asignada a las características relevadas}

La tabla a continuación expone los resultados obtenidos en la encuesta realizada en la región de La Plata, Berisso y Ensenada.

\begin{tabular}{|c|c|c|c|}
\hline \multirow[b]{2}{*}{ Item } & \multirow[b]{2}{*}{ Características } & \multicolumn{2}{|c|}{ Importancia } \\
\hline & & \begin{tabular}{|c|} 
Calificación \\
$1-10$ (a)
\end{tabular} & \begin{tabular}{|c|} 
Jerarquía \\
1-35 (b)
\end{tabular} \\
\hline 2 & Todos son tratados igualitaria y equitativamente por la ley & 9,71 & 1 \\
\hline 4 & Buena calidad de los servicios básicos (salud, educación, etc.) para todos & 9,66 & 2 \\
\hline 3 & Los derechos humanos básicos de todos los ciudadanos están fuertemente protegidos & 9,61 & 3 \\
\hline 5 & Eliminación del crimen y la violencia & 9,52 & 4 \\
\hline 1 & Altos niveles de honestidad en la política y la vida pública & 9,47 & 5 \\
\hline 26 & Vigorosa libertad de opinión, múltiples opiniones públicas (disensos) & 9,43 & 6 \\
\hline 9 & Confianza justificada en que las instituciones públicas actúan con limpieza y justicia & 9,42 & 7 \\
\hline 7 & Igualdad de oportunidades para hombres y mujeres & 9,33 & 8 \\
\hline 18 & Respeto por, y estricta aplicación de las leyes & 9,28 & 9 \\
\hline 15 & Se alienta la vida familiar y los valores de la familia & 9,24 & 10 \\
\hline 20 & Fuerte protección social (edad, enfermedad, desempleo, etc.) & 9,20 & 11 \\
\hline 30 & Libertad para hacer lo que nos gusta siempre que no perjudiquemos a otros & 9,19 & 12 \\
\hline 11 & Buena atención a las personas vulnerables, disminuidos y de clase baja & 9,16 & 13 \\
\hline 17 & Eliminación de la pobreza & 9,14 & 14 \\
\hline 31 & Generosidad en ayudar a regiones perjudicadas & 9,13 & 15 \\
\hline 10 & Las comunidades locales tienen buena calidad de servicios públicos (transporte, luz, etc.) & 9,12 & 16 \\
\hline 19 & Trabajos seguros, satisfactorios y equitativamente pagados para todos los que quieren trabajar & 9,07 & 17 \\
\hline 6 & Protección del medioambiente, recursos y fauna & 9,01 & 18 \\
\hline 8 & Todos pagan impuestos equitativamente, acorde con el ingreso y riqueza & 8,99 & 19 \\
\hline 12 & Reducción de la contaminación medioambiental, desarrollo de fuentes de energía renovables & 8,93 & 20 \\
\hline 25 & Altos niveles de progreso científico y tecnológico & 8,84 & 21 \\
\hline 27 & Las personas participan en la toma de decisiones de hechos que los afectan & 8,76 & 22 \\
\hline 16 & Las personas jóvenes son valoradas, y tienen perspectivas de futuro seguras & 8,67 & 23 \\
\hline 23 & Protección de la libertad religiosa & 8,60 & 24 \\
\hline 24 & Relaciones justas, limpias e independientes con otras naciones & 8,56 & 25 \\
\hline 13 & Las personas se sienten responsables por cada uno de los demás y por la comunidad & 8,50 & 26 \\
\hline 14 & Las personas que trabajan duramente pueden tener éxito en la vida & 8,47 & 27 \\
\hline 33 & Una fuerte economía de libre empresa y un gobierno eficiente en sus tareas básicas & 8,46 & 28 \\
\hline 32 & No hay grandes diferencias en la riqueza y poder entre las personas & 8,43 & 29 \\
\hline 29 & Comunidades y organizaciones locales fuertes & 8,33 & 30 \\
\hline 21 & Capacidad para confiar en otras personas, incluso extraños & 8,22 & 31 \\
\hline 22 & Ciudad atractiva y bien planificada & 8,03 & 32 \\
\hline 28 & Atomización en la propiedad y control de los medios de comunicación & 7,55 & 33 \\
\hline 35 & Las personas tienen valores sociales y estilos de vida similares & 6,58 & 34 \\
\hline 34 & Establecer una economía fuerte antes que la equidad y las metas medioambientales & 6,51 & 35 \\
\hline
\end{tabular}

Según los datos procesados, las características que la población bajo análisis considera más importantes para el desarrollo de una sociedad son las siguientes:

* Todos son tratados igualitaria y equitativamente por la ley $(9,71$ puntos). 
* Buena calidad de los servicios básicos (salud, educación, etc.) para todos (9,66 puntos).

* Los derechos humanos básicos de todos los ciudadanos están fuertemente protegidos (9,61 puntos).

* Eliminación del crimen y la violencia (9,52 puntos).

* Altos niveles de honestidad en la política y la vida pública $(9,47$ puntos).

En cuanto a los atributos que menos relevancia se les ha dado, se encuentran:

* Establecer una economía fuerte antes que la equidad y las metas medioambientales. (6,51 puntos).

* Las personas tienen valores sociales y estilos de vida similares. (6,58 puntos).

* Atomización en la propiedad y control de los medios de comunicación. (7,55 puntos).

* Ciudad atractiva y bien planificada. (8,03 puntos).

* Capacidad para confiar en otras personas, incluso extraños. (8,22 puntos).

\subsubsection{Desempeño de real percibido para las características relevadas}

Como se explicó anteriormente, el desempeño real percibido para las características relevadas, es el resultante de las respuestas a las preguntas formuladas a partir de que en encuestado "Califique que en medida se da en la realidad...". Los resultados obtenidos fueron los siguientes: 


\begin{tabular}{|c|c|c|}
\hline \multirow[b]{2}{*}{ Item } & \multirow[b]{2}{*}{ Características } & Desempeño \\
\hline & & \begin{tabular}{|c} 
Calificación \\
$1-10(c)$
\end{tabular} \\
\hline 23 & Protección de la libertad religiosa & 7,78 \\
\hline 7 & Igualdad de oportunidades para hombres y mujeres & 6,89 \\
\hline 31 & Generosidad en ayudar a regiones perjudicadas & 6,58 \\
\hline 26 & Vigorosa libertad de opinión, múltiples opiniones públicas (disensos) & 6,26 \\
\hline 15 & Se alienta la vida familiar y los valores de la familia & 5,78 \\
\hline 24 & Relaciones justas, limpias e independientes con otras naciones & 5,48 \\
\hline 25 & Altos niveles de progreso científico y tecnológico & 5,47 \\
\hline 30 & Libertad para hacer lo que nos gusta siempre que no perjudiquemos a otros & 5,11 \\
\hline 28 & Atomización en la propiedad y control de los medios de comunicación & 5,06 \\
\hline 22 & Ciudad atractiva y bien planificada & 5,04 \\
\hline 3 & Los derechos humanos básicos de todos los ciudadanos están fuertemente protegidos & 5,01 \\
\hline 11 & Buena atención a las personas vulnerables, disminuidos y de clase baja & 5,00 \\
\hline 4 & Buena calidad de los servicios básicos (salud, educación, etc.) para todos & 4,98 \\
\hline 14 & Las personas que trabajan duramente pueden tener éxito en la vida & 4,94 \\
\hline 29 & Comunidades y organizaciones locales fuertes & 4,94 \\
\hline 34 & 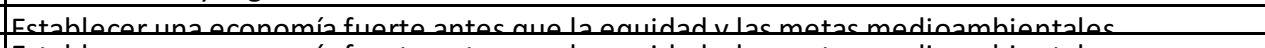 & $\triangle 92$ \\
\hline 34 & Establecer una economía fuerte antes que la equidad y las metas medioambientales & 4,93 \\
\hline 27 & Las personas participan en la toma de decisiones de hechos que los afectan & 4,82 \\
\hline 20 & Fuerte protección social (edad, enfermedad, desempleo, etc.) & 4,80 \\
\hline 16 & Las personas jóvenes son valoradas, y tienen perspectivas de futuro seguras & 4,79 \\
\hline 6 & Protección del medioambiente, recursos y fauna & 4,70 \\
\hline 10 & Las comunidades locales tienen buena calidad de servicios públicos (transporte, luz, etc.) & 4,66 \\
\hline 17 & Eliminación de la pobreza & 4,47 \\
\hline 19 & Trabajos seguros, satisfactorios y equitativamente pagados para todos los que quieren trabajar & 4,38 \\
\hline 8 & Todos pagan impuestos equitativamente, acorde con el ingreso y riqueza & 4,34 \\
\hline 2 & Todos son tratados igualitaria y equitativamente por la ley & 4,32 \\
\hline 13 & Las personas se sienten responsables por cada uno de los demás y por la comunidad & 4,23 \\
\hline 35 & Las personas tienen valores sociales y estilos de vida similares & 4,10 \\
\hline 12 & Reducción de la contaminación medioambiental, desarrollo de fuentes de energía renovables & 4,08 \\
\hline 33 & Una fuerte economía de libre empresa y un gobierno eficiente en sus tareas básicas & 3,96 \\
\hline 18 & Respeto por, y estricta aplicación de las leyes & 3,89 \\
\hline 9 & Confianza justificada en que las instituciones públicas actúan con limpieza y justicia & 3,81 \\
\hline 1 & Altos niveles de honestidad en la política y la vida pública & 3,68 \\
\hline 21 & Capacidad para confiar en otras personas, incluso extraños & 3,60 \\
\hline 5 & Eliminación del crimen y la violencia & 3,52 \\
\hline 32 & No hay grandes diferencias en la riqueza y poder entre las personas & 3,28 \\
\hline
\end{tabular}

\section{Las características que mejor desempeño percibido presentan según los} resultados de la encuesta son:

- Protección de la libertad religiosa. (7,78 puntos).

* Igualdad de oportunidades para hombres y mujeres. (6,89 puntos).

* Generosidad en ayudar a regiones perjudicadas. (6,58 puntos).

* Vigorosa libertad de opinión, múltiples opiniones públicas (disensos). $(6,26$ puntos).

* Se alienta la vida familiar y los valores de la familia. (5,78 puntos). 
$\rightarrow$ Ninguna de las características que mejor puntuación han recibido en materia de desempeño, está presente entre las consideradas más importantes para el grupo social bajo análisis.

Por su parte, las características en que la población percibe un peor desempeño resultaron ser:

* No hay grandes diferencias en la riqueza y poder entre las personas. $(3,28)$.

* Eliminación del crimen y la violencia. $(3,52)$.

- Capacidad para confiar en otras personas, incluso extraños. $(3,68)$

* Altos niveles de honestidad en la política y la vida pública. $(3,81)$.

* Confianza justificada en que las instituciones públicas actúan con limpieza y justicia. $(3,89)$.

$\rightarrow$ Dos de las características percibidas como de peor desempeño ("Eliminación del crimen..." y "Altos niveles de honestidad...") están presentes entre las consideradas más importantes para la misma población bajo análisis.

10.2.1.3 Discrepancia entre importancia asignada y desempeño percibido 
La siguiente tabla expone las discrepancias detectadas para cada una de las características relevadas.

\begin{tabular}{|c|c|c|}
\hline & & $\begin{array}{c}\text { Discrepancia } \\
\text { LP, B, E }\end{array}$ \\
\hline Item & Características & $\begin{array}{c}\text { Valor } \\
(\mathrm{d}=\mathrm{c}-\mathrm{a})\end{array}$ \\
\hline 23 & Protección de la libertad religiosa & $-0,82$ \\
\hline 34 & Establecer una economía fuerte antes que la equidad y las metas medioambientales & $-1,58$ \\
\hline 7 & Igualdad de oportunidades para hombres y mujeres & $-2,43$ \\
\hline 35 & Las personas tienen valores sociales y estilos de vida similares & $-2,48$ \\
\hline 28 & Atomización en la propiedad y control de los medios de comunicación & $-2,49$ \\
\hline 31 & Generosidad en ayudar a regiones perjudicadas & $-2,55$ \\
\hline 22 & Ciudad atractiva y bien planificada & $-2,99$ \\
\hline 24 & Relaciones justas, limpias e independientes con otras naciones & $-3,08$ \\
\hline 26 & Vigorosa libertad de opinión, múltiples opiniones públicas (disensos) & $-3,17$ \\
\hline 25 & Altos niveles de progreso científico y tecnológico & $-3,37$ \\
\hline 29 & Comunidades y organizaciones locales fuertes & $-3,39$ \\
\hline 15 & Se alienta la vida familiar y los valores de la familia & $-3,46$ \\
\hline 14 & Las personas que trabajan duramente pueden tener éxito en la vida & $-3,53$ \\
\hline 16 & Las personas jóvenes son valoradas, y tienen perspectivas de futuro seguras & $-3,89$ \\
\hline 27 & Las personas participan en la toma de decisiones de hechos que los afectan & $-3,95$ \\
\hline 30 & Libertad para hacer lo que nos gusta siempre que no perjudiquemos a otros & $-4,08$ \\
\hline 11 & Buena atención a las personas vulnerables, disminuidos y de clase baja & $-4,16$ \\
\hline 13 & Las personas se sienten responsables por cada uno de los demás y por la comunidad & $-4,27$ \\
\hline 6 & Protección del medioambiente, recursos y fauna & $-4,31$ \\
\hline 20 & Fuerte protección social (edad, enfermedad, desempleo, etc.) & $-4,41$ \\
\hline 10 & Las comunidades locales tienen buena calidad de servicios públicos (transporte, luz, etc.) & $-4,46$ \\
\hline 33 & Una fuerte economía de libre empresa y un gobierno eficiente en sus tareas básicas & $-4,50$ \\
\hline 3 & Los derechos humanos básicos de todos los ciudadanos están fuertemente protegidos & $-4,60$ \\
\hline 21 & Capacidad para confiar en otras personas, incluso extraños & $-4,62$ \\
\hline 8 & Todos pagan impuestos equitativamente, acorde con el ingreso y riqueza & $-4,64$ \\
\hline 17 & Eliminación de la pobreza & $-4,67$ \\
\hline 4 & Buena calidad de los servicios básicos (salud, educación, etc.) para todos & $-4,68$ \\
\hline 19 & Trabajos seguros, satisfactorios y equitativamente pagados para todos los que quieren trabajar & $-4,70$ \\
\hline 12 & Reducción de la contaminación medioambiental, desarrollo de fuentes de energía renovables & $-4,85$ \\
\hline 32 & No hay grandes diferencias en la riqueza y poder entre las personas & $-5,15$ \\
\hline 2 & Todos son tratados igualitaria y equitativamente por la ley & $-5,39$ \\
\hline 18 & Respeto por, y estricta aplicación de las leyes & $-5,39$ \\
\hline 9 & Confianza justificada en que las instituciones públicas actúan con limpieza y justicia & $-5,61$ \\
\hline 1 & Altos niveles de honestidad en la política y la vida pública & $-5,80$ \\
\hline 5 & Eliminación del crimen y la violencia & $-6,00$ \\
\hline
\end{tabular}

Las características donde la población percibe un desempeño real más cercano al nivel de importancia que le asigna son:

* Protección de la libertad religiosa. (-0,82 puntos de diferencia).

* Establecer una economía fuerte antes que la equidad y las metas medioambientales (-1,58 puntos de diferencia).

* Igualdad de oportunidades para hombres y mujeres. (-2,43 puntos de diferencia).

* Las personas tienen valores sociales y estilos de vida similares. (2,48 puntos de diferencia). 
Atomización en la propiedad y control de los medios de comunicación. (-2,49 puntos de diferencia).

$\rightarrow$ Tres de estas características son consideradas entre las menos importantes ("Establecer una economía..."; "Las personas tienen...”; "Atomización en la propiedad...").

Las mayores brechas se presentan en el siguiente grupo de características:

* Eliminación del crimen y la violencia (-6,00 puntos de diferencia).

* Altos niveles de honestidad en la política y la vida pública $(-5,80$ puntos de diferencia).

* Confianza justificada en que las instituciones públicas actúan con limpieza y justicia. (-5,61 puntos de diferencia).

* Todos son tratados igualitaria y equitativamente por la ley 5,39 puntos de diferencia).

* Respeto por, y estricta aplicación de las leyes. (-5,39 puntos de diferencia).

$\rightarrow$ En contraste con lo antes expuesto, tres de estas características son consideradas entre las más importantes según las puntuaciones asignadas por la población bajo estudio (“Todos son tratados...”; "Eliminación del crimen..."; "Altos niveles de honestidad...").

\subsubsection{Gravedad de la situación de las características analizadas}

La última etapa de procesamiento de resultados para la región de La Plata, Berisso y Ensenada, pretende medir la gravedad de la situación en que se encuentra cada característica estudiada según las percepciones de la población. Como ser explicó en la sección de metodología, esta "Gravedad" es la resultante de relacionar la importancia que una población le asigna a una característica, con la discrepancia que percibe en su desempeño. 


\begin{tabular}{|c|c|c|c|}
\hline \multirow[b]{2}{*}{ Item } & \multirow[b]{2}{*}{ Características } & \multicolumn{2}{|c|}{ Gravedad Percibida } \\
\hline & & $\begin{array}{c}\text { Ponderación } \\
(e=-d * a)\end{array}$ & $\begin{array}{r}\text { Jerarquía } \\
1-35 \text { (f) } \\
\end{array}$ \\
\hline 5 & Eliminación del crimen y la violencia & 58,29 & 1 \\
\hline 1 & Altos niveles de honestidad en la política y la vida pública & 55,73 & 2 \\
\hline 9 & Confianza justificada en que las instituciones públicas actúan con limpieza y justicia & 53,89 & 3 \\
\hline 2 & Todos son tratados igualitaria y equitativamente por la ley & 52,77 & 4 \\
\hline 18 & Respeto por, y estricta aplicación de las leyes & 51,48 & 5 \\
\hline 32 & No hay grandes diferencias en la riqueza y poder entre las personas & 47,30 & 6 \\
\hline 4 & Buena calidad de los servicios básicos (salud, educación, etc.) para todos & 45,73 & 7 \\
\hline 3 & Los derechos humanos básicos de todos los ciudadanos están fuertemente protegidos & 44,99 & 8 \\
\hline 12 & Reducción de la contaminación medioambiental, desarrollo de fuentes de energía renovables & 44,93 & 9 \\
\hline 19 & Trabajos seguros, satisfactorios y equitativamente pagados para todos los que quieren trabajar & 44,32 & 10 \\
\hline 8 & Todos pagan impuestos equitativamente, acorde con el ingreso y riqueza & 44,08 & 11 \\
\hline 17 & Eliminación de la pobreza & 43,83 & 12 \\
\hline 33 & Una fuerte economía de libre empresa y un gobierno eficiente en sus tareas básicas & 43,31 & 13 \\
\hline 10 & Las comunidades locales tienen buena calidad de servicios públicos (transporte, luz, etc.) & 41,93 & 14 \\
\hline 20 & Fuerte protección social (edad, enfermedad, desempleo, etc.) & 41,62 & 15 \\
\hline 6 & Protección del medioambiente, recursos y fauna & 40,58 & 16 \\
\hline 21 & Capacidad para confiar en otras personas, incluso extraños & 40,46 & 17 \\
\hline 11 & Buena atención a las personas vulnerables, disminuidos y de clase baja & 39,46 & 18 \\
\hline 30 & Libertad para hacer lo que nos gusta siempre que no perjudiquemos a otros & 38,87 & 19 \\
\hline 13 & Las personas se sienten responsables por cada uno de los demás y por la comunidad & 38,13 & 20 \\
\hline 27 & Las personas participan en la toma de decisiones de hechos que los afectan & 36,20 & 21 \\
\hline 16 & Las personas jóvenes son valoradas, y tienen perspectivas de futuro seguras & 35,78 & 22 \\
\hline 15 & Se alienta la vida familiar y los valores de la familia & 34,21 & 23 \\
\hline 14 & Las personas que trabajan duramente pueden tener éxito en la vida & 32,37 & 24 \\
\hline 25 & Altos niveles de progreso científico y tecnológico & 31,48 & 25 \\
\hline 29 & Comunidades y organizaciones locales fuertes & 30,67 & 26 \\
\hline 26 & Vigorosa libertad de opinión, múltiples opiniones públicas (disensos) & 30,45 & 27 \\
\hline 24 & Relaciones justas, limpias e independientes con otras naciones & 28,75 & 28 \\
\hline 22 & Ciudad atractiva y bien planificada & 27,41 & 29 \\
\hline 35 & Las personas tienen valores sociales y estilos de vida similares & 24,52 & 30 \\
\hline 31 & Generosidad en ayudar a regiones perjudicadas & 24,23 & 31 \\
\hline 7 & Igualdad de oportunidades para hombres y mujeres & 23,86 & 32 \\
\hline 28 & Atomización en la propiedad y control de los medios de comunicación & 23,80 & 33 \\
\hline 34 & Establecer una economía fuerte antes que la equidad y las metas medioambientales & 18,95 & 34 \\
\hline 23 & Protección de la libertad religiosa & 10,63 & 35 \\
\hline
\end{tabular}

\section{Según los resultados obtenidos, las características que esta sociedad} entiende que están en una situación más crítica son:

* Eliminación del crimen y la violencia. (58,29 puntos).

* Altos niveles de honestidad en la política y la vida pública. (55,73 puntos).

* Confianza justificada en que las instituciones públicas actúan con limpieza y justicia. (53,89 puntos).

* Todos son tratados igualitaria y equitativamente por la ley. (52,77 puntos).

* Respeto por, y estricta aplicación de las leyes. (51,48 puntos).

En cambio, las siguientes características se presentan con un menor nivel de gravedad: 
* Protección de la libertad religiosa. (10,63 puntos).

* Establecer una economía fuerte antes que la equidad y las metas medioambientales (18,95 puntos).

- Atomización en la propiedad y control de los medios de comunicación. (23,80 puntos).

* Igualdad de oportunidades para hombres y mujeres. (23,86 puntos).

* Generosidad en ayudar a regiones perjudicadas. (24,23 puntos).

$\rightarrow$ Es destacable la presencia de la característica "Igualdad de oportunidades..." que se encuentra entre las diez más importantes para la población bajo análisis, y a su vez es un aspecto en el que se tiene un buen desempeño.

\subsubsection{Situación: Australia}

\subsubsection{Importancia asignada a las características relevadas}

La tabla a continuación expone los resultados obtenidos en la encuesta realizada para el proyecto desarrollado en Australia. 


\begin{tabular}{|c|c|c|c|}
\hline \multirow[b]{2}{*}{ Item } & \multirow[b]{2}{*}{ Características } & \multicolumn{2}{|c|}{ Importancia } \\
\hline & & $\begin{array}{c}\text { Calificación 1- } \\
10 \text { (a) }\end{array}$ & $\begin{array}{l}\text { Jerarquía 1-35 } \\
\text { (b) }\end{array}$ \\
\hline 1 & Altos niveles de honestidad en la política y la vida pública & 9,30 & 1 \\
\hline 3 & Los derechos humanos básicos de todos los ciudadanos están fuertemente protegidos & 9,10 & 3 \\
\hline 4 & Buena calidad de los servicios básicos (salud, educación, etc.) para todos & 9,10 & 4 \\
\hline 7 & Igualdad de oportunidades para hombres y mujeres & 9,00 & 7 \\
\hline 8 & Todos pagan impuestos equitativamente, acorde con el ingreso y riqueza & 9,00 & 8 \\
\hline 9 & Confianza justificada en que las instituciones públicas actúan con limpieza y justicia & 9,00 & 9 \\
\hline 10 & Las comunidades locales tienen buena calidad de servicios públicos (transporte, luz, etc.) & 9,00 & 10 \\
\hline 11 & Buena atención a las personas vulnerables, disminuidos y de clase baja & 8,80 & 11 \\
\hline 15 & Se alienta la vida familiar y los valores de la familia & 8,60 & 15 \\
\hline 16 & Las personas jóvenes son valoradas, y tienen perspectivas de futuro seguras & 8,60 & 16 \\
\hline 17 & Eliminación de la pobreza & 8,60 & 17 \\
\hline 18 & Respeto por, y estricta aplicación de las leyes & 8,60 & 18 \\
\hline 19 & Trabajos seguros, satisfactorios y equitativamente pagados para todos los que quieren trabajar & 8,60 & 19 \\
\hline 20 & Fuerte protección social (edad, enfermedad, desempleo, etc.) & 8,50 & 20 \\
\hline 21 & Capacidad para confiar en otras personas, incluso extraños & 8,40 & 21 \\
\hline 22 & Ciudad atractiva y bien planificada & 8,30 & 22 \\
\hline 23 & Protección de la libertad religiosa & 8,20 & 23 \\
\hline 24 & Relaciones justas, limpias e independientes con otras naciones & 8,20 & 24 \\
\hline 25 & Altos niveles de progreso científico y tecnológico & 8,10 & 25 \\
\hline 33 & Una fuerte economía de libre empresa y un gobierno eficiente en sus tareas básicas & 6,70 & 33 \\
\hline 34 & Establecer una economía fuerte antes que la equidad y las metas medioambientales & 5,20 & 34 \\
\hline 35 & Las personas tienen valores sociales y estilos de vida similares & 4,50 & 35 \\
\hline
\end{tabular}

Según los datos procesados, las características que la población bajo análisis considera más importantes para el desarrollo de una sociedad son las siguientes:

* Altos niveles de honestidad en la política y la vida pública $(9,30$ puntos).

* Todos son tratados igualitaria y equitativamente por la ley. $(9,30$ puntos).

* Los derechos humanos básicos de todos los ciudadanos están fuertemente protegidos ( 9,10 puntos).

* Buena calidad de los servicios básicos (salud, educación, etc.) para todos $(9,10$ puntos).

* Eliminación del crimen y la violencia (9,10 puntos).

* Protección del medio ambiente, recursos y fauna (9,10 puntos). 
En cuanto a los atributos que menos relevancia se les ha dado, se encuentran:

* Las personas tienen valores sociales y estilos de vida similares. (4,50 puntos).

* Establecer una economía fuerte antes que la equidad y las metas medioambientales. (5,20 puntos).

* Una fuerte economía de libre empresa y un gobierno eficiente en sus tareas básicas $(6,70$ puntos).

* No hay grandes diferencias en la riqueza y poder entre las personas. (6,80 puntos).

* Generosidad en ayudar a regiones perjudicadas. (7,00 puntos).

\subsubsection{Desempeño real percibido para las características relevadas}

En el caso de Australia, el desempeño real percibido para las características relevadas, los resultados obtenidos fueron los siguientes: 


\begin{tabular}{|c|c|c|}
\hline & & $\begin{array}{c}\text { Desempeño } \\
\text { AUSTRALIA }\end{array}$ \\
\hline Item & Características & $\begin{array}{c}\text { Calificación } \\
1-10\left(c^{*}\right)\end{array}$ \\
\hline 23 & Protección de la libertad religiosa & 7,50 \\
\hline 30 & Libertad para hacer lo que nos gusta siempre que no perjudiquemos a otros & 7,10 \\
\hline 34 & Establecer una economía fuerte antes que la equidad y las metas medioambientales & 6,80 \\
\hline 25 & Altos niveles de progreso científico y tecnológico & 6,80 \\
\hline 14 & Las personas que trabajan duramente pueden tener éxito en la vida & 6,80 \\
\hline 22 & Ciudad atractiva y bien planificada & 6,60 \\
\hline 3 & Los derechos humanos básicos de todos los ciudadanos están fuertemente protegidos & 6,60 \\
\hline 7 & Igualdad de oportunidades para hombres y mujeres & 6,40 \\
\hline 26 & Vigorosa libertad de opinión, múltiples opiniones públicas (disensos) & 6,30 \\
\hline 31 & Generosidad en ayudar a regiones perjudicadas & 6,20 \\
\hline 24 & Relaciones justas, limpias e independientes con otras naciones & 6,10 \\
\hline 33 & Una fuerte economía de libre empresa y un gobierno eficiente en sus tareas básicas & 6,10 \\
\hline 29 & Comunidades y organizaciones locales fuertes & 6,00 \\
\hline 15 & Se alienta la vida familiar y los valores de la familia & 5,80 \\
\hline 11 & Buena atención a las personas vulnerables, disminuidos y de clase baja & 5,60 \\
\hline 6 & Protección del medioambiente, recursos y fauna & 5,60 \\
\hline 4 & Buena calidad de los servicios básicos (salud, educación, etc.) para todos & 5,50 \\
\hline 18 & Respeto por, y estricta aplicación de las leyes & 5,50 \\
\hline 20 & Fuerte protección social (edad, enfermedad, desempleo, etc.) & 5,40 \\
\hline 2 & Todos son tratados igualitaria y equitativamente por la ley & 5,40 \\
\hline 27 & Las personas participan en la toma de decisiones de hechos que los afectan & 5,10 \\
\hline 13 & Las personas se sienten responsables por cada uno de los demás y por la comunidad & 5,10 \\
\hline 9 & Confianza justificada en que las instituciones públicas actúan con limpieza y justicia & 5,10 \\
\hline 10 & Las comunidades locales tienen buena calidad de servicios públicos (transporte, luz, etc.) & 4,80 \\
\hline 12 & Reducción de la contaminación medioambiental, desarrollo de fuentes de energía renovables & 4,80 \\
\hline 35 & Las personas tienen valores sociales y estilos de vida similares & 4,60 \\
\hline 16 & Las personas jóvenes son valoradas, y tienen perspectivas de futuro seguras & 4,30 \\
\hline 1 & Altos niveles de honestidad en la política y la vida pública & 4,30 \\
\hline 19 & Trabajos seguros, satisfactorios y equitativamente pagados para todos los que quieren trabajar & 4,20 \\
\hline 21 & Capacidad para confiar en otras personas, incluso extraños & 3,90 \\
\hline 17 & Eliminación de la pobreza & 3,80 \\
\hline 28 & Atomización en la propiedad y control de los medios de comunicación & 3,70 \\
\hline 8 & Todos pagan impuestos equitativamente, acorde con el ingreso y riqueza & 3,40 \\
\hline 5 & Eliminación del crimen y la violencia & 3,40 \\
\hline 32 & No hay grandes diferencias en la riqueza y poder entre las personas & 3,30 \\
\hline
\end{tabular}

\section{Las características que mejor desempeño percibido presentan según los} resultados de la encuesta son:

* Protección de la libertad religiosa. (7,50 puntos).

* Libertad para hacer lo que nos gusta siempre que no perjudiquemos a otros. (7,10 puntos).

* Las personas que trabajan duramente pueden tener éxito en la vida. (6,80 puntos).

* Altos niveles de progreso científico y tecnológico. (6,80 puntos).

* Establecer una economía fuerte antes que la equidad y las metas medioambientales. (6,80 puntos). 
$\rightarrow$ Ninguna de las características que mejor puntuación han recibido en materia de desempeño real, está presente entre las consideradas más importantes para el grupo social bajo análisis.

Por su parte, las características en que la población percibe un peor desempeño resultaron ser:

* No hay grandes diferencias en la riqueza y poder entre las personas. (3,30 puntos).

* Todos pagan impuestos equitativamente, acorde con el ingreso y la riqueza. (3,40 puntos)

* Eliminación del crimen y la violencia. (3,40 puntos).

* Atomización en la propiedad y control de los medios de comunicación. (3,70 puntos).

* Eliminación de la pobreza. (3,80 puntos)

$\rightarrow$ Una sola de las características percibidas como de peor desempeño ("Eliminación del crimen...") está presentes entre las consideradas más importantes para la misma población bajo análisis.

\subsubsection{Discrepancia entre importancia asignada y desempeño percibido}

La siguiente tabla expone las discrepancias detectadas para cada una de las características relevadas. 


\begin{tabular}{|c|c|c|}
\hline & & $\begin{array}{l}\text { Discrepancia } \\
\text { AUSTRALIA }\end{array}$ \\
\hline Item & Características & $\begin{array}{c}\text { Valor } \\
\left(d^{*}=c^{*}-a^{*}\right)\end{array}$ \\
\hline 34 & Establecer una economía fuerte antes que la equidad y las metas medioambientales & 1,60 \\
\hline 35 & Las personas tienen valores sociales y estilos de vida similares & 0,10 \\
\hline 30 & Libertad para hacer lo que nos gusta siempre que no perjudiquemos a otros & $-0,30$ \\
\hline 33 & Una fuerte economía de libre empresa y un gobierno eficiente en sus tareas básicas & $-0,60$ \\
\hline 23 & Protección de la libertad religiosa & $-0,70$ \\
\hline 31 & Generosidad en ayudar a regiones perjudicadas & $-0,80$ \\
\hline 25 & Al tos niveles de progreso científico y tecnológico & $-1,30$ \\
\hline 22 & Ciudad atractiva y bien planificada & $-1,70$ \\
\hline 14 & Las personas que trabajan duramente pueden tener éxito en la vida & $-1,80$ \\
\hline 26 & Vigorosa libertad de opinión, múltiples opiniones públicas (disensos) & $-1,80$ \\
\hline 29 & Comunidades y organizaciones locales fuertes & $-1,80$ \\
\hline 24 & Relaciones justas, limpias e independientes con otras naciones & $-2,10$ \\
\hline 3 & Los derechos humanos básicos de todos los ciudadanos están fuertemente protegidos & $-2,50$ \\
\hline 7 & Igualdad de oportunidades para hombres y mujeres & $-2,60$ \\
\hline 15 & Se alienta la vida familiar y los valores de la familia & $-2,80$ \\
\hline 27 & Las personas participan en la toma de decisiones de hechos que los afectan & $-3,00$ \\
\hline 18 & Res peto por, y estricta aplicación de las leyes & $-3,10$ \\
\hline 20 & Fuerte protección social (edad, enfermedad, desempleo, etc.) & $-3,10$ \\
\hline 11 & Buena atención a las personas vulnerables, disminuidos y de clase baja & $-3,20$ \\
\hline 6 & Protección del medioambiente, recursos y fauna & $-3,50$ \\
\hline 32 & No hay grandes diferencias en la riqueza y poder entre las personas & $-3,50$ \\
\hline 4 & Buena calidad de los servicios básicos (salud, educación, etc.) para todos & $-3,60$ \\
\hline 13 & Las personas se sienten responsables por cada uno de los demás y por la comunidad & $-3,60$ \\
\hline 2 & Todos son tratados igualitaria y equitativamente por la ley & $-3,90$ \\
\hline 9 & Confianza justificada en que las instituciones públicas actúan con limpieza y justicia & $-3,90$ \\
\hline 12 & Reducción de la contaminación medioambiental, desarrollo de fuentes de energía renovables & $-4,00$ \\
\hline 10 & Las comunidades locales tienen buena calidad de servicios públicos (transporte, luz, etc.) & $-4,20$ \\
\hline 28 & Atomización en la propiedad y control de los medios de comunicación & $-4,20$ \\
\hline 16 & Las personas jóvenes son valoradas, $y$ tienen perspectivas de futuro seguras & $-4,30$ \\
\hline 19 & Trabajos seguros, satisfactorios y equitativamente pagados para todos los que quieren trabajar & $-4,40$ \\
\hline 21 & Capacidad para confiar en otras personas, incluso extraños & $-4,50$ \\
\hline 17 & Eliminación de la pobreza & $-4,80$ \\
\hline 1 & Altos niveles de honestidad en la política y la vida pública & $-5,00$ \\
\hline 8 & Todos pagan impuestos equitativamente, acorde con el ingreso y riqueza & $-5,60$ \\
\hline 5 & Eliminación del crimen y la violencia & $-5,70$ \\
\hline
\end{tabular}

Las características donde la población percibe un desempeño real más cercano al nivel de importancia que le asigna son:

* Establecer una economía fuerte antes que la equidad y las metas medioambientales (1,6 puntos de diferencia).

Las personas tienen valores sociales y estilos de vida similares. $(0,1$ puntos de diferencia).

* Libertad para hacer lo que nos gusta siempre que perjudiquemos a otros (-0,3 puntos de diferencia).

* Una fuerte economía de libre empresa y un gobierno eficiente en sus tareas básicas (-0,6 puntos de diferencia).

* Protección de la libertad religiosa. (-0,7 puntos de diferencia). 
$\rightarrow$ Tres de estas características son consideradas entre las menos importantes (“Establecer una economía...”; “Una fuerte economía de libre empresa..."; Las personas tienen...").

Las mayores brechas se presentan en el siguiente grupo de características:

* Eliminación del crimen y la violencia (-5,7 puntos de diferencia).

* Todos pagan impuestos equitativamente, acorde el ingreso y la riqueza (-5,6 puntos de diferencia).

- Altos niveles de honestidad en la política y la vida pública $(-5,0$ puntos de diferencia).

- Eliminación de la pobreza (-4,8 puntos de diferencia).

* Capacidad para confiar en otras personas, incluso extraños. $(-4,5$ puntos de diferencia).

$\rightarrow$ En contraste con lo antes expuesto, dos de estas características son consideradas entre las más importantes según las puntuaciones asignadas por la población bajo estudio ("Eliminación del crimen..."; "Altos niveles de honestidad...").

\subsubsection{Gravedad de la situación de las características analizadas}

Los últimos resultados procesados para la población analizada en Australia miden la gravedad de la situación en que se encuentra cada característica bajo estudio según la percepción de la muestra. Como ya se ha mencionado, esta "Gravedad" es la resultante de relacionar la importancia que una población le asigna a una característica, con la discrepancia que percibe en su desempeño. 


\begin{tabular}{|c|c|c|c|}
\hline \multirow[b]{2}{*}{ Item } & \multirow[b]{2}{*}{ Características } & \multicolumn{2}{|c|}{$\begin{array}{c}\text { Gravedad Percibida } \\
\text { AUSTRALIA }\end{array}$} \\
\hline & & $\begin{array}{c}\text { Ponderación } \\
\left(e^{*}=-d^{*} \times a^{*}\right)\end{array}$ & $\begin{array}{l}\text { Jerarquía } \\
\text { 1-35 (f*) }\end{array}$ \\
\hline 5 & Eliminación del crimen y la violencia & 51,9 & 1 \\
\hline 8 & Todos pagan impuestos equitativamente, acorde con el ingreso y riqueza & 50,4 & 2 \\
\hline 1 & Altos niveles de honestidad en la política y la vida pública & 46,5 & 3 \\
\hline 17 & Eliminación de la pobreza & 41,3 & 4 \\
\hline 19 & Trabajos seguros, satisfactorios y equitativamente pagados para todos los que quieren trabajar & 37,8 & 5 \\
\hline 10 & Las comunidades locales tienen buena calidad de servicios públicos (transporte, luz, etc.) & 37,8 & 6 \\
\hline 21 & Capacidad para confiar en otras personas, incluso extraños & 37,8 & 7 \\
\hline 16 & Las personas jóvenes son valoradas, y tienen perspectivas de futuro seguras & 37,0 & 8 \\
\hline 2 & Todos son tratados igualitaria y equitativamente por la ley & 36,3 & 9 \\
\hline 12 & Reducción de la contaminación medioambiental, desarrollo de fuentes de energía renovables & 35,2 & 10 \\
\hline 9 & Confianza justificada en que las instituciones públicas actúan con limpieza y justicia & 35,1 & 11 \\
\hline 28 & Atomización en la propiedad y control de los medios de comunicación & 33,2 & 12 \\
\hline 4 & Buena calidad de los servicios básicos (salud, educación, etc.) para todos & 32,8 & 13 \\
\hline 6 & Protección del medioambiente, recursos y fauna & 31,9 & 14 \\
\hline 13 & Las personas se sienten responsables por cada uno de los demás y por la comunidad & 31,3 & 15 \\
\hline 11 & Buena atención a las personas vulnerables, disminuidos y de clase baja & 28,2 & 16 \\
\hline 18 & Respeto por, y estricta aplicación de las leyes & 26,7 & 17 \\
\hline 20 & Fuerte protección social (edad, enfermedad, desempleo, etc.) & 26,4 & 18 \\
\hline 27 & Las personas participan en la toma de decisiones de hechos que los afectan & 24,3 & 19 \\
\hline 15 & Se alienta la vida familiar y los valores de la familia & 24,1 & 20 \\
\hline 32 & No hay grandes diferencias en la riqueza y poder entre las personas & 23,8 & 21 \\
\hline 7 & Igualdad de oportunidades para hombres y mujeres & 23,4 & 22 \\
\hline 3 & Los derechos humanos básicos de todos los ciudadanos están fuertemente protegidos & 22,8 & 23 \\
\hline 24 & Relaciones justas, limpias e independientes con otras naciones & 17,2 & 24 \\
\hline 14 & Las personas que trabajan duramente pueden tener éxito en la vida & 15,5 & 25 \\
\hline 26 & Vigorosa libertad de opinión, múltiples opiniones públicas (disensos) & 14,6 & 26 \\
\hline 22 & Ciudad atractiva y bien planificada & 14,1 & 27 \\
\hline 29 & Comunidades y organizaciones locales fuertes & 14,0 & 28 \\
\hline 25 & Altos niveles de progreso científico y tecnológico & 10,5 & 29 \\
\hline 23 & Protección de la libertad religiosa & 5,7 & 30 \\
\hline 31 & Generosidad en ayudar a regiones perjudicadas & 5,6 & 31 \\
\hline 33 & Una fuerte economía de libre empresa y un gobierno eficiente en sus tareas básicas & 4,0 & 32 \\
\hline 30 & Libertad para hacer lo que nos gusta siempre que no perjudiquemos a otros & 2,2 & 33 \\
\hline 35 & Las personas tienen valores sociales y estilos de vida similares & $-0,4$ & 34 \\
\hline 34 & Establecer una economía fuerte antes que la equidad y las metas medioa mbientales & $-8,3$ & 35 \\
\hline
\end{tabular}

Según los resultados obtenidos, las características que esta sociedad entiende que están en una situación más crítica son:

* Eliminación del crimen y la violencia. (51,87 puntos).

* Todos pagan impuestos equitativamente, acorde con el ingreso y riqueza (50,4 puntos).

* Altos niveles de honestidad en la política y la vida pública. (46,5 puntos).

Eliminación de la pobreza (41,28 puntos).

* Trabajos seguros, satisfactorios y equitativamente pagados para todos los que quieren trabajar. (37,84 puntos).

En cambio, las siguientes características se presentan con un menor nivel de gravedad: 
* Establecer una economía fuerte antes que la equidad y las metas medioambientales (-8,32 puntos).

* Las personas tienen valores sociales y estilos de vida similares. (0,45 puntos).

* Libertad para hacer lo que nos gusta siempre que no perjudiquemos a otros (2,22 puntos).

* Una fuerte economía de libre empresa y un gobierno eficiente en sus tareas básicas. (4,02 puntos).

* Generosidad en ayudar a regiones perjudicadas. (5,6 puntos).

$\rightarrow$ Ninguna de las características presentadas como de menor gravedad forman parte de las más importantes para la población bajo análisis.

10.2.3 Situación comparativa: Australia con la región de La Plata, Berisso y Ensenada

\subsubsection{Importancia asignada a las características relevadas}

En la tabla que se encuentra a continuación se exponen los resultados obtenidos en la encuesta realizada en la región de La Plata, Berisso y Ensenada y su comparación con el estudio realizado en Australia. 


\begin{tabular}{|c|c|c|c|c|c|}
\hline \multirow[b]{2}{*}{ Item } & \multirow[b]{2}{*}{ Características } & \multicolumn{2}{|c|}{ Importancia LP, B, E } & \multicolumn{2}{|c|}{ Importancia AUSTRALIA } \\
\hline & & $\begin{array}{c}\text { Calificación } \\
1-10 \text { (a) }\end{array}$ & $\begin{array}{c}\text { Jerarquía } \\
\text { 1-35 (b) }\end{array}$ & $\begin{array}{c}\text { Calificación } \\
1-10\left(a^{*}\right)\end{array}$ & $\begin{array}{l}\text { Jerarquía } \\
1-35\left(b^{*}\right)\end{array}$ \\
\hline 1 & Altos niveles de honestidad en la política y la vida pública & 9,47 & 5 & 9,30 & 1 \\
\hline 2 & Todos son tratados igualitaria y equitativamente por la ley & 9,71 & 1 & 9,30 & 2 \\
\hline 3 & Los derechos humanos básicos de todos los ciudadanos están fuertemente protegidos & 9,61 & 3 & 9,10 & 3 \\
\hline 4 & Buena calidad de los servicios básicos (salud, educación, etc.) para todos & 9,66 & 2 & 9,10 & 4 \\
\hline 5 & Eliminación del crimen y la violencia & 9,52 & 4 & 9,10 & 5 \\
\hline 6 & Protección del medioambiente, recursos y fauna & 9,01 & 18 & 9,10 & 6 \\
\hline 7 & Igualdad de oportunidades para hombres y mujeres & 9,33 & 8 & 9,00 & 7 \\
\hline 8 & Todos pagan impuestos equitativamente, acorde con el ingreso y riqueza & 8,99 & 19 & 9,00 & 8 \\
\hline 9 & Confianza justificada en que las instituciones públicas actúan con limpieza y justicia & 9,42 & 7 & 9,00 & 9 \\
\hline 10 & Las comunidades locales tienen buena calidad de servicios públicos (transporte, luz, etc.) & 9,12 & 16 & 9,00 & 10 \\
\hline 11 & Buena atención a las personas vulnerables, disminuidos y de clase baja & 9,16 & 13 & 8,80 & 11 \\
\hline 12 & Reducción de la contaminación medioambiental, desarrollo de fuentes de energía renovables & 8,93 & 20 & 8,80 & 12 \\
\hline 13 & Las personas se sienten responsables por cada uno de los demás y por la comunidad & 8,50 & 26 & 8,70 & 13 \\
\hline 14 & Las personas que trabajan duramente pueden tener éxito en la vida & 8,47 & 27 & 8,60 & 14 \\
\hline 15 & Se alienta la vida familiar y los valores de la familia & 9,24 & 10 & 8,60 & 15 \\
\hline 16 & Las personas jóvenes son valoradas, $\mathrm{y}$ tienen perspectivas de futuro seguras & 8,67 & 23 & 8,60 & 16 \\
\hline 17 & Eliminación de la pobreza & 9,14 & 14 & 8,60 & 17 \\
\hline 18 & Respeto por, y estricta aplicación de las leyes & 9,28 & 9 & 8,60 & 18 \\
\hline 19 & Trabajos seguros, satisfactorios y equitativamente pagados para todos los que quieren trabajar & 9,07 & 17 & 8,60 & 19 \\
\hline 20 & Fuerte protección social (edad, enfermedad, desempleo, etc.) & 9,20 & 11 & 8,50 & 20 \\
\hline 21 & Capacidad para confiar en otras personas, incluso extraños & 8,22 & 31 & 8,40 & 21 \\
\hline 22 & Ciudad atractiva y bien planificada & 8,03 & 32 & 8,30 & 22 \\
\hline 23 & Protección de la libertad religiosa & 8,60 & 24 & 8,20 & 23 \\
\hline 24 & Relaciones justas, limpias e independientes con otras naciones & 8,56 & 25 & 8,20 & 24 \\
\hline 25 & Altos niveles de progreso científico y tecnológico & 8,84 & 21 & 8,10 & 25 \\
\hline 26 & Vigorosa libertad de opinión, múltiples opiniones públicas (disensos) & 9,43 & 6 & 8,10 & 26 \\
\hline 27 & Las personas participan en la toma de decisiones de hechos que los afectan & 8,76 & 22 & 8,10 & 27 \\
\hline 28 & Atomización en la propiedad y control de los medios de comunicación & 7,55 & 33 & 7,90 & 28 \\
\hline 29 & Comunidades y organizaciones locales fuertes & 8,33 & 30 & 7,80 & 29 \\
\hline 30 & Libertad para hacer lo que nos gusta siempre que no perjudiquemos a otros & 9,19 & 12 & 7,40 & 30 \\
\hline 31 & Generosidad en ayudar a regiones perjudicadas & 9,13 & 15 & 7,00 & 31 \\
\hline 32 & No hay grandes diferencias en la riqueza y poder entre las personas & 8,43 & 29 & 6,80 & 32 \\
\hline 33 & Una fuerte economía de libre empresa y un gobierno eficiente en sus tareas básicas & 8,46 & 28 & 6,70 & 33 \\
\hline 34 & Establecer una economía fuerte antes que la equidad y las metas medioambientales & 6,51 & 35 & 5,20 & 34 \\
\hline 35 & Las personas tienen valores sociales y estilos de vida similares & 6,58 & 34 & 4,50 & 35 \\
\hline
\end{tabular}

Nótese que tanto la sociedad de la región como la de Australia consideran los mismos cinco factores como prioritarios. Si bien la jerarquización de esas características no es la misma, si tomamos el grupo representativo mencionado, veremos que todos ellos están presentes en ambos casos.

Entonces, los atributos que mayor relevancia se les ha dado, son:

- Altos niveles de honestidad en la política y la vida pública (P1 Australia - P5 Región).

- Todos son tratados igualitaria y equitativamente por la ley (P2 Australia - P1 Región).

- Los derechos humanos básicos de todos los ciudadanos están fuertemente protegidos (Puesto 3 para ambas sociedades).

- Buena calidad de los servicios básicos (salud, educación, etc.) para todos (P4 Australia - P2 Región).

○ Eliminación del crimen y la violencia. (P5 Australia - P4 Región). 
$\rightarrow$ Si se tomara el grupo de las diez primeras características, ambas poblaciones comparten siete de ellas.

En cuanto a los atributos que menos relevancia se les ha dado, se encuentran:

* Generosidad en ayudar a regiones perjudicadas. (P31 Australia P15 Región)

* No hay grandes diferencias en la riqueza y poder entre las personas. (P32 Australia - P29 Región)

* Una fuerte economía de libre empresa y un gobierno eficiente en sus tareas básicas. (P33 Australia - P28 Región)

* Establecer una economía fuerte antes que la equidad y las metas medioambientales. (P34 Australia - P35 Región)

* Las personas tienen valores sociales y estilos de vida similares. (P35 Australia - P34 Región)

$\rightarrow$ Si extendemos la base de comparación a las diez características menos importantes, seis de ellas son compartidas.

\subsubsection{Desempeño de real percibido para las características relevadas}

Como se explicó anteriormente, el desempeño real percibido para las características relevadas, es el resultante de las respuestas a las preguntas formuladas a partir de que el encuestado "Califique en qué medida se da en la realidad...". Los resultados obtenidos fueron los siguientes: 


\begin{tabular}{|c|c|c|c|c|}
\hline \multirow[b]{2}{*}{ Item } & \multirow[b]{2}{*}{ Características } & \multirow{2}{*}{\begin{tabular}{|c|}
$\begin{array}{c}\text { Desempeño } \\
\text { LP, B, E }\end{array}$ \\
$\begin{array}{c}\text { Calificación } \\
1-10 \text { (c) }\end{array}$ \\
\end{tabular}} & \multirow{2}{*}{$\begin{array}{c}\begin{array}{c}\text { Desempeño } \\
\text { AUSTRALIA }\end{array} \\
\text { Calificación } \\
1-10\left(c^{*}\right)\end{array}$} & \multirow[b]{2}{*}{$\begin{array}{c}\Delta \% \text { (AUS vs } \\
\text { LP) }\end{array}$} \\
\hline & & & & \\
\hline 1 & Altos niveles de honestidad en la política y la vida pública & 3,68 & 4,30 & $17,0 \%$ \\
\hline 2 & Todos son tratados igualitaria y equitativamente por la ley & 4,32 & 5,40 & $25,1 \%$ \\
\hline 3 & Los derechos humanos básicos de todos los ciudadanos están fuertemente protegidos & 5,01 & 6,60 & $31,7 \%$ \\
\hline 4 & Buena calidad de los servicios básicos (salud, educación, etc.) para todos & 4,98 & 5,50 & $10,4 \%$ \\
\hline 5 & Eliminación del crimen y la violencia & 3,52 & 3,40 & $-3,4 \%$ \\
\hline 6 & Protección del medioambiente, recursos y fauna & 4,70 & 5,60 & $19,1 \%$ \\
\hline 7 & Igualdad de oportunidades para hombres y mujeres & 6,89 & 6,40 & $-7,2 \%$ \\
\hline 8 & Todos pagan impuestos equitativamente, acorde con el ingreso y riqueza & 4,34 & 3,40 & $-21,7 \%$ \\
\hline 9 & Confianza justificada en que las instituciones públicas actúan con limpieza y justicia & 3,81 & 5,10 & $34,0 \%$ \\
\hline 10 & Las comunidades locales tienen buena calidad de servicios públicos (transporte, luz, etc.) & 4,66 & 4,80 & $3,0 \%$ \\
\hline 11 & Buena atención a las personas vulnerables, disminuidos y de clase baja & 5,00 & 5,60 & $12,0 \%$ \\
\hline 12 & Reducción de la contaminación medioambiental, desarrollo de fuentes de energía renovables & 4,08 & 4,80 & $17,6 \%$ \\
\hline 13 & Las personas se sienten responsables por cada uno de los demás y por la comunidad & 4,23 & 5,10 & $20,6 \%$ \\
\hline 14 & Las personas que trabajan duramente pueden tener éxito en la vida & 4,94 & 6,80 & $37,6 \%$ \\
\hline 15 & Se alienta la vida familiar y los valores de la familia & 5,78 & 5,80 & $0,3 \%$ \\
\hline 16 & Las personas jóvenes son valoradas, y tienen perspectivas de futuro seguras & 4,79 & 4,30 & $-10,2 \%$ \\
\hline 17 & Eliminación de la pobreza & 4,47 & 3,80 & $-15,0 \%$ \\
\hline 18 & Respeto por, y estricta aplicación de las leyes & 3,89 & 5,50 & $41,5 \%$ \\
\hline 19 & Trabajos seguros, satisfactorios y equitativamente pagados para todos los que quieren trabajar & 4,38 & 4,20 & $-4,0 \%$ \\
\hline 20 & Fuerte protección social (edad, enfermedad, desempleo, etc.) & 4,80 & 5,40 & $12,6 \%$ \\
\hline 21 & Capacidad para confiar en otras personas, incluso extraños & 3,60 & 3,90 & $8,3 \%$ \\
\hline 22 & Ciudad atractiva y bien planificada & 5,04 & 6,60 & $31,0 \%$ \\
\hline 23 & Protección de la libertad religiosa & 7,78 & 7,50 & $-3,6 \%$ \\
\hline 24 & Relaciones justas, limpias e independientes con otras naciones & 5,48 & 6,10 & $11,4 \%$ \\
\hline 25 & Altos niveles de progreso científico y tecnológico & 5,47 & 6,80 & $24,2 \%$ \\
\hline 26 & Vigorosa libertad de opinión, múltiples opiniones públicas (disensos) & 6,26 & 6,30 & $0,6 \%$ \\
\hline 27 & Las personas participan en la toma de decisiones de hechos que los afectan & 4,82 & 5,10 & $5,9 \%$ \\
\hline 28 & Atomización en la propiedad y control de los medios de comunicación & 5,06 & 3,70 & $-26,8 \%$ \\
\hline 29 & Comunidades y organizaciones locales fuertes & 4,94 & 6,00 & $21,4 \%$ \\
\hline 30 & Libertad para hacer lo que nos gusta siempre que no perjudiquemos a otros & 5,11 & 7,10 & $39,0 \%$ \\
\hline 31 & Generosidad en ayudar a regiones perjudicadas & 6,58 & 6,20 & $-5,7 \%$ \\
\hline 32 & No hay grandes diferencias en la riqueza y poder entre las personas & 3,28 & 3,30 & $0,6 \%$ \\
\hline 33 & Una fuerte economía de libre empresa y un gobierno eficiente en sus tareas básicas & 3,96 & 6,10 & $54,0 \%$ \\
\hline 34 & Establecer una economía fuerte antes que la equidad y las metas medioambientales & 4,93 & 6,80 & $37,9 \%$ \\
\hline 35 & Las personas tienen valores sociales y estilos de vida similares & 4,10 & 4,60 & $12,3 \%$ \\
\hline & Promedio 5 más importantes --> & 4,30 & 5,04 & $17,2 \%$ \\
\hline & Promedio 10 más importantes --> & 4,59 & 5,05 & $10,0 \%$ \\
\hline & Promedio TOTAL --> & 4,82 & 5,40 & $12,1 \%$ \\
\hline
\end{tabular}

Si se realiza un análisis general, se evidencia que el promedio total del desempeño de los atributos evaluados en Australia es mayor que en la Región de La Plata, Berisso y Ensenada. Esto implica que los encuestados de Australia consideran que los aspectos para ellos de importancia, en la realidad se ven concretados un $12,1 \%$ más que en la zona de La Plata, Berisso y Ensenada.

Cuando se profundiza el análisis y se observa el desempeño promedio para las cinco características más importantes, existe una diferencia significativa siendo el valor resultante para Australia de 5,04 puntos en promedio, mientras que para la Región de 4,30 puntos (17,2\% menor). Si se extiende el análisis a las primeras diez características, aunque algo menor, la brecha se mantiene promediando 5,05 Australia versus 4,59 para La Plata, Berisso y Ensenada (un 10\% menor). 
Las características que mejor desempeño percibido presentan según los resultados de la encuesta son:

- Protección de la libertad religiosa. (7,50 puntos en Australia y 7,78 puntos en la Región).

- Libertad para hacer lo que nos gusta siempre que no perjudiquemos a otros (7,10 puntos en Australia y 5,11 puntos en la Región).

- Las personas que trabajan duramente pueden tener éxito en la vida (6,80 puntos en Australia y 4,94 puntos en la Región).

- Altos niveles de progreso científico y tecnológico $(6,80$ puntos en Australia y 5,47 puntos en la Región).

- Establecer una economía fuerte antes que la equidad y las metas medioambientales (6,80 puntos en Australia y 4,93 puntos en la Región).

$\rightarrow$ Tanto en el estudio de Australia como en el de La Plata, Berisso y Ensenada, ninguna de las características que mejor puntuación han recibido en materia de desempeño, está presente entre las consideradas más importantes para ambos grupos.

Por su parte, las características en que la población percibe un peor desempeño resultaron ser:

* Eliminación de la pobreza (3,80 puntos en Australia y 4,47 puntos en la Región).

* Atomización en la propiedad y control de los medios de comunicación (3,70 puntos en Australia y 5,06 puntos en la Región).

* Eliminación del crimen y la violencia (3,40 puntos en Australia y 3,52 puntos en la Región).

* Todos pagan impuestos equitativamente, acorde con el ingreso y riqueza (3,40 puntos en Australia y 4,34 puntos en la Región).

* No hay grandes diferencias en la riqueza y poder de las personas (3,30 puntos en Australia y 3,28 puntos en la Región). 
$\rightarrow$ "Eliminación del crimen..." y "Altos niveles de...", dos de las características que peor puntuación han recibido en materia de desempeño, está presente entre las consideradas más importantes para Australia por un lado (Puesto cinco y uno respectivamente) y también en el caso de la Región (Puesto cuatro y cinco respectivamente).

\subsubsection{Discrepancia entre importancia asignada y desempeño percibido}

Cuando se realiza la comparación de las brechas existentes entre la importancia asignada a los diferentes atributos y el desempeño real de los mismos, según las percepciones de la sociedad, se comienzan a evidenciar más claramente los puntos donde la sociedad de Australia supera a la región de La Plata, Berisso y Ensenada.

La siguiente tabla expone las discrepancias detectadas para cada una de las características relevadas.

\begin{tabular}{|c|c|c|c|c|}
\hline & & $\begin{array}{c}\text { Discrepancia } \\
\text { LP, B, E }\end{array}$ & $\begin{array}{l}\text { Discrepancia } \\
\text { AUSTRALIA }\end{array}$ & \\
\hline Item & Características & $\begin{array}{c}\text { Valor } \\
(d=c-a)\end{array}$ & $\begin{array}{c}\text { Valor } \\
\left(d^{*}=c^{*}-a^{*}\right)\end{array}$ & $\begin{array}{c}\Delta \% \text { (LP vs } \\
\text { AUS) }\end{array}$ \\
\hline 1 & Altos niveles de honestidad en la política y la vida pública & $-5,80$ & $-5,00$ & $15,9 \%$ \\
\hline 2 & Todos son tratados igualitaria y equitativamente por la ley & $-5,39$ & $-3,90$ & $38,3 \%$ \\
\hline 3 & Los derechos humanos básicos de todos los ciudadanos están fuertemente protegidos & $-4,60$ & $-2,50$ & $84,1 \%$ \\
\hline 4 & Buena calidad de los servicios básicos (salud, educación, etc.) para todos & $-4,68$ & $-3,60$ & $29,9 \%$ \\
\hline 5 & Eliminación del crimen y la violencia & $-6,00$ & $-5,70$ & $5,3 \%$ \\
\hline 6 & Protección del medioambiente, recursos y fauna & $-4,31$ & $-3,50$ & $23,2 \%$ \\
\hline 7 & Igualdad de oportunidades para hombres y mujeres & $-2,43$ & $-2,60$ & $-6,4 \%$ \\
\hline 8 & Todos pagan impuestos equitativamente, acorde con el ingreso y riqueza & $-4,64$ & $-5,60$ & $-17,1 \%$ \\
\hline 9 & Confianza justificada en que las instituciones públicas actúan con limpieza y justicia & $-5,61$ & $-3,90$ & $43,9 \%$ \\
\hline 10 & Las comunidades locales tienen buena calidad de servicios públicos (transporte, luz, etc.) & $-4,46$ & $-4,20$ & $6,3 \%$ \\
\hline 11 & Buena atención a las personas vulnerables, disminuidos y de clase baja & $-4,16$ & $-3,20$ & $30,1 \%$ \\
\hline 12 & Reducción de la contaminación medioambiental, desarrollo de fuentes de energía renovables & $-4,85$ & $-4,00$ & $21,3 \%$ \\
\hline 13 & Las personas se sienten responsables por cada uno de los demás y por la comunidad & $-4,27$ & $-3,60$ & $18,7 \%$ \\
\hline 14 & Las personas que trabajan duramente pueden tener éxito en la vida & $-3,53$ & $-1,80$ & $95,9 \%$ \\
\hline 15 & Se alienta la vida familiar y los valores de la familia & $-3,46$ & $-2,80$ & $23,5 \%$ \\
\hline 16 & Las personas jóvenes son valoradas, $y$ tienen perspectivas de futuro seguras & $-3,89$ & $-4,30$ & $-9,6 \%$ \\
\hline 17 & Eliminación de la pobreza & $-4,67$ & $-4,80$ & $-2,7 \%$ \\
\hline 18 & Respeto por, y estricta aplicación de las leyes & $-5,39$ & $-3,10$ & $74,0 \%$ \\
\hline 19 & Trabajos seguros, satisfactorios y equitativamente pagados para todos los que quieren traba & $-4,70$ & $-4,40$ & $6,7 \%$ \\
\hline 20 & Fuerte protección social (edad, enfermedad, des empleo, etc.) & $-4,41$ & $-3,10$ & $42,2 \%$ \\
\hline 21 & Capacidad para confiar en otras personas, incluso extraños & $-4,62$ & $-4,50$ & $2,6 \%$ \\
\hline 22 & Ciudad atractiva y bien planificada & $-2,99$ & $-1,70$ & $75,9 \%$ \\
\hline 23 & Protección de la libertad religiosa & $-0,82$ & $-0,70$ & $17,6 \%$ \\
\hline 24 & Relaciones justas, limpias e independientes con otras naciones & $-3,08$ & $-2,10$ & $46,7 \%$ \\
\hline 25 & Altos niveles de progreso científico y tecnológico & $-3,37$ & $-1,30$ & $159,0 \%$ \\
\hline
\end{tabular}




\begin{tabular}{|c|c|c|c|c|}
\hline 26 & Vigorosa libertad de opinión, múltiples opiniones públicas (disensos) & $-3,17$ & $-1,80$ & $76,1 \%$ \\
\hline 27 & Las personas participan en la toma de decisiones de hechos que los afectan & $-3,95$ & $-3,00$ & $31,6 \%$ \\
\hline 28 & Atomización en la propiedad y control de los medios de comunicación & $-2,49$ & $-4,20$ & $-40,6 \%$ \\
\hline 29 & Comunidades y organizaciones locales fuertes & $-3,39$ & $-1,80$ & $88,3 \%$ \\
\hline 30 & Libertad para hacer lo que nos gusta siempre que no perjudiquemos a otros & $-4,08$ & $-0,30$ & $1261,1 \%$ \\
\hline 31 & Generosidad en ayudar a regiones perjudicadas & $-2,55$ & $-0,80$ & $219,2 \%$ \\
\hline 32 & No hay grandes diferencias en la riqueza y poder entre las personas & $-5,15$ & $-3,50$ & $47,1 \%$ \\
\hline 33 & Una fuerte economía de libre empresa y un gobierno eficiente en sus tareas básicas & $-4,50$ & $-0,60$ & $649,4 \%$ \\
\hline 34 & Establecer una economía fuerte antes que la equidad y las metas medioambientales & $-1,58$ & 1,60 & $-198,8 \%$ \\
\hline 35 & Las personas tienen valores sociales y estilos de vida similares & $-2,48$ & 0,10 & $-2580,0 \%$ \\
\hline \multicolumn{2}{|r|}{ Promedio 5 más importantes --> } & $-5,29$ & $-4,14$ & $27,9 \%$ \\
\hline & \multirow{2}{*}{$\begin{array}{r}\text { Promedio } 10 \text { más importantes -.> } \\
\text { Promedio TOTAL -.> }\end{array}$} & $-4,79$ & $-4,05$ & $18,4 \%$ \\
\hline & & $-3,99$ & $-2,80$ & $42,3 \%$ \\
\hline
\end{tabular}

En el análisis general, se observa que la diferencia promedio total de los atributos evaluados en la Región es de 3,99 puntos versus los 2,80 puntos reflejados en los resultados de Australia (un 42,3\% mayor en el primer caso).

Si se profundiza la mirada, se detecta que la brecha promedio para las cinco características más importantes, es de 5,29 puntos en el caso de La Plata, Berisso y Ensenada contra 4,14 puntos en el caso de Australia (un $27,9 \%$ superior). Si extendemos el análisis a las diez primeras características, aunque algo menor, el diferencial promedia 4,79 puntos para la Región versus 4,05 puntos para Australia (un $18,4 \%$ mayor).

Las características donde la población percibe un desempeño real más cercano al nivel de importancia que le asigna son:

- Protección de la libertad religiosa. $(-0,82$ puntos de diferencia en la Región versus $-0,70$ puntos en Australia).

- Establecer una economía fuerte antes que la equidad y las metas medioambientales (-1,58 puntos de diferencia en la Región versus 1,60 puntos en Australia).

- Igualdad de oportunidades para hombres y mujeres. $(-2,43$ puntos de diferencia en la Región versus -2,60 puntos en Australia).

- Las personas tienen valores sociales y estilos de vida similares. (2,48 puntos de diferencia en la Región versus 0,10 puntos en Australia).

- Atomización en la propiedad y control de los medios de comunicación. (-2,49 puntos de diferencia en la Región versus -4,2 puntos en Australia). 
Las mayores brechas se presentan en el siguiente grupo de características:

* Eliminación del crimen y la violencia (-6 puntos de diferencia en la Región versus -5,7 puntos en Australia).

* Altos niveles de honestidad en la política y la vida pública (-5,8 puntos de diferencia en la Región versus -5 puntos en Australia).

* Confianza justificada en que las instituciones públicas actúan con limpieza y justicia (-5,61 puntos de diferencia en la Región versus 3,9 puntos en Australia).

* Todos son tratados igualitaria y equitativamente por la ley $(-5,39$ puntos de diferencia en la Región versus -3,9 puntos en Australia).

* Respeto por, y estricta aplicación de las leyes (-5,39 puntos de diferencia en la Región versus -3,1 puntos en Australia).

$\rightarrow$ Tres de estas características son consideradas entre las cinco más importantes según las puntuaciones asignadas por las poblaciones bajo estudio ("Eliminación del crimen..."; "Altos niveles de honestidad..."; "Todos son tratados igualitaria....").

\subsubsection{Gravedad de la situación de las características analizadas}

La última etapa de procesamiento de resultados para la población de La Plata, Berisso y Ensenada en comparación con Australia, pretende medir la gravedad de la situación en que se encuentra cada característica estudiada según las percepciones de la población. 


\begin{tabular}{|c|c|c|c|c|}
\hline & & $\begin{array}{c}\text { Gravedad Percibida } \\
\text { LP, B, E }\end{array}$ & $\begin{array}{c}\text { Gravedad Percibida } \\
\text { AUSTRALIA }\end{array}$ & \\
\hline Item & Características & $\begin{array}{l}\text { Ponderación } \\
(e=-d x a)\end{array}$ & $\begin{array}{l}\text { Ponderación } \\
\left(e^{*}=-d^{*} \times a^{*}\right)\end{array}$ & $\begin{array}{c}\Delta \% \text { (LP vs } \\
\text { AUS) }\end{array}$ \\
\hline 1 & Al tos niveles de honestidad en la política y la vida pública & 55,73 & 46,50 & $19,9 \%$ \\
\hline 2 & Todos son tratados igualitaria y equitativamente por la ley & 52,77 & 36,27 & $45,5 \%$ \\
\hline 3 & Los derechos humanos básicos de todos los ciudadanos están fuertemente protegidos & 44,99 & 22,75 & $97,8 \%$ \\
\hline 4 & Buena calidad de los servicios básicos (salud, educación, etc.) para todos & 45,73 & 32,76 & $39,6 \%$ \\
\hline 5 & Eliminación del crimen y la violencia & 58,29 & 51,87 & $12,4 \%$ \\
\hline 6 & Protección del medioambiente, recursos y fauna & 40,58 & 31,85 & $27,4 \%$ \\
\hline 7 & Igualdad de oportunidades para hombres y mujeres & 23,86 & 23,40 & $2,0 \%$ \\
\hline 8 & Todos pagan impuestos equitativamente, acorde con el ingreso y riqueza & 44,08 & 50,40 & $-12,5 \%$ \\
\hline 9 & Confianza justificada en que las instituciones públicas actúan con limpieza y justicia & 53,89 & 35,10 & $53,5 \%$ \\
\hline 10 & Las comunidades locales tienen buena calidad de servicios públicos (transporte, luz, etc.) & 41,93 & 37,80 & $10,9 \%$ \\
\hline 11 & Buena atención a las personas vulnerables, disminuidos y de clase baja & 39,46 & 28,16 & $40,1 \%$ \\
\hline 12 & Reducción de la contaminación medioambiental, desarrollo de fuentes de energía renovables & 44,93 & 35,20 & $27,6 \%$ \\
\hline 13 & Las personas se sienten responsables por cada uno de los demás y por la comunidad & 38,13 & 31,32 & $21,7 \%$ \\
\hline 14 & Las personas que trabajan duramente pueden tener éxito en la vida & 32,37 & 15,48 & $109,1 \%$ \\
\hline 15 & Se alienta la vida familiar y los valores de la familia & 34,21 & 24,08 & $42,1 \%$ \\
\hline 16 & Las personas jóvenes son valoradas, $y$ tienen perspectivas de futuro seguras & 35,78 & 36,98 & $-3,2 \%$ \\
\hline 17 & Eliminación de la pobreza & 43,83 & 41,28 & $6,2 \%$ \\
\hline 18 & Respeto por, y estricta aplicación de las leyes & 51,48 & 26,66 & $93,1 \%$ \\
\hline 19 & Trabajos seguros, satisfactorios y equitativamente pagados para todos los que quieren trabajar & 44,32 & 37,84 & $17,1 \%$ \\
\hline 20 & Fuerte protección social (edad, enfermedad, desempleo, etc.) & 41,62 & 26,35 & $57,9 \%$ \\
\hline 21 & Capacidad para confiar en otras personas, incluso extraños & 40,46 & 37,80 & $7,0 \%$ \\
\hline 22 & Ciudad atractiva y bien planificada & 27,41 & 14,11 & $94,3 \%$ \\
\hline 23 & Protección de la libertad religiosa & 10,63 & 5,74 & $85,1 \%$ \\
\hline 24 & Relaciones justas, limpias e independientes con otras naciones & 28,75 & 17,22 & $66,9 \%$ \\
\hline 25 & Al tos niveles de progreso científico y tecnológico & 31,48 & 10,53 & $199,0 \%$ \\
\hline 26 & Vigorosa libertad de opinión, múltiples opiniones públicas (disensos) & 30,45 & 14,58 & $108,9 \%$ \\
\hline 27 & Las personas participan en la toma de decisiones de hechos que los afectan & 36,20 & 24,30 & $49,0 \%$ \\
\hline 28 & Atomización en la propiedad y control de los medios de comunicación & 23,80 & 33,18 & $-28,3 \%$ \\
\hline 29 & Comunidades y organizaciones locales fuertes & 30,67 & 14,04 & $118,4 \%$ \\
\hline 30 & Libertad para hacer lo que nos gusta siempre que no perjudiquemos a otros & 38,87 & 2,22 & $1650,8 \%$ \\
\hline 31 & Generosidad en ayudar a regiones perjudicadas & 24,23 & 5,60 & $332,7 \%$ \\
\hline 32 & No hay grandes diferencias en la riqueza y poder entre las personas & 47,30 & 23,80 & $98,7 \%$ \\
\hline 33 & Una fuerte economía de libre empresa y un gobierno eficiente en sus tareas básicas & 43,31 & 4,02 & $977,3 \%$ \\
\hline 34 & Establecer una economía fuerte antes que la equidad y las metas medioambientales & 18,95 & $-8,32$ & $-327,7 \%$ \\
\hline \multirow[t]{4}{*}{35} & Las personas tienen valores sociales y estilos de vida similares & 24,52 & $-0,45$ & $-5548,1 \%$ \\
\hline & Promedio 5 más importantes --> & 51,50 & 38,03 & $35,4 \%$ \\
\hline & Promedio 10 más importantes --> & 46,19 & 36,87 & $25,3 \%$ \\
\hline & Promedio TOTAL --> & 37,86 & 24,23 & $56,2 \%$ \\
\hline
\end{tabular}

La gravedad promedio en cuanto al estado general de las diferentes características para Australia es de 24,23 puntos; mientras que para La Plata, Berisso y Ensenada este valor asciende a 37,86 puntos (un $56,2 \%$ mayor).

La gravedad promedio para las cinco características más importantes, es de 51,5 puntos en el caso de la Región contra 38,03 puntos en el caso de Australia (un $35,4 \%$ superior). Si el análisis se lleva a las diez características de mayor relevancia, la gravedad promedia 46,19 puntos para La Plata, Berisso y Ensenada versus 36,87 puntos para Australia (un $25,3 \%$ mayor).

Según los resultados obtenidos, las características que esta sociedad entiende que están en una situación más crítica son:

- Eliminación del crimen y la violencia (58,29 puntos de diferencia en la Región versus 51,87 puntos en Australia). 
- Altos niveles de honestidad en la política y la vida pública $(55,73$ puntos de diferencia en la Región versus 46,5 puntos en Australia)

- Confianza justificada en que las instituciones públicas actúan con limpieza y justicia $(53,89$ puntos de diferencia en la Región versus 35,1 puntos en Australia).

- Todos son tratados igualitaria y equitativamente por la ley $(52,77$ puntos de diferencia en la Región versus 36,27 puntos en Australia).

- Respeto por, y estricta aplicación de las leyes (51,48 puntos de diferencia en la Región versus 26,66 puntos en Australia).

Todas las características que se plantean como críticas en esta sección aparecen entre las diez más importantes para la población de La Plata, Berisso y Ensenada. En el caso de Australia la única que aparece por fuera de las primeras importantes es "Respeto por....." que se posiciona en el puesto dieciocho de la jerarquía de importancia.

En cambio, las siguientes características se presentan con un menor $\underline{\text { nivel de gravedad: }}$

* Protección de la liberta religiosa (10,63 puntos de diferencia en la Región versus 5,74 puntos en Australia).

* Establecer una economía fuerte antes que la equidad y las metas medioambientales (18,95 puntos de diferencia en la Región versus 8,32 puntos en Australia).

* Atomización en la propiedad y control de los medios de comunicación. (23,8 puntos de diferencia en la Región versus 33,18 puntos en Australia).

* Igualdad de oportunidades para hombres y mujeres. (23,86 puntos de diferencia en la Región versus 23,4 puntos en Australia).

* Generosidad en ayudar a regiones perjudicadas. (24,23 puntos de diferencia en la Región versus 5,6 puntos en Australia).

$\rightarrow$ Solamente la característica de "Igualdad de oportunidades....." aparece dentro de las diez más importantes para la población bajo análisis, lo 
que nos permite comprender que es la única que resulta prioritaria para ambas poblaciones (Octavo puesto para la Región y Séptimo para los Australianos).

\subsubsection{Análisis de correlaciones}

Para verificar si existe relación entre las variables demográficas y las respuestas obtenidas en la encuesta, se llevó a cabo un análisis de etha cuadrado entre cada una de las siguientes variables:

demográficas:

- Importancia de los atributos con las siguientes variables

- Zonas: norte, sur, este, oeste, Berisso y Ensenada.

- Grupos Etarios: de 20 a 24, de 25 a 29, de 30 a 34, de 35 a 39, de 40 a 44 , de 45 a 49 , de 50 a 54 , de 55 a 59 y de 60 a 64 años de edad.

- Sexo: masculino y femenino.

- Educación: primaria incompleta, secundaria incompleta, terciaria o universitaria incompleta, terciaria o universitaria completa, postgrado completo.

- Ocupación: desocupado, jubilado, ama de casa, relación de dependencia tiempo parcial, relación de dependencia tiempo completo, profesional independiente, comerciante y empresario.

- Desempeño de los atributos con las siguientes variables demográficas:

- Zonas: norte, sur, este, oeste, Berisso y Ensenada.

- Grupos Etarios: de 20 a 24, de 25 a 29, de 30 a 34, de 35 a 39, de 40 a 44 , de 45 a 49 , de 50 a 54 , de 55 a 59 y de 60 a 64 años de edad.

- Sexo: masculino y femenino.

- Educación: primaria incompleta, secundaria incompleta, terciaria o universitaria incompleta, terciaria o universitaria completa, postgrado completo.

- Ocupación: desocupado, jubilado, ama de casa, relación de dependencia tiempo parcial, relación de dependencia tiempo completo, profesional independiente, comerciante y empresario. 
- Discrepancia entre la importancia y el desempeño de los atributos con las siguientes variables demográficas:

- Zonas: norte, sur, este, oeste, Berisso y Ensenada.

- Grupos Etarios: de 20 a 24, de 25 a 29, de 30 a 34, de 35 a 39, de 40 a 44 , de 45 a 49 , de 50 a 54 , de 55 a 59 y de 60 a 64 años de edad.

- Sexo: masculino y femenino.

- Educación: primaria incompleta, secundaria incompleta, terciaria o universitaria incompleta, terciaria o universitaria completa, postgrado completo.

- Ocupación: desocupado, jubilado, ama de casa, relación de dependencia tiempo parcial, relación de dependencia tiempo completo, profesional independiente, comerciante y empresario.

- Gravedad percibida en cada uno de los atributos con las siguientes variable demográficas:

- Zonas: norte, sur, este, oeste, Berisso y Ensenada.

- Grupos Etarios: de 20 a 24, de 25 a 29, de 30 a 34, de 35 a 39, de 40 a 44 , de 45 a 49 , de 50 a 54 , de 55 a 59 y de 60 a 64 años de edad.

- Sexo: masculino y femenino.

- Educación: primaria incompleta, secundaria incompleta, terciaria o universitaria incompleta, terciaria o universitaria completa, postgrado completo.

- Ocupación: desocupado, jubilado, ama de casa, relación de dependencia tiempo parcial, relación de dependencia tiempo completo, profesional independiente, comerciante y empresario.

Al respecto se pudo observar para cada una de las correlaciones realizadas, que los valores de etha cuadrado se encuentran entre 0 y 0,25 (Ver Anexo II), es decir, no existe relación significativa entre las respuestas obtenidas por los encuestados y las variables demográficas analizadas. 
Página 109 